EDUARDO VILODRES CAMPANHA

\title{
MODULAÇÃO ATENCIONAL DA PERCEPÇÃO DE TEMPO E SUAS RELAÇÕES COM O ENVELHECIMENTO E A DOENÇA DE ALZHEIMER
}

\author{
Tese de Doutorado apresentada ao \\ Instituto de Ciências Biomédicas da \\ Universidade de São Paulo, para a \\ obtenção do Título de Doutor em \\ Ciências (Fisiologia Humana).
}

UNIVERSIDADE DE SÃO PAULO

São Paulo

2008 
EDUARDO VILODRES CAMPANHA

\section{MODULAÇÃO ATENCIONAL DA PERCEPÇÃO DE TEMPO E SUAS RELAÇÕES COM O ENVELHECIMENTTO E A DOENÇA DE ALZHEIMER}

Tese apresentada ao Instituto de Ciências Biomédicas da Universidade de São Paulo, para a obtenção do Título de Doutor em Ciências.

Área de concentração:

Fisiologia Humana.

Orientador:

Professor Doutor Marcus Vinícius Chrysóstomo Baldo.

São Paulo 
DADOS DE CATALOGAÇÃO NA PUBLICAÇÃO (CIP)

Serviço de Biblioteca e Informação Biomédica do

Instituto de Ciências Biomédicas da Universidade de São Paulo

(c) reprodução total

\section{Campanha, Eduardo Vilodres.}

Modulação atencional da percepção de tempo e suas relações com o envelhecimento e a doença de Alzheimer / Eduardo Vilodres Campanha. -- São Paulo, 2009.

Orientador: Marcus Vinicius Chrysostomo Baldo.

Tese (Doutorado) - Universidade de São Paulo. Instituto de Ciências Biomédicas. Departamento de Fisiologia e Biofísica. Área de concentração: Fisiologia Humana. Linha de pesquisa: Neurofisiologia sensorial.

Versão do título para o inglês: The effects of aging and Alzheimer's disease on the attencional modulation of time perception.

Descritores: 1. Percepção de tempo 2. Atenção 3 . Reprodução de tempo 4. Discriminação de tempo 5. Envelhecimento 6. Doença de Alzheimer I. Baldo, Marcus Vinicius Chrysostomo II. Universidade de São Paulo. Instituto de Ciências Biomédicas. Programa de Pós Graduação em Fisiologia Humana. III. Título. 
Candidato(a): $\quad$ Eduardo Vilodres Campanha.

Título da Tese: $\quad$ Modulação atencional da percepção de tempo e suas relações com o envelhecimento e a doença de Alzheimer .

Orientador(a): $\quad$ Marcus Vinicius Chrysostomo Baldo.
A Comissão Julgadora dos trabalhos de Defesa da Tese de Doutorado, em sessão pública realizada a .1 . considerou

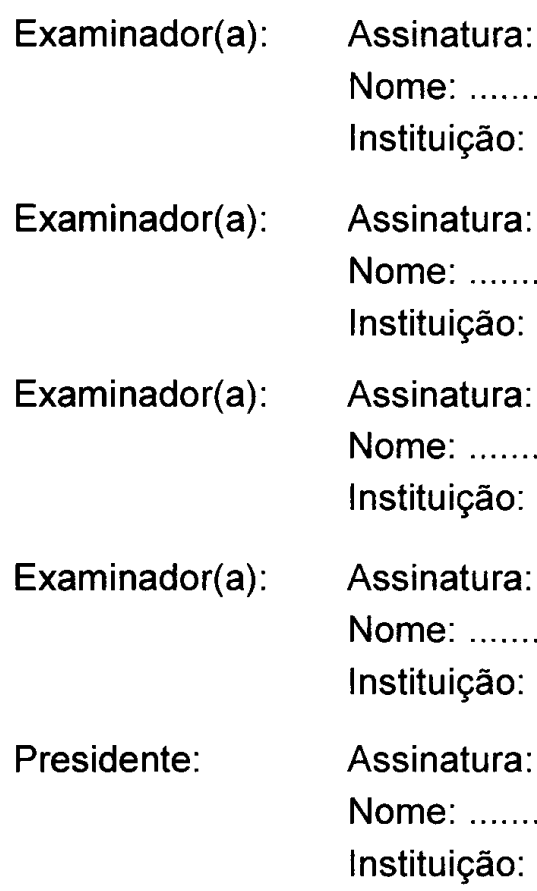




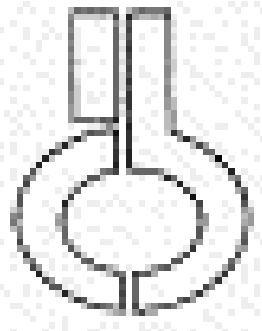

UHNERSIDADE DE GHO PAULD

INSTITUTO DE GIÉRLASS EAONEDACAS

Ded. CEFH $067 \mathrm{OOO}$.

$$
\text { DE LARAG }
$$

Desaro que o teldoto Porcial apresentado pelo

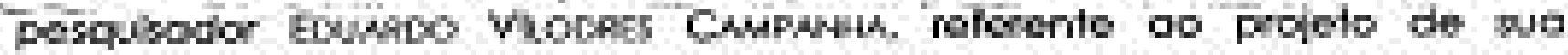
rapanatidode intuade Motulacho otencianal da percepcóo de

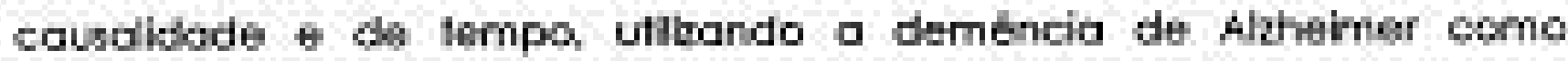

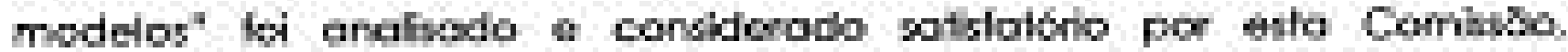

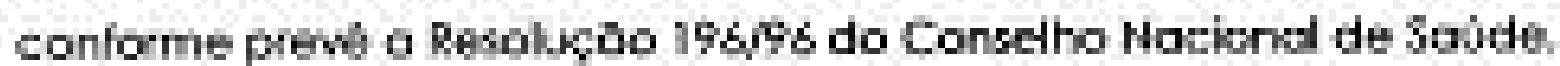

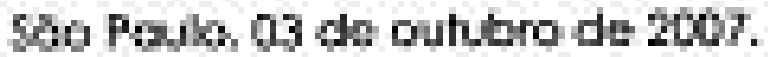<smiles>CCCC(C)C</smiles><smiles>CCCCC</smiles>

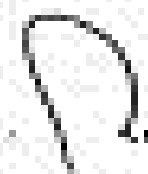
13

Prot. Dr. LuI Yutante RLES Cocrdanador da Combsos te Eliks am Pewdint con seres Humano a lC /USP 
A meus pais Diones José e Rosa Maria pelo incentivo, afeto e exemplo de vida e a minha noiva Caryne pelo amor e compreensão. 


\section{AGRADECIMENTOS}

Ao professor Marcus Vinícius, pela oportunidade, confiança e altissonante paciência. Seus conhecimentos e as oportunidades dadas foram fundamentais não só para aumentar meus conhecimentos sobre a metodologia científica e neurofisiologia, mas também permitiram a aquisição de conhecimento formal sobre a área da física.

Ao professor Cássio, pela colaboração e assessoria indispensáveis na parte clínica de meu trabalho, bem como pela indicação dos pacientes provenientes do PROTER.

Ao professor Ribeiro, responsável pelo pareceres relativos à $\mathrm{CNPq}$, pelos comentários e sugestões.

Aos membros da banca de qualificação, professor Cássio, professor Koichi e professor Ribeiro, cujas críticas e comentários contribuíram significativamente para o aprimoramento de meu trabalho.

Aos colegas de laboratório, Amanda, André, Carolina, Hamilton, Kelly, Milene e Peter, pelo companheirismo. Particularmente, agradeço a Milene e Carolina pela colaboração em meu trabalho.

Á Marli, técnica chefe de eletroencefalografia do Hospital das Clínicas, pela grande gentileza e dedicação que foram fundamentais para a realização deste trabalho.

Aos voluntários que participaram deste trabalho, minha sincera gratidão e respeito.

À minha família, meu amado Pai, minha amada Mãe, Fernando, Marcos e Vinícius, pela solicitude nos momentos difíceis, afeto e compreensão que me permitiram vencer os obstáculos da vida.

À minha amada noiva e sua família, Rubens, Maria, Cristiane e Tiago, pelo carinho, apoio e acolhimento que tenho recebido.

Aos meus grandes amigos, Joel, Márcia, Mário, Aretuza, Rafael, Elaine pelo apoio e amizades inquebrantáveis.

Por fim, agradeço a Deus, autor e princípio de tudo o que existe, pelos dons abundantes e pela força, sem a qual nada faríamos e sem a qual nada seríamos.

Ao Conselho Nacional de Desenvolvimento Científico e Tecnológico (CNPq) pelo apoio financeiro. 
"Nullo ergo tempore non feceras aliquid, quia ipsum tempus tu feceras. Et nulla tempora tibi coaeterna sunt, quia tu permanes; at illa si permanerent, non essent tempora." (Confissões XI, 14, 17).

"Não foi no tempo, portanto, que Tu, meu Deus, não fizeste coisa alguma, porque o tempo mesmo Tu tiveras feito. E nenhum dos tempos é coeternos a $\mathbf{T i}$, porque $\mathbf{T u}$ permaneces, mas eles não seriam tempos se permanecessem."

Santo Agostinho 


\section{RESUMO}

CAMPANHA, E. V. Modulação atencional da percepção de tempo e suas relações com o envelhecimento e a doença de Alzheimer. 2008. $130 \mathrm{f}$. Tese (Doutorado em Fisiologia Humana) - Instituto de Ciência Biomédica, Universidade de São Paulo, 2008.

O modo como o cérebro apreende o lapso de tempo é um tema fundamental e de crescente interesse nas neurociências, particularmente no sentido de compreender os mecanismos neurofisiológicos subjacentes à percepção de tempo. A atenção tem um papel fundamental na apreensão do lapso de tempo. Neste intuito, nosso objetivo é avaliar o papel da atenção na percepção de tempo, separando seus efeitos modulatórios de outros fatores tais como a memória. Além disto, outro objetivo é estudar o efeito do envelhecimento e da doença de Alzheimer (DA), que sabidamente leva a um comprometimento da atenção. Com isto, pretende-se avançar na compreensão tanto da percepção de tempo, como também na melhor caracterização das deficiências que envolvem tanto o envelhecimento como uma situação patológica muito prevalente, como a DA. Nosso trabalho experimental consiste de quatro experimentos. O primeiro e o segundo experimentos avaliaram a percepção de tempo em jovens, empregando tarefas de reprodução e de discriminação de durações temporais, respectivamente. Os resultados mostram um efeito atencional nas durações curtas, que está associado ao número de estímulos apresentados (1,2, 4 com apenas 1 alvo) e ao conhecimento ( $a$ priori ou a posteriori) do alvo. Quanto maior a demanda atencional, maior a superestimação do tempo físico, em durações curtas (menores que 2 segundos). Os resultados referentes ao d' (discriminabilidade) corroboram a hipótese de que as diferenças no desempenho sejam de origem atencional. $O$ terceiro e quarto experimentos compararam a percepção de tempo entre jovens, idosos e pacientes com doença de DA, empregando tarefas de reprodução e de discriminação de tempo, respectivamente. Nas tarefas, variaram-se o número de estímulos apresentados $(1$ e 4, com apenas um alvo) e o conhecimento do alvo (a priori ou a posteriori). Os resultados mostram um pior desempenho de idosos e pacientes com DA em relação aos jovens, que parece corresponder a uma deficiência atencional. Houve correlação entre o teste de trilhas (parte B), que mede atenção, e o desempenho nas tarefas de reprodução de tempo. Concluímos que a modulação da atenção, considerando nosso arranjo experimental, apresenta papel fundamental e crítico na percepção de tempo, particularmente em situações nas quais os participantes devem atentar aos vários estímulos que são apresentados concomitantemente. Outra conclusão é de que os déficits na percepção de tempo em idosos e em pacientes com DA parecem estar associada a uma menor quantidade de recursos atencionais ou a uma dificuldade de focar a atenção, que é mais pronunciada no grupo de pacientes com DA.

Palavras-Chave: Percepção de tempo; atenção; reprodução de tempo; discriminação de tempo; envelhecimento; idade; doença de Alzheimer. 


\begin{abstract}
CAMPANHA, E. V. The effects of aging and Alzheimer's disease on the attencional modulation of time perception. 2008. $130 \mathrm{f}$. Ph. D. Thesis (Physiology) - Instituto de Ciência Biomédica, Universidade de São Paulo, 2008.

The way in which the brain perceives a time interval is a fundamental subject in neuroscience. Also, understanding the factors that modulate time perception is an essential step towards the analysis of how this perception proceeds; specifically, our work focused on the attentional modulation of the perception of time. Additionally, other objective was to study the effect of aging and Alzheimer's disease (DA) on temporal perception. We have performed four experiments. The first and the second experiments evaluated time perception in young volunteers, by means of the reproduction and discrimination of time intervals, respectively. The results showed an effect of attention on short durations, whose magnitude was associated both to the number of stimuli presented (1, 2 and 4, with only one stimulus being the target and the others acting as distracters) and to the prior knowledge of the target (a priori or $a$ posteriori). We have found that the greater the attentional requirements, the longer the perceptual overestimation of time intervals for short durations ( $<2$ seconds). The evaluation of d' (detectability) confirmed the idea according to which the differences in performance originates from attentional demands. The third and fourth experiments had the objective to compare time perception among young volunteers, elderly and DA patients, utilizing reproduction and discrimination of time intervals, respectively. As in the first two experiments, we manipulated the number of presented stimuli ( 1 or 4 , with only one target) and the prior knowledge of target (a priori or a posteriori). Our findings showed a worse performance in both elderly volunteers and patients with DA in comparison with the group of young volunteers, which was interpreted as an attentional deficit. There was a significant correlation between the score evaluated by means of the "trial making - part B" procedure, an attentional test, and the performance in reproduction tasks. We conclude that attentional modulation is fundamental to time perception, particularly in situations in which DA patients need to attend to several stimuli presented at the same time. Our conclusion is that time perception deficits in elderly and patients with DA are associated either to lesser attentional resources or to an increased difficulty in focusing attention on the target, which is more evident in patients suffering of Alzheimer's disease.
\end{abstract}

Key-words: time perception; attention; reproduction of time; discrimination of time; elderly; aging; Alzheimer's disease. 


\title{
LISTA DE ABREVIATURAS E SIGLAS
}

\author{
APA - "American Psychiatry Association" \\ $\beta$ - critério \\ d'- discriminabilidade
}

CAMDEX - "Cambridge mental examination for mental disorders of the elderly"

CID-10 - Classificação Internacional de Doenças, 10 edição

CDR - "Clinical Dementia Rating"

CV - coeficiente de variação

DA - doença de Alzheimer

Dob - duração objetiva

Drep - duração reproduzida

DSM-IV - "Diagnostic and Statistical Manual of Mental Disorders", 4 edição

EEG - eletroencefalografia

FOME - "Fuld object-memory evaluation"

IBGE - Instituto Brasileiro de Geografia e Estatística

MEEM - mini-exame do estado mental 
NINCDS-ADRDA - "National Institute of Neurological and Communicative Disorders and Stroke" e "Alzheimer's Disease and Related Disorders Association"

OMS - Organização Mundial de Saúde

PI - ponto de igualdade ou indiferença

PET - "Positron emission tomography"

PROTER - Projeto Terceira Idade

SPECT - "Single photon emission computed tomography"

$\Delta \mathrm{t}$ - diferença entre duração do alvo e duração do estímulo padrão

1C - bloco experimental, no qual se apresenta apenas um estímulo, sendo concomitantemente prospectivo e retrospectivo.

2P - bloco experimental prospectivo, no qual são apresentado dois estímulos.

4P - bloco experimental prospectivo, no qual são apresentados quatros estímulos.

$2 \mathrm{R}$ - bloco experimental retrospectivo, no qual são apresentados dois estímulos.

4R - bloco experimental retrospectivo, no qual são apresentados quatro estímulos. 


\section{LISTA DE TABELAS}

Tabela 4.3.1. Valores do teste post hoc para as durações do alvo. 56

Tabela 4.3.2. Parâmetros encontrados pela regressão exponencial. 57

Tabela 4.3.3. Pontos de igualdade (experimento 1) 58

Tabela 5.3.1. Tabela usada na teoria de detecção de sinais. 69

Tabela 5.3.2. Comparações entre $\Delta \mathrm{t}=-250 \mathrm{~ms}$ e $\Delta \mathrm{t}=+250 \mathrm{~ms}$ 74

Tabela 6.2.1. Medicação utilizada pelos pacientes com DA. 79

Tabela 6.2.2. Escores das escalas neuropsiquiátricas e do CAMCOG 80

Tabela 6.3.1. Coeficientes da regressão exponencial (experimento 3). 83

Tabela 6.3.2. Pontos de igualdade (experimento 3) .83 


\section{LISTA DE ILUSTRAÇÕES}

Figura 1.1.1. Modelo do oscilador interno .18

Figura 1.4.1. Comparação entre um cérebro de idoso de um paciente com DA. 39

Figura 4.2.1. Esquema geral de uma tarefa de reprodução (bloco 4P) 52

Figura 4.3.1. Diferença relativa da quantidade de estímulos. .56

Figura 4.3.2. Diferença relativa em função da duração do alvo 57

Figura 4.3.3. Coeficiente de variação em função do número de estímulo. .59

Figura 4.3.4. Coeficiente de variação em função da duração do alvo 59

Figura 5.2.1. Esquema geral de uma tarefa de discriminação (bloco 4P). 66

Figura 5.3.1. Gaussiana em função da densidade de probabilidade. 69

Figura 5.3.2. Resultado do d' para experimento 2 .71

Figura 5.3.3. Regressão linear para condição prospectiva e retrospectiva. 71

Figura 5.3.4. Critério em função do número de estímulos .72

Figura 5.3.5. Porcentagem de acertos em função de $\Delta t$. .74

Figura 6.3.1. Comparação do desempenha de jovens x idosos (experimento 3) 81

Figura 6.3.2. Diferença Relativa em função da duração do alvo 82 
Figura 6.3.3. Desempenho nas tarefas cognitivas.

Figura 6.3.4. O escore de idosos/ escore de pacientes com DA................................... 85

Figura 7.3.1. d' em função do tipo de experimento....................................................91

Figura 7.3.2. d' em função do tipo de experimento..................................................... 92

Figura 7.3.3. d' em função do grupo experimental.................................................... 93






\section{SUMÁRIO}

1 INTRODUÇÃO.................................................................................................................. 16

1.1 Percepção de tempo........................................................................................... 17

1.1.1 Tarefas Psicofísicas na Percepção de tempo.....................................................224

1.2 Atenção...................................................................................................................27

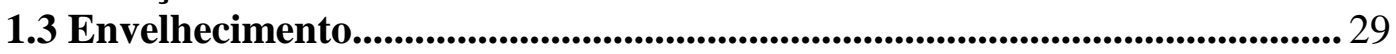

1.3.1 Atenção e Envelhecimento...................................................................................... 31

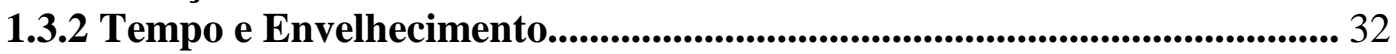

1.4 Demência de Alzheimer...............................................................................38

1.4.1 Atenção e Demência de Alzheimer.................................................................... 40

1.4.2 Tempo e Demência de Alzheimer................................................................... 41

1.5 Justificativa do Trabalho................................................................................. 43



2.1 Objetivos Gerais................................................................................ 45

2.2 Objetivos Específicos...............................................................................45

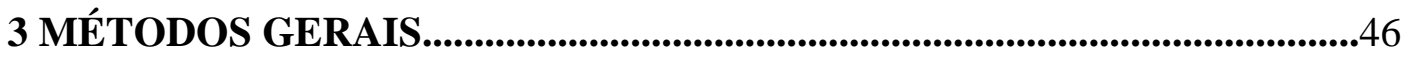

3.1 Participantes...................................................................................................................44

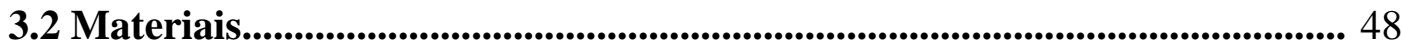

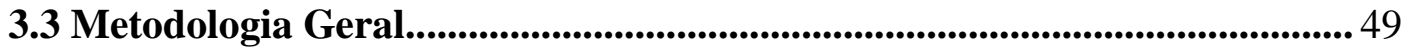

4 EXPERIMENTO 1...................................................................................... 51

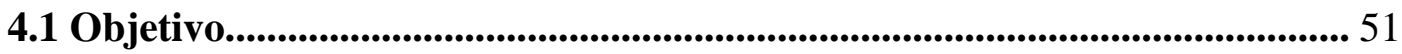

4.2 Arranjo Experimental................................................................................51

4.3 Análise e Resultados............................................................................. 53

4.4 Discussão do Experimento 1............................................................................ 60





5.2 Arranjo Experimental........................................................................................6 65

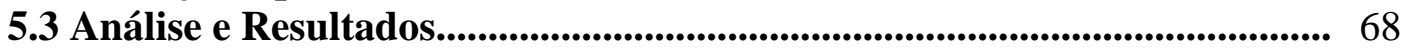

5.4 Discussão do Experimento 2 ........................................................................ 74

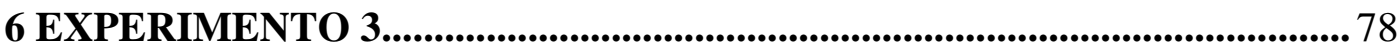



6.2 Arranjo Experimental................................................................................... 78

6.3 Análise e Resultados.................................................................................... 80

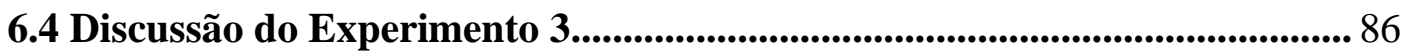

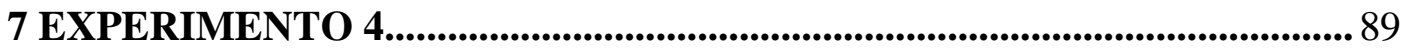

7.1 Objetivo.......................................................................................................................... 89

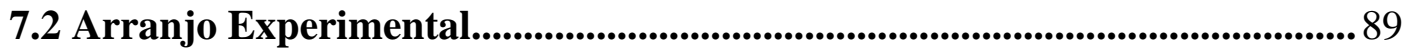

7.3 Análise e Resultados.................................................................................... 90

7.4 Discussão do Experimento 4....................................................................................... 94 


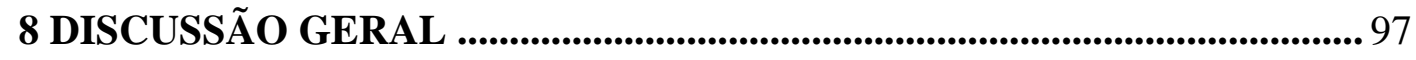

9 CONCLUSÃ

REFERÊNCIAS BIBLIOGRAFICAS............................................................106

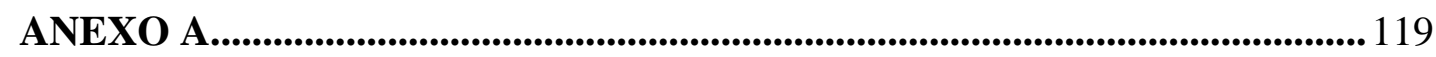

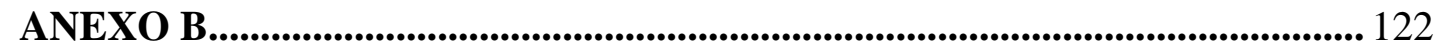

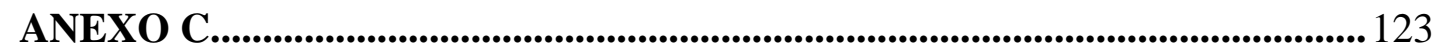






\section{INTRODUÇÃO}

A percepção do tempo é fundamental para que nossos comportamentos se realizem de forma efetiva no meio em que vivemos. O conhecimento, em física, sobre a localização e sobre o tempo de um evento são suficientes para definirmos com precisão o movimento ou o fenômeno estudado. Mesmo na física relativística, a definição deste quadrivetor (espaço e tempo) permite que mudemos de um referencial para outro, mantendo nosso conhecimento sobre um dado fenômeno. Assim, podemos dizer que a matéria, guardadas as limitações quânticas, está definida por este quadrivetor.

Destarte, o conhecimento acerca do tempo é fundamental para todos os comportamentos humanos. Por outro lado, não apresentamos um órgão sensorial responsável por perceber o tempo, ainda que haja considerável divergência sobre o que seja tempo. Apesar disto, possuímos mecanismos neurais que permitem nossa apreensão do que denominamos tempo físico, mediadas pelas vias sensoriais de que dispomos. Esta apreensão é chamada de percepção de tempo.

Devemos salientar que o que denominamos percepção de tempo, na verdade, corresponde à apreensão do lapso de tempo, isto é, da duração que um estímulo permanece no campo perceptivo de nossas vias sensoriais ou, alternativamente, do intervalo entre dois estímulos. Segundo James (1952), não podemos perceber o tempo de forma dissociada de um estímulo, isto é, perceber o tempo em si mesmo: “ ... we can no more intuit a duration than we can intuit an extension, devoid of all sensible content ..."(JAMES, 1952, p. 406).

Além disto, apenas com a finalidade de dimensionar as questões envolvidas no estudo do tempo, devemos citar as questões sobre o que é o tempo e sobre a existência do tempo físico independente da consciência. A obscuridade destas questões relativas ao tempo é expressa por Santo Agostinho no trecho abaixo.

Que é o tempo? Quem poderá explicá-lo clara e brevemente? Quem o poderá apreender, mesmo só com o pensamento, para depois nos traduzir, por palavras, o seu conceito? E que assunto mais familiar e mais batido em nossas conversas do que o tempo? Quando dele falamos, compreendemos o que dizemos; compreendemos também o que nos dizem quando nos falam dele. Que é, por conseguinte, o tempo? Se ninguém mo perguntar, eu sei; se o quiser explicar a quem me fizer a pergunta, já não sei (AGOSTINHO, 1996, livro XI, p. 322). 
Estas questões ainda não foram resolvidas e a existência do tempo como propriedade da consciência, ou seja, como tempo sendo uma propriedade subjetiva é advogada por muitos filósofos tais com Santo Agostinho e Kant, Bérgson e Husserl em contraposição à concepção de que o tempo é absoluto e independente do observador, defendida por Newton. Neste sentido o problema da essência do tempo ainda é uma questão em aberto, como nos alerta Husserl:

A análise da consciência do tempo é uma antiqüíssima cruz da psicologia descritiva e da teoria do conhecimento. O primeiro que sentiu a fundo as poderosas dificuldades que aqui residem e que com elas lutou até quase ao desespero foi Santo Agostinho. Os capítulos 14-28 do Livro XI das Confissões devem ainda hoje ser profundamente estudados por quem se ocupe com o problema do tempo. Portanto, nestas coisas, a época moderna, orgulhosa do seu saber, nada mais grandioso e mais considerável trouxe do que este grande e, na verdade, incansável pensador (HUSSERL, 1994, p.5).

Considerando todas as restrições conceituais descritas, manteremos o termo "percepção de tempo" por este ser empregado de forma freqüente na literatura especializada.

Para melhor compreensão da apreensão do tempo, é necessário avaliar os fatores que podem interferir ou que são partes constituintes da percepção de tempo, destacandose entre estes fatores a atenção. Outra perspectiva muito útil é avaliar como a percepção de tempo se modifica com o envelhecimento e como está alterada em virtude das lesões cerebrais.

\subsection{Percepção de Tempo}

O processamento neurofisiológico do tempo cobre ordens de magnitude e pode ser dividido em quatro escalas temporais: microssegundos (ecolocalização e localização sonora), milissegundos (coordenação motora, reconhecimento e produção da fala), segundos (percepção consciente de tempo) e horas a dias (ritmos circadianos). Tais escalas temporais supostamente apresentam mecanismos neurais diferentes (MAUK; BUONOMANO, 2004).

A percepção temporal humana é estudada com métodos psicofísicos e há uma extensa literatura a respeito deste tema (DEBRU, 2006; GRONDIN, 2001). Há ainda 
um número relativamente grande de modelos que tentam explicar os diversos resultados encontrados tanto em humanos como em animais.

Os modelos cognitivos podem ser divididos em dois tipos: modelos que postulam a existência de um oscilador ou marca-passo que produziria pulsos, através dos quais, o tempo percebido seria subjetivamente mensurado e modelos que propõem que funções cognitivas tais como a atenção e a memória seriam responsáveis pela percepção de tempo, sem assumir a existência de ritmos neurais que medeiem a apreensão do tempo.

Os modelos com osciladores são os mais citados e começaram a ser descritos por Treisman (1963). Tais modelos consistem em um marca-passo ou oscilador que manda pulsos, um interruptor que regula a passagem dos pulsos, um acumulador que conta os pulsos (memória operacional) e um comparador que compara o número de pulsos com a memória de referência. As diferenças se referem ao número de osciladores e às características do oscilador. O modelo de Gibbon, Church e Meck (1984), um dos mais citados na literatura, postula que o tempo subjetivo tem uma relação linear com o tempo objetivo e que a variabilidade seria proporcional a duração percebida, isto é, o coeficiente de variação (desvio padrão/ média) seria constante. Tal teoria explica muitos resultados obtidos em animais e humanos (GIBBON et al., 1997), ainda que haja tarefas nas quais as previsões do modelo, denominadas propriedades escalares, não são verificadas (WEARDEN; LEJEUNE, 2008). Com relação ao número de osciladores há autores que propõem a existência de um oscilador (PÖPPEL, 1997), enquanto outros, a existência de múltiplos osciladores (IVRY; RICHARDSON, 2001). Deve-se citar ainda, que a atenção teria um papel importante na abertura e fechamento do interruptor (LEJEUNE, 1998), regulando a passagem de pulsos para o acumulador.

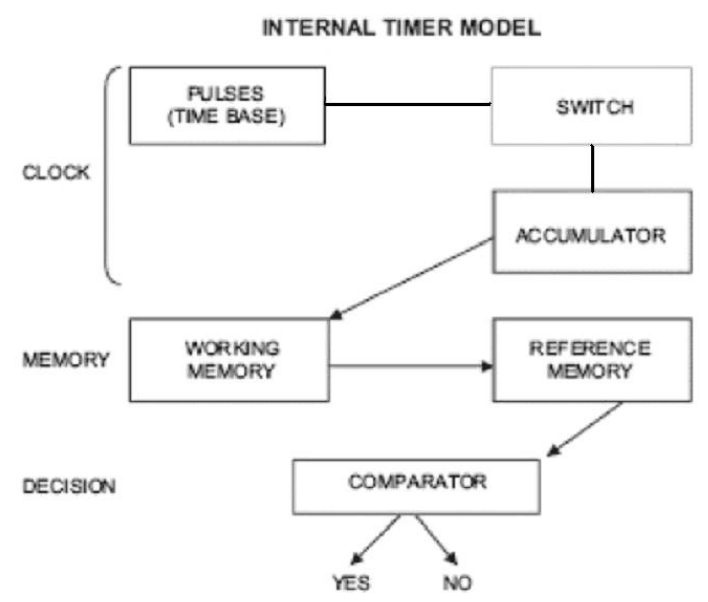

Figura 1.1.1. Mostra o modelo do oscilador interno proposto por Gibbon, Church e Meck (1984). 
Dentre os modelos que não usam osciladores, cita-se aquele desenvolvido por Ornstein (1969) que postula que o tempo é percebido em função da quantidade e complexidade de informação que é armazenada na memória. Este modelo apresenta boa aplicabilidade em tarefas com o paradigma retrospectivo. Para Block e Zacay (2004), o número de diferentes funções ou estratégias cognitivas que ocorre no período é que determina a sensação subjetiva de duração.

Nos modelos com relógios internos, particularmente naqueles que consideram apenas um marca-passo, têm sido envidados esforços de estabelecer as características do oscilador. A frequiência do oscilador levaria a um intervalo no qual a percepção de tempo seria mais acurada e precisa, o que foi denominado de ponto de indiferença por Vierordt $^{1}$ (1868 apud James, 1952). Pöppel (2004) tem mostrado evidências de que o intervalo de maior acurácia estaria em torno de 3 segundos (entre 2 e 3 segundos), valor este similar ao encontrado para o presente psicológico por Fraisse (1984). Entretanto, há evidências de que até 1 segundo haja um tipo diferente de mecanismo envolvido na percepção de tempo. Tal evidência advém de estudos de pacientes com lesões cerebrais, que apresentam maior acurácia em durações em torno de 1 segundo quando não se verificam lesões nos núcleos da base (HARRINGTON; HAALAND; NEAL, 1998; NICHELLI et al., 1993). É curioso notar que um dos trabalhos psicofísicos mais antigos sobre o tema, realizado por Wundt, encontrou 0,72 segundos como ponto de indiferença (JAMES, 1952), ou como, atualmente, denominamos ponto de igualdade (PI).

Em crianças de diversas faixas etárias, Szelag et al. (2002), usando uma tarefa de reprodução de tempo, encontraram que o tempo de maior acurácia foi de 2 segundos. Tal achado concorda com meta-análise empreendida por Block, Zakay e Hancock (1999) que mostrou que crianças tendem a apresentar maior estimativa verbal e reproduções mais curtas, com conseqüente desvio para esquerda do ponto PI, isto é, as durações de maior acurácia têm valores menores que aquelas obtidas em estudos com adultos.

Com relação ao presente psicológico, pode ser considerado como o intervalo de tempo, no qual temos a sensação de presente. James (1952) chega à conclusão de que a sucessão de percepções não corresponde à sensação da sucessão, ou seja, para que a

\footnotetext{
${ }^{1}$ VIERORDT, K. (1868). Der Zeitsinn nach. Tübingen, Germany: Laupp, 1868
} 
sensação de sucessão ocorra, os estados de consciência deveriam ocorrer simultaneamente, com constantes de tempo que permitissem à consciência saber qual destas percepções "está indo" e qual "está chegando". Desta forma, o presente subjetivo se apresenta como o presente fictício definido por James, o que, na verdade, é o passado recente.

Its objects are given as being of the present, but the past of time referred to by the datum is a very different thing from the conterminous of the past and future which philosophy denotes by the name Present. The present to which the datum refers is really a part of the past - a recent past - delusively given as being a time that intervenes between the past and the future. Let it be named the specious present [...] (JAMES, 1952, p. 398).

O presente subjetivo é uma evidência de que nosso cérebro trata, de forma diferente, certas durações de tempo, o que sugere mecanismos neurais diferentes na apreensão do lapso de tempo.

As tarefas que são utilizadas para avaliar o tempo são de quatro tipos: estimativa de tempo, produção de tempo, discriminação temporal e reprodução de tempo (BLOCK; ZAKAY; HANCOCK, 1998; WITTMANN, 1999). A estimativa verbal consiste em avaliar a duração de um estímulo e dizer ou escolher, entre alternativas, um número em segundos ou minutos que traduza a duração do estímulo. A produção de tempo consiste em gerar um ritmo ou uma duração apresentada pelo examinador. Um exemplo para tornar claro: o sujeito deve apertar uma tecla a cada 1 segundo. Na discriminação temporal, o sujeito deve responder se o alvo foi maior que o estímulo padrão, que geralmente é fixo. A reprodução pode ser dividida em uma fase de codificação, na qual o sujeito deve atentar para duração dos estímulos e uma fase de reprodução ou resposta, onde o sujeito deve reproduzir a duração percebida do estímulo, através de um ato motor.

Para cobrirmos também estudos realizados com animais, devemos citar a tarefa de bissecção temporal, que pode ser classificada como uma tarefa de discriminação. Neste procedimento são apresentados dois estímulos: um de curta duração e outro de longa duração, que servem como padrão. Em seguida são apresentados estímulos de durações que variam entre os valores padrão referentes aos estímulos curtos e longos e a resposta consiste em definir se o estímulo apresentado está mais próximo de qual estímulo padrão. O ponto, no qual há $50 \%$ de resposta para estímulo longo ou curto é definido como bissetor temporal (WEARDEN; FERRARA, 1996). Outra variante é o 
procedimento chamado de generalização temporal, no qual deve-se responder se a duração de um estímulo é igual ou diferente da duração do estímulo padrão. Nas tarefas denominadas "peak-interval procedure", que se trata de uma tarefa de reprodução, dois estímulos padrão devem ser reproduzidos (BUHUSI; MECK, 2005). Tais procedimentos, ainda que possam ser reproduzidos por humanos, foram desenvolvidos para experimentação animal e foram importantes para a formulação da teoria escalar, visto que, em animais, as previsões do modelo são frequentemente alcançadas (tempo subjetivo é uma função linear do tempo físico e coeficiente de variação é constante) o que nem sempre ocorre nos estudos de seres humanos (LEJEUNE; WEARDEN, 2006).

Nas tarefas de estimativa de tempo e nas de generalização temporal realizadas em humanos (um tipo de tarefa de discriminação) as previsões da teoria escalar tendem a ser verificadas (WEARDEN; JONES, 2007; WEADEN; LEJEUNE, 2008). Já tarefas de produção, reprodução e discriminação tendem a violar as previsões. Particularmente, a reprodução de tempo tende a seguir a lei de Vierordt, segundo a qual, a reprodução de durações mais curtas tendem as ser superestimadas e as durações mais longas serem subestimadas. Apesar de ter sido reconhecido que a capacidade humana de contagem tenha interferido nestes resultados, mesmo estudos que impediram tal estratégia, mostraram violações da teoria escalar e reproduções que seguiam a lei de Vierordt (WEADEN; LEJEUNE, 2008).

Um achado interessante é que pacientes com doença de Parkinson tratados com L-DOPA exibem a propriedade escalar, mas isto não acontece com pacientes não tratados, nos quais o desvio padrão aumenta de forma não linear com a média. Já lesões no cerebelo não alteram a propriedade escalar (BUHUSI; MECK, 2005).

Outro exemplo de diferenças entre os resultados obtidos em humanos e em animais é o ponto bissetor temporal que, em animais, se encontra na média geométrica entre as duas durações padrão (ALLAN; GIBBON, 1991). Em humanos, Wearden e Ferrara (1996) mostraram que tomando a razão entre a duração padrão longa e curta, quando a relação é 2:1, o ponto bissetor se encontra na média geométrica. Para as outras relações, o ponto bissetor esteve mais próximo da média aritmética.

A apresentação dos estímulos a serem avaliados quanto ao lapso de tempo pode ser classificada como intervalo e duração. O intervalo é definido por dois estímulos abruptos e na duração o tempo é definido pelo período no qual o estímulo é apresentado. 
$\mathrm{Na}$ literatura relativa à percepção de tempo, diferenciam-se procedimentos prospectivos e retrospectivos. No procedimento prospectivo, o sujeito sabe, previamente, que deve prestar a atenção no tempo do alvo. Já no procedimento retrospectivo, deve avaliar o tempo de um dado evento ou estímulo a posteriori, isto é, não sabia que deveria prestar atenção no tempo, ou seja, na duração de um dado estímulo ou evento. Esta diferenciação é importante, uma vez que mecanismos atencionais são mais importantes em tarefas prospectivas e a memória tem papel fundamental em tarefas retrospectivas (ZAKAY; BLOCK, 2004).

Em parte, estas diferenças em relação às tarefas empregadas podem explicar resultados diferentes na literatura.

Um grande número de trabalhos tem abordado as estruturas neurais envolvidas na percepção de tempo. É interessante notar que regiões cerebrais similares estão envolvidas no tempo vinculado à motricidade e aos aspectos perceptivos (RUBIA; SMITH, 2004). As evidências são obtidas tanto de estudos de pacientes com lesão e de estudos que usam técnicas funcionais de imagem.

Uma das regiões mais implicadas na percepção de tempo seria o córtex préfrontal dorsolateral (HARRINGTON; HAALAND; KNIGHT, 1998; LEWIS, 2002). Pacientes com lesões nestas regiões apresentam desempenho prejudicado na estimativa temporal de tempo de segundos a minutos (CASINI; MACAR, 1999; MANGELS; IVRY; SHIMIZU, 1998). Estudos de neuroimagem, usando ressonância magnética funcional e PET, têm confirmado a participação do córtex pré-frontal dorsolateral, particularmente no lado direito, em tarefas de percepção de tempo. Autores como Rubia et al. (2004) têm proposto que esta região poderia ter funções semelhantes àquelas pensadas, hipoteticamente, para o acumulador.

Lesões na área motora suplementar têm sido associadas a alterações na produção de ritmos e em tarefas puramente perceptivas com a estimativa verbal de tempo, a despeito de sua função conhecida no controle postural (MACAR et al., 2002; LEWIS; MIALL, 2003). Apesar de Livesey, Wall e Smith (2007) sugerirem que as ativações encontradas nas áreas motoras suplementares e córtex pré-frontal dorsolateral estivessem vinculadas à dificuldade da tarefa e não à percepção de tempo em si, estudo prévio (COULL et al., 2004) que tinha usado como parâmetro o aumento de ativação das estruturas, conforme o aumento da demanda atencional (técnica paramétrica) dirigida a uma tarefa de percepção de tempo, apontam para que tanto a área motora 
suplementar e córtex pré-frontal dorsolateral são estrutura importantes para perceber o lapso de tempo, em associação com o putamen e o córtex parietal posterior.

O lobo parietal também tem sido implicado na percepção de tempo. Estudos com pacientes que apresentam lesões focais têm mostrado um déficit na estimativa de tempo da ordem de segundos (HARRINGTON; HAALAND; KNIGHT, 1998). Acredita-se que os lobos estão envolvidos na atenção sustentada, uma vez que em estudos de neuroimagem funcional não há ativação adicional se na tarefa controle há demanda atencional (SMITH et al., 2003).

Outras regiões não corticais têm papel fundamental na percepção de tempo: núcleos da base e cerebelo. Os núcleos da base tendem a ser considerados como um dos hipotéticos osciladores e teriam uma função particular na percepção de tempo de centenas de milissegundos a alguns segundos (MECH; BENSON, 2001; MATTHEW; MECK, 2000). O cerebelo em sua porção lateral tem sido implicado na percepção de tempo da ordem de milissegundos e também de minutos para tarefas exclusivamente perceptivas (IVRY, 1996; IVRY; SPENCER, 2004; HAZELTINE; HELMUTH; IVRY, 1997). Todavia, a importância do cerebelo na percepção tempo na ordem de minutos tem sido seriamente questionada (BUHUSI; MECK, 2005; HARRINGTON et al., 2004).

Com relação à neurofarmacologia, a dopamina apresenta importante função na percepção de tempo de segundos a minutos e estaria vinculada à função dos circuitos fronto-striatais (MECK, 1996). A acetilcolina apresenta, em tarefas temporais, relação com a memória e a atenção e se vincularia a função cortical dos lobos frontais e parietais (MECK; BENSON, 2002).

A administração de haloperidol ou outro antagonista do receptor $\mathrm{D}_{2}$ leva a uma tendência de superestimar o tempo. O contrário acontece quando é administrado um agonista dopaminérgico, como a metanfetamina. Assim, nas tarefas de reprodução de tempo, com a administração de um antagonista $\mathrm{D}_{2}$ teríamos uma superestimação dos intervalos curtos e subestimação destes intervalos se fosse empregados agonistas dopaminégicos. Meck (1986) mostrou que esta superestimação é proporcional à afinidade dos antipsicóticos ao receptor D2 e sugeriu que a via dopaminérgica estriatal estaria associada à velocidade do oscilador.

Já a administração de acetilcolina em ratos reverteu parcialmente o pior desempenho que ratos mais velhos tiveram em relação aos ratos mais jovens (MECK; ANGELLS, 1992). 
Outras substâncias, no entanto, podem interferir com a percepção de tempo: benzodiazepínicos levaram a um pior desempenho na percepção de tempo de um segundo, mas não para a duração de 100 ms (RAMMSAYER, 1992). Já o etanol leva a uma piora na discriminação de tempo na ordem de milissegundos (RAMMSAYER; VOGEL, 1992). Estas evidências, somadas àquelas oriundas de estudos com lesões e neuroimagem funcional, sugerem a presença de mecanismos diferentes para a percepção de tempo nas ordens de milissegundos e segundos (STEINBÜCHEL, 1998) e estes mecanismos seriam multimodais, isto é, funcionariam independentemente da modalidade sensorial empregada para apreender o lapso de tempo, para uma dada ordem temporal (SZELAG et al., 2004).

\subsubsection{Tarefas Psicofísicas na percepção de tempo}

Descreveremos, nesta seção, achados recentes envolvendo as tarefas psicofísicas usadas na avaliação da percepção de tempo. Enfatizaremos as tarefas de reprodução e discriminação de tempo.

Poucos trabalhos relativos à estimativa de tempo têm sido realizados, nos últimos dez anos. O trabalho de Vitulli e Crimmins (1999) avaliou possíveis variáveis que interfeririam na estimativa de tempo e verificaram que quanto maior a latência para dar a estimativa de tempo, tais estimativas tendem a ser maiores. Neste estudo, não houve correlação entre uma tarefa de memória concorrente e a estimativa de tempo. Por outro lado, Chaston e Kingstone (2004) mostraram que na presença de maior demanda atencional, há subestimação maior do tempo. Tal achado pode ser explicado pelo modelo do oscilador: quanto menor atenção dispensada à percepção do tempo, menos pulsos irão chegar ao acumulador, uma vez que a abertura do interruptor depende da atenção. Como há menor quantidade de pulsos, a tendência é subestimar.

Schmitter-Edgecombe e Rueda (2008) compararam a estimativa verbal de jovens com indivíduos que sofreram traumatismo craniano e mostraram que este grupo apresentou maior subestimação em relação ao grupo controle para durações longas (45 e 60 segundos).

Nas tarefas de produção de uma duração ou intervalo, o efeito de uma maior demanda atencional é superestimação do tempo (FORTIN; MASSÉ, 2000). Isto pode ser explicado pelo fato de que é necessário mais tempo para que os pulsos cheguem ao 
acumulador (interruptor não está totalmente aberto). O estudo de Tracy et al. (2000) mostrou ativação cerebelar, ativação esta que também foi encontrada em tarefas que envolviam a produção de um ritmo (SAKAI et al., 1999).

Nas tarefas de reprodução temos duas fases bem demarcadas e que permitem avaliar a fase perceptiva ou de codificação e a fase de reprodução ou de resposta. A modulação atencional e de memória leva a respostas diferentes dependendo da fase em que é usada. Neste sentido, o trabalho de Fortin e Rousseau (1998) é elucidativo. Apresentaram duas tarefas concorrentes com a finalidade de aumentar a demanda atencional em dois experimentos: no primeiro, a tarefa era simultânea à fase de reprodução e o resultado foi um superestimação dos intervalos de tempo e, no segundo, a tarefa era apresentada concomitantemente à fase de codificação com conseqüente subestimação dos intervalos. Tais achados podem ser interpretados com o modelo baseado em osciladores, considerando que quanto menor demanda atencional for dispensada à tarefa que avalia a reprodução de tempo, menor será o tempo de abertura do interruptor. Quando há uma maior demanda atencional na fase de reprodução, é necessário maior tempo para que o número de pulsos chegue ao acumulador, da mesma forma que ocorre para a produção de tempo. Na fase de codificação, se um número menor de pulsos para uma dada duração chega ao acumulador, então o tempo percebido é menor que o tempo físico, a exemplo do que ocorre na estimativa de tempo. Os intervalos utilizados neste experimento foram 1600, 2000 e $2400 \mathrm{~ms}$, o que torna o primeiro experimento similar em alguns aspectos aos nossos experimentos. Achados similares aos obtidos pela modulação da atenção na fase de codificação foram encontrados para intervalos de 70 a 270 ms (MATTES; ULRICH, 1998).

A comparação de estudos de reprodução temporal deve levar em conta a natureza da modulação (atenção ou memória) e a duração dos estímulos empregados. Macar (1996) encontrou uma subestimação do tempo, em intervalos que iam de 15 a 20 segundos, relacionada à complexidade da tarefa concorrente e outros estudos mostraram dados similares para tarefas que exigiam maior capacidade da memória operacional, sendo que a subestimação era particularmente expressiva em um paciente com síndrome amméstica (POUTHAS; PERBAL, 2004). Neste mesmo estudo, pacientes com doença de Parkinson tratados com L-dopa tenderam a subestimar. Outro fator que parece mudar a magnitude dos resultados é o fato da tarefa concorrente ser apresentada no início ou no final da fase de codificação (MACAR, 2002), sugerindo que a expectativa e a atenção automática tenham papel relevante na reprodução de tempo. 
Outro estudo, que avaliou a reprodução de tempo em durações maiores que 6 segundos (BROWN e WEST, 1990), mostrou um aumento proporcional da subestimação, conforme maior demanda atencional fosse requerida.

O estudo conduzido por Macar et al. (2002) usou durações de 2,2 a 3,2 e de 9 a 13 segundos e mostrou que a área motora suplementar estava ativada no PET. Neste estudo, é interessante notar que seus dados indicam um melhor desempenho nas durações entre 2,2 e 3,2 s. Em trabalho anterior (CASINI; MACAR, 1996), haviam encontrado ativação do córtex pré-frontal, usando a técnica de laplaciano de superfície em EEG de alta resolução. Jones et al. (2004) também mostraram, através de estimulação magnética transcraniana, que o córtex pré-frontal dorsolateral tem um importante papel na reprodução de tempo. Deve-se enfatizar que estes dois estudos avaliaram a reprodução de duração de $2 \mathrm{~s}$.

Não há uma uniformidade nas medidas de desempenho das tarefas de reprodução de tempo, o que dificulta a comparação de resultados psicofísicos. Entretanto, podemos diferenciar dois tipos: medidas contínuas e medidas discretas. $\mathrm{Na}$ primeira podem ser citadas: diferenças relativas ((duração reproduzida - duração real)/duração real) e acurácia (duração reproduzida/duração real). Nas medidas discretas, determina-se um intervalo de tempo que contenha a reprodução real como média e as respostas são definidas como corretas, se o tempo reproduzido estiver no intervalo considerado. Há um maior número de trabalhos usando as medidas contínuas.

O mesmo acontece para as tarefas de discriminação, cujas medidas de desempenho mais frequentemente encontradas são: porcentagem de erro, duração (usando método adaptativo), discriminabilidade e critério (usando a teoria de detecção de sinal). A vantagem da utilização da teoria de detecção de sinal é que esta permite separar o que é discriminabilidade (d') do critério ( $\beta$ ), uma vez que o primeiro fator estaria vinculado a uma maior acurácia e à atenção dispensada à tarefa, enquanto o critério estaria mais associado à estratégia usado pelo sujeito.

Estudos de discriminação temporal, que utilizaram ressonância magnética funcional, têm mostrado ativação da área motora suplementar, pré-frontal dorsolateral, cerebelo e núcleos da base (MANGELS; IVRY; SHIMIZU, 1998; FERRANDEZ et al., 2003; POUTHAS et al., 2005). Parece haver uma contribuição do lobo parietal em durações mais longas, com cerca de 3 segundos (LEWIS; MIALL, 2003). Com relação à lateralidade, Grondin e Girard (2005) mostraram que a discriminabilidade foi maior para os estímulos apresentados no campo visual esquerdo. Ratificando este achado, 
temos os achados com um paciente que sofreu calosotomia (HANDY; GAZZANIGA; IVRY, 2003). Neste estudo os dois hemisférios mostraram capacidade de discriminar o tempo, com superioridade do hemisfério direito. Não houve diferenças deste padrão de resposta considerando intervalos da ordem de segundos e centenas de milissegundos.

Estudo que avaliou a atenção mostrou um piora do d' em função da demanda atencional dispensada a tarefa de discriminação, bem com uma tendência à subestimação (CASINI; MACAR, 1999). Tal achado pode ser explicado usando-se o modelo de osciladores. Neste caso, com a menor quantidade de recursos atencionais dispensados à discriminação de tempo, um menor número de pulsos chegam ao acumulador, número este que será comparado com a representação da duração do estímulo padrão, registrada na memória.

\subsection{Atenção}

A atenção tem sido objeto de pesquisa desde o fim do século XIX, nos quais se destacam os trabalhos de Herman von Helmholtz (1871/1894) e William James $(1842 / 1910)$.

Von Helmholtz mostrou que, mesmo mantendo os olhos fixados em um ponto de uma página impressa, era possível perceber estímulos em outra parte desta folha, desde que a atenção fosse dirigida para tal localização. Outra observação importante era de que as localizações para onde a atenção não era dirigida, os estímulos não eram claramente percebidos. James, por outro lado, mostrou que a atenção influenciava tanto fenômenos sensoriais (maior acuidade e velocidade na percepção dos estímulos) quanto a parte motora (velocidade de resposta).

Desde os primórdios encontrou-se uma dificuldade de conceituar o que era a atenção, indefinição esta que foi expressa por James em seu famoso aforismo: "todo mundo sabe o que atenção é". Esta dificuldade se mantém até os dias de hoje, a despeito das tentativas, cada vez mais refinadas, de caracterizar fenomenologicamente a atenção. Mesmo aspectos sobre sua possibilidade de ser apenas seletiva ou poder ser dividida, ocorrer precoce ou tardiamente e ser relacionada ao espaço ou ao objeto ainda não são completamente claros (PASHLER, 1998).

Apesar de não ser completamente caracterizada, a atenção é uma função cognitiva imprescindível no estudo de qualquer fenômeno sensorial (BALDO; 
NAMBA, 2002). Para tornar a atenção mais fácil de ser compreendida, algumas metáforas são usadas, tais como foco de luz ou lente zoom. Ainda que haja limitações evidentes no uso de metáforas, elas são importantes para caracterização de efeitos da atenção. Um exemplo é o estudo realizado em nosso meio (CARREIRO; HADDAD; BALDO, 2003) que mapeou a distribuição espacial da atenção. Os autores valeram-se da metáfora de lente zoom da atenção, cuja distribuição espacial da atenção pode ser descrita como uma gaussiana tridimensional, no qual o ponto médio se situa no centro do foco atencional e a largura da gaussiana pode ser ajustada pelo sujeito, dependendo da tarefa a ser realizada.

Deve-se ressaltar que a atenção não é entendida como um processo único (RAZ; BUHLE, 2006). Não há, contudo, um consenso sobre os componentes da atenção, inclusive a memória operacional tem sido considerada por vários autores como um componente atencional e não uma função cognitiva isolada (AWH; JONIDES, 2001; KNUDSEN, 2007).

Existem diversas estruturas neurais envolvidas na atenção. A estrutura mais estuda a este respeito é o córtex parietal posterior (especialmente, do lado direito). Uma das síndromes mais curiosas é obtida em pacientes que apresentaram lesão desta região, produzindo um quadro de heminegligência para estímulos sensoriais que são apresentados no lado esquerdo (ADAMS; VICTOR; ROPPER, 1997). Outras estruturas envolvidas são: córtex frontal anterior (neurônios do córtex frontal respondem seletivamente a um alvo visual), pulvinar do tálamo (ativado em tarefas que exigem filtragem de estímulos), núcleo reticular do tálamo e colículo superior (GAZZANIGA; IVRY; MANGUN, 2002; KANDEL; SCHMARTZ; JESSEL, 2000).

O prosencéfalo basal, estrutura responsável por grande parte das aferências colinérgicas corticais, tem sido associado não somente à vigilância, mas também à atenção dirigida a um dado estímulo (PARIKH; SARTER, 2008). Estudos têm relacionado o aumento na transmissão colinérgica no córtex pré-frontal a um maior processamento cortical (SARTER et al., 2005) e à inibição de informações irrelevantes (SARTER; PARIKH, 2005).

Outros neurotransmissores também estariam associados a certos aspectos da atenção, tais como a noradrenalina estaria associada ao alerta e a dopamina, ao controle atencional executivo (POSNER, 2008). 


\subsection{Envelhecimento}

O envelhecimento tem sido uma característica marcante da população dos tempos hodiernos. Calcula-se que, no século XIX, apenas $4 \%$ da população era formada por indivíduos com mais de 65 anos. Em 1998, na Grã-Bretanha, esta porcentagem era de 18\% (IAN-STUART, 2002). No Brasil, o senso do Instituto Brasileiro de Geografia e Estatística (IBGE) já mostrava que em algumas cidades, como o Rio de Janeiro, a porcentagem de idosos era maior que $12 \%$.

Devido ao aumento da porcentagem de idosos e diminuição da porcentagem de crianças na sociedade contemporâneas, pode se descrever a estrutura da sociedade como uma estrutura retangular, uma vez que uma proporção similar de pessoas estão vivas em cada década de vida. Isto se contrapõe à estrutura piramidal, encontrada no início do século XX.

O envelhecimento, além de aumentar o risco de determinadas doenças, como as demências e outras doenças degenerativas, traz algumas alterações biológicas, tidas como fisiológicas. Sabemos, por exemplo, que as células têm um número finito de duplicações e que a população celular da maior parte dos tecidos tende a diminuir com a idade.

O encéfalo apresenta alterações com envelhecimento. Todavia, as diversas regiões encefálicas não se alteram da mesma forma e mesma intensidade. Por exemplo, as células de Purkinje apresentam um declínio com a idade de aproximadamente 2,5\% por década (BOTTINO et al., 2006). Já a maior parte do tronco encefálico e regiões neocorticais como o córtex motor e sensorial primário não apresentam declínio com idade. Com relação ao metabolismo cerebral, estudos mostram uma diminuição de $2 \%$ por década do metabolismo de glicose, principalmente nos lobos frontais e temporais (HOF; MOBBS, 2001).

A atividade elétrica cerebral de idosos também mostra modificações, cuja completa caracterização ainda não foi obtida. O registro eletroencefalográfico de idosos em vigília tende a apresentar uma diminuição da frequiência do ritmo alfa, ainda que esta freqüência não se mostre menor que 8 Hz (HUGHES, 1994), além de apresentar modificações na sua topografia, com a diminuição deste ritmo em regiões anteriores (LANDOLT, 2001). Em um estudo multicêntrico conduzido por Babiloni et al. (2007), encontrou-se uma diminuição da magnitude do ritmo teta na região occipital e do ritmo 
alfa nas regiões corticais posteriores. Outro estudo de Koyama et al. (1997) mostrou uma diminuição da coerência intra-hemisférica, mas não inter-hemisférica, em idosos.

Outras alterações no registro eletroencefalográfico aparecem na realização de uma tarefa, como é o caso do estudo de Karrasch (2004), que mostra diferenças na dessincronização e sincronização relacionada a eventos entre idosos e jovens, durante uma tarefa de memória, apesar do desempenho ter sido similar nos dois grupos.

Um fato interessante é a redução da assimetria hemisférica (CABEZA, 2001), o que é interpretado pelos autores como um mecanismo compensatório, no qual os dois hemisférios estariam engajados para melhorar o desempenho em uma tarefa.

As funções cognitivas também são afetadas de formas diferentes com o envelhecimento. Entretanto há grande variabilidade individual, que depende da inteligência prévia, escolaridade e saúde física. Apesar deste problema, podemos destacar algumas alterações consistentemente encontradas na literatura a respeito do envelhecimento.

As habilidades visuoespaciais e de planejamento não mostram diferenças com o envelhecimento (LUCZYWEK, 2007). A memória, particularmente a memória explicita episódica, apresenta diminuição com a idade (KEEFOVER, 1998). A memória operacional apresenta menor capacidade, particularmente na presença de distratores (FOOS; WRIGHT, 1992). Devemos citar que muitos pesquisadores consideram a memória operacional e a atenção funções mutuamente dependentes e que compartilham os mesmos substratos neurais, tais como o córtex pré-frontal dorsolateral (MILHAM et al., 2002). Na seção subseqüente detalharemos mais os déficits atencionais.

A linguagem também mostra alterações principalmente no reconhecimento de palavras e em tarefas de fluência verbal (IAN-STUART, 2002).

Fatores psicomotores também estão diminuídos com o envelhecimento: tempo de reação (MOTA, 2006) e maior latência para fazer movimentos oculares sacádicos (KANEKO et al., 2004).

Com o uso das técnicas funcionais de neuroimagem, a ativação de regiões cerebrais de idosos em comparação com jovens tem sido investigada, particularmente em tarefas de memória. Achados freqüentes são a hipoativação da região hipocampal durante a fase de codificação e de evocação e a hipoativação de áreas perceptivas visuais (DENNIS; DASELAAR; CABEZA, 2007). Por outro lado, um achado intrigante, descrito na literatura, tem sido a hiperativação do pré-frontal esquerdo em tarefas de memória, particularmente em idosos que apresentam melhor desempenho. Tal 
achado tem sido interpretado como um recrutamento adicional na tentativa de compensar a diminuição da eficiência de outra região cortical, como a região hipocampal (GRADY, 2008).

\subsubsection{Atenção e Envelhecimento}

A atenção é fundamental para a realização de um grande número de tarefas. Os idosos apresentam declínio em algumas "formas" de atenção e não em outras. A atenção sustentada, cujo teste típico seria pedir a um sujeito que respondesse sempre que um determinado alvo aparecesse em um fluxo contínuo de estímulos, mostra-se preservada em idosos (STUART-HAMILTON, 2002).

Já os estudos de atenção seletiva, que se refere à capacidade de concentrar-se em uma tarefa ignorando estímulos irrelevantes, apresentam resultados contraditórios na literatura, apesar de haver uma tendência em se admitir um déficit atencional, em especial nas tarefas que requerem maior demanda atencional. Madden (2007) descreve um declínio da atenção em tarefas de busca visual, em idosos, para alvos que sejam semelhantes aos distratores. Idosos também apresentam pior desempenho em localizar o alvo (OWSLEY et al., 2000). Usando o teste de Stroop e ressonância magnética funcional, Milham et al. (2002) mostraram uma menor ativação do córtex pré-frontal e parietal posterior em idosos e uma maior ativação da via ventral visual (córtex temporal) o que foi interpretado como uma inabilidade de inibir estímulos irrelevantes.

O envelhecimento mostra um declínio em tarefas de atenção dividida, nas quais se deve prestar atenção a duas ou mais tarefas simultaneamente (VANESTE; POUTHAS, 1999; CASTEL; CRAIK, 2003). Outras tarefas usando outras vias sensoriais, como audição e tato, mostram resultados semelhantes (ANDRÉS et al., 2006; VALERIANI et al., 2003).

Há diferenças na ativação cerebral de idosos em relação a jovens, em tarefas que avaliem a atenção. Os achados mais freqüentes se referem a uma diminuição da ativação de algumas regiões cerebrais. A diminuição da ativação frontal em idosos foi encontrada em alguns estudos, que usaram tanto ressonância magnética funcional (FERNANDES et al., 2006) como PET (ANDERSON et al., 2000) para avaliar idosos e jovens em tarefas de atenção dividida. Dennis et al. (2007) sugerem que o déficit encontrado em tarefas de memória se deva, principalmente, à fase de codificação, isto é, 
à fase perceptiva o que estaria ligado aos recursos atencionais empregados na percepção.

A interpretação mais encontrada na literatura é de que esta hipoativação esteja vinculada ao declínio inibitório dos mecanismos neurais da atenção, tendo como substrato neural uma menor ativação do córtex pré-frontal, ou seja, tal região seria importante para a inibição da resposta a estímulos irrelevantes e sua hipoatividade estaria associada a uma deficiência na inibição (VALERIANI; RANGHI; GIAQUINTO, 2003; ANDRÉS; PARMENTIER; ESCERA, 2006).

Todavia, em algumas tarefas este declínio na ativação de algumas regiões cerebrais é também acompanhado de uma ativação de outros componentes da rede frontoparietal vinculada à atenção e que pode ser interpretada como um recrutamento compensatório de regiões cerebrais, a fim de auxiliar na execução da tarefa (MADDEN et al., 2006). No estudo de Madden et al. (1997), a ativação da via occipitotemporal foi maior em jovens e a ativação de regiões pré-frontais foi maior em idosos, o que sugere a utilização de estratégias cognitivas diferentes.

Deve-se salientar que as tarefas empregadas por Madden et al. (2006) eram de busca visual e as tarefas utilizadas por Milham (2002) eram de inibição de resposta o que pode explicar os resultados divergentes, em relação à região pré-frontal.

\subsubsection{Tempo e Envelhecimento}

A tentativa de explicar o fato de que os idosos tendem a descrever o tempo passando mais rápido do que os jovens já vêm de longa data (JAMES, 1952). Estudos que utilizam questionários tendem a suportar este fato, frequentemente notado pelos idosos (JOUVET, 1983). Um fator que poderia interferir na percepção de tempo a ser avaliado em idosos seria o presente psicológico, que de acordo com Block, Zackay e Hancock (1999) pode ser definido como o período no qual um intervalo de tempo é percebido e presenciado como uma unidade de tempo, constituindo o agora do sujeito, que duraria cerca de 3 a 5 segundos. Assim, fatores que influenciassem a percepção de tempo nesta janela temporal influenciariam o modo como avaliamos o tempo transcorrido.

Há evidências, como descrito na seção 1.1, de que os mecanismos envolvidos na percepção de tempo de durações menores são diferentes daqueles envolvidos na 
percepção de tempo de durações maiores (BLOCK; ZAKAY; HANCOCK, 1998; FRAISSE, 1984; PÖPPEL, 1997). Estes mecanismos poderiam ser alterados de forma diferente pelo envelhecimento.

O declínio do desempenho em idosos é mais expressivo para durações relativamente longas (segundos a minutos), particularmente em tarefas nas quais as demandas atencionais sejam maiores (VANNESTE; POUTHAS, 1999).

Várias tarefas foram propostas para avaliar a percepção de tempo em idosos, o que provavelmente explica os resultados divergentes encontrados nos diversos estudos realizados avaliando percepção de tempo em idosos.

Vários modelos têm sido propostos para explicar as diferenças de percepção de tempo em idosos e jovens. O modelo mais utilizado é o relógio interno. Neste modelo, as explicações, inicialmente propostas, para o pior desempenho em idosos, em tarefas que envolvam a percepção de tempo, seria a lentidão do marca-passo, oriunda de uma diminuição do metabolismo e da temperatura (WEARDEN; PENTON-VOAK, 1995). Mais recentemente, outros fatores ganharam maior destaque, sendo os mais citados a atenção e a memória.

Alguns estudos sugeriram que a lentidão do relógio com a idade parece não ser o fator preponderante, mas alterações nos processos de memória poderiam explicar as diferenças encontradas (WEARDEN; WEARDEN; RABBITT, 1997). Estas alterações podem ser entendidas utilizando-se a teoria escalar: os pulsos advindos do relógio interno são mantidos na memória operacional e depois podem ser transferidos para a memória de longa duração. Com o envelhecimento, haveria uma distorção das memórias de longo prazo. Esta distorção mostrou ocorrer em idosos para tarefas de discriminação temporal de estímulos auditivos, mas não ocorreu em tarefas de discriminação da frequiência, mostrando ser específica para a apreensão do lapso de tempo (MCCORMACK; BROWN; MAYLOR, 2002).

A atenção, por outro lado, interferiria na passagem dos pulsos: quanto maior a atenção dispensada à duração de um estímulo, maior seria a passagem de pulsos para o acumulador, conseqüentemente melhor o desempenho. Quanto menor forem os recursos atencionais disponíveis, seja por uma diminuição geral destes recursos ou pela utilização destes em outras tarefas, haveria uma menor passagem de pulsos, tendo como consequiência, um pior desempenho na avaliação de uma dada duração (BLOCK; ZACKAY; HANCOCK, 1998). Na verdade, para ser mais preciso, a atenção aumentaria a probabilidade do interruptor ficar aberto, consequentemente seria maior o tempo de 
abertura. $\mathrm{O}$ interruptor teria uma freqüência própria de abertura, com distribuição normal, sendo por esta causa que, ao diminuir os recursos atencionais dirigidos à percepção do lapso de tempo, haveria uma tendência de aumentar o desvio padrão, isto é, a variabilidade da resposta.

Há quatro métodos para avaliar a percepção e a ação do envelhecimento: estimativa verbal (digo, verbalmente, quanto durou), produção temporal (devo produzir uma duração dada verbalmente), reprodução (reproduzo uma duração percebida) e discriminação (comparo duas durações).

Em teoria, a lentidão do ritmo do marca-passo pode ser avaliada pela estimativa verbal e pela produção. Os demais métodos não deveriam mostrar diferenças entre jovens e idosos, visto que usariam o mesmo ritmo do marca passo para reproduzir ou para comparar dois estímulos. Entretanto, os estudos mostram dados discordantes a este respeito. Descreveremos a seguir uma breve revisão da literatura sobre percepção de tempo e envelhecimento.

Em um estudo de Arenberg (1968), usando uma tarefa de discriminação temporal, não foram encontradas diferenças entre idosos e jovens. O problema é que houve fase de treinamento com retro-alimentação e há autores que sugerem que a retroalimentação recalibre o marca passo (BLOCK; ZACKAY; HANCOCK, 1998). Há um estudo prévio, de discriminação de tempo conduzido por Smythe e Goldstone (1957) que não mostrou diferenças entre jovens e adultos, mas apresentava problemas metodológicos. Já o estudo de Goldstone, Boardman e Lhamon (1958), utilizando produção de tempo, mostrou diferenças significativas.

$\mathrm{Na}$ década de oitenta houve uma ausência de estudos enfocando o tema envelhecimento e tempo, mas neste período se desenvolveram teorias cognitivas que deram suporte aos estudos posteriores. O primeiro estudo a abordar a percepção de tempo em idosos foi aquele produzido por Eisler e Eisler (1994), usando reprodução de tempo, mostrou diferenças entre jovens e adultos de idade entre 40 e 50 anos. A diferença foi uma superestimação do tempo reproduzido, no grupo dos idosos em relação aos jovens, em intervalos maiores que 5 segundos. Não foram encontradas diferenças para durações de 1,5 a 4,5 segundos.

Block, Zakay e Hancock (1998) fizeram uma meta-análise mostrando diferenças significativas entre idosos e jovens para tarefas de produção e estimativa verbal de tempo, mas não encontraram diferenças significativas na reprodução de tempo. $O$ achado de que idosos tendem a produzir intervalos mais curtos e estimativas verbais 
mais longas tende a se opor a idéia de que a lentidão do marca-passo seria um fenômenos básico para explicar as diferenças na percepção de tempo em idosos e jovens. Esta meta-análise sugere que o fato de utilizar intervalos e não durações tenham contribuído nas diferenças e que os recursos atencionais limitados tenham um papel relevante na percepção de tempo em idosos.

Os resultados de Vanneste e Pouthas (1999), usando reprodução de intervalo com vários alvos, mostraram uma piora no desempenho de idosos em relação aos jovens, quando há uma maior demanda atencional. Não houve diferença na situação na qual havia pequena demanda atencional. Outro dado interessante é que não houve correlação com tarefas que avaliam memória operacional como os dígitos diretos, o que permitiu aos autores suporem que a atenção tenha papel mais pronunciado no desempenho dos idosos. Neste estudo, os idosos tenderam a subestimar e tiveram maior variabilidade em suas reproduções.

O trabalho de Carrasco, Guillem e Redolat (2001), que utilizou tarefa de reprodução de intervalo temporal para 5 e 10 segundos, apresentou um subestimação para idosos e superestimação para jovens do intervalo considerado. Postularam que o relógio interno dos idosos estaria mais acelerado e que as unidades subjetivas de tempo seriam menores com o envelhecimento.

Rammsayer (2001) avaliou a percepção de tempo em idosos e jovens, utilizando estímulos auditivos. Encontrou diferenças na discriminação temporal (usando método adaptativo). Não encontrou diferenças nas tarefas de produção e reprodução de tempo, considerando a acurácia (erro absoluto) e os coeficientes de variação (desvio padrão dividido pela média do tempo reproduzido). Portanto, neste estudo, a discriminação temporal foi método que melhor diferenciou idosos de jovens.

Neste estudo, apesar de não ter ocorrido diferença significativa na acurácia e coeficiente de variação, há uma tendência significativa de idosos superestimarem a reprodução de 1 segundo. $O$ autor sugere que mecanismos atencionais possam estar envolvidos neste achado, particularmente na alocação de recursos atencionais à fase de reprodução. Destarte, um número maior de pulsos é necessário sair do marca-passo (uma parte deles são perdidos pela falta de atenção) e chegar ao acumulador (para serem comparados com o número de pulsos obtidos na fase de codificação), levando a superestimação da reprodução. Deve-se citar que os pulsos, teoricamente, são gerados de forma regular. 
Quanto ao mecanismo neuroquímico que poderia explicar as alterações da percepção de tempo encontradas no envelhecimento, o sistema dopaminérgico tem sido o mais implicado (MECK, 1996). Supostamente, as vias dopaminérgicas seriam importantes tanto na velocidade do marca-passo como no controle do interruptor, considerando o modelo do relógio interno. O estudo de Braver e Barch (2002) aponta que alterações na memória e atenção encontradas em idosos se deveriam ao declínio da função das projeções dopaminérgicas para o córtex pré-frontal. Este artigo, entretanto, avaliou tarefas não relacionadas diretamente a percepção de tempo.

Todavia, Ratikin, Scarmeas e Li (2006) administraram 1-dopa a jovens e idosos, comparando a produção temporal antes e depois da utilização da medicação. O resultado mostrou o efeito de subestimação da dopamina na tarefa de produção de tempo, mas não houve efeito adicional da l-dopa em idosos, o que não confirma a hipótese que a dopamina esteja vinculada às alterações da percepção de tempo encontradas no envelhecimento.

O artigo de Espinosa-Fenández et al. (2003) traz como resultados uma subestimação do tempo, utilizando uma tarefa de produção de tempo. Sua explicação tende a justificar a diferença de desempenho entre idosos e jovens como sendo relativa a uma diminuição da capacidade dos idosos em direcionar recursos atencionais para o tempo.

Coelho et al. (2004) avaliaram a estimativa de tempo e a produção de tempo em idosos com várias idades. Neste estudo, encontrou-se uma correlação positiva com a estimativa de tempo e negativa com a produção de tempo, indicando uma possível aceleração do relógio interno ou alternativamente, um déficit atencional. Utilizando potenciais evocados (ERP) para avaliar o efeito do envelhecimento no processamento de características temporais de um estímulo, Kisley et al. (2005) mostrou redução da amplitude de potenciais lentos nos lobos frontais, o que foi interpretado com um possível déficit na memória operacional ou déficit atencional.

Para tarefas de reprodução, sabe-se que se uma tarefa é realizada durante a fase de percepção as reproduções de uma dada duração tendem a ser menores. Se a tarefa concorrente é realizada durante a fase de reprodução, as durações reproduzidas tendem a ser maiores. Há duas explicações para o fenômeno. Na primeira interpretação a diminuição de recursos atencionais para a tarefa temporal, levaria uma menor quantidade de pulsos contabilizados no acumulador, visto que o interruptor é ligado apenas quando a atenção está voltada para a percepção do tempo (ZACKAY; BLOCK, 
2007). A outra interpretação seria de que o acumulador dependesse da memória operacional e tarefas que tivessem demanda alta por recursos da memória operacional levariam a um interferência na capacidade de armazenar pulsos no acumulador (FORTIN; ROSSEAU, 1998).

O estudo de Ulbrich et al. (2007) que utilizou uma tarefa de reprodução semelhante àquela que empregamos em nosso trabalho, encontrou evidências de que a reprodução de duração de intervalos maiores que 3000 ms estão correlacionados com o desempenho em tarefas que exijam memória operacional. Esta correlação não foi encontrada para durações menores que $3000 \mathrm{~ms}$. Outro fato interessante, encontrado neste estudo, é que a reprodução de durações curtas para estímulos visuais se correlaciona com aquela encontrada para estímulos auditivos. Entretanto, a reprodução de durações curtas não se apresenta correlacionada à reprodução de durações longas, evidenciando a hipótese de que haja dois processos distintos para a percepção de tempo: um para intervalos curtos e outro para intervalos longos. Neste artigo, não foram verificados diferenças significativas entre idosos e jovens.

Resumindo, podemos verificar uma grande variabilidade de resultados que está vinculada às tarefas, ao desenho do estudo, à duração empregada, ao uso de intervalo ou duração e tipo de análise utilizada.

Nas durações menores que 3 segundos, a atenção apresenta-se como um fator importante (ULBRICH, 2007). Verificamos que as tarefas de reprodução de tempo e de discriminação temporal mostram-se particularmente interessantes para avaliar os efeitos da atenção e da memória operacional, uma vez que o mesmo marca-passo está envolvido na percepção de tempo e na resposta, seja ela uma reprodução ou uma comparação (discriminação). O mesmo já não acontece com tarefas de estimativa verbal de tempo e de produção de tempo, uma vez que neste caso não poderíamos diferenciar com facilidade os efeitos oriundos do atraso ou aceleração do relógio daqueles produzidos pela atenção.

Com relação à análise, não foram encontrados estudos que usassem a teoria de detecção de sinais em tarefas de discriminação de tempo, em idosos. 


\subsection{Doença de Alzheimer}

Com o envelhecimento da população, o impacto da doença de Alzheimer vem aumentando na saúde da população. Estima-se que a prevalência de demência em nosso meio seja de 7,1 \% (HERRERA et al., 2002). A prevalência de demência aumenta com o avanço da idade em todas as regiões do mundo. Com relação ao gênero, há um predomínio de mulheres, que no estudo brasileiro chegou a 2:1. A doença de Alzheimer (DA) é o tipo de demência mais prevalente, representando cerca de 55\% das demências.

As deficiências oriundas desta doença incapacitam progressivamente a pessoa acometida de forma a impedir que mantenha atividades laborativas e, posteriormente, a execução das atividades básicas, incluindo sua própria higiene. Além disso, sobrecarrega consideravelmente os cuidadores por um período longo.

A doença de Alzheimer (DA) é uma doença neurodegenerativa caracterizada por intensa perda neuronal, degeneração sináptica, placas senis e os emaranhados neurofibrilares. A fase pré-clínica da doença se inicia por volta da quarta década de vida, com acúmulo progressivo de placas senis e de emaranhados neurofibrilares. Nesta fase, as lesões não são suficientes para destruir a reserva funcional do indivíduo.

O diagnóstico de certeza envolve o exame anatomopatológico, que é baseado na densidade das placas senis e na classificação de Braak e Brak para os emaranhados neurofibrilares (BRAAK; BRAAK, 1991).

O quadro clínico geralmente se inicia com uma síndrome amnéstica, seguida por alterações de personalidade, apatia, déficits de atenção, de linguagem e das funções visuoconstrutivas. Com a progressão da doença, todas as funções cognitivas são afetadas o que corresponde a uma atrofia generalizada do córtex cerebral (MESULAM, 2000), como pode ser observado na figura abaixo. 


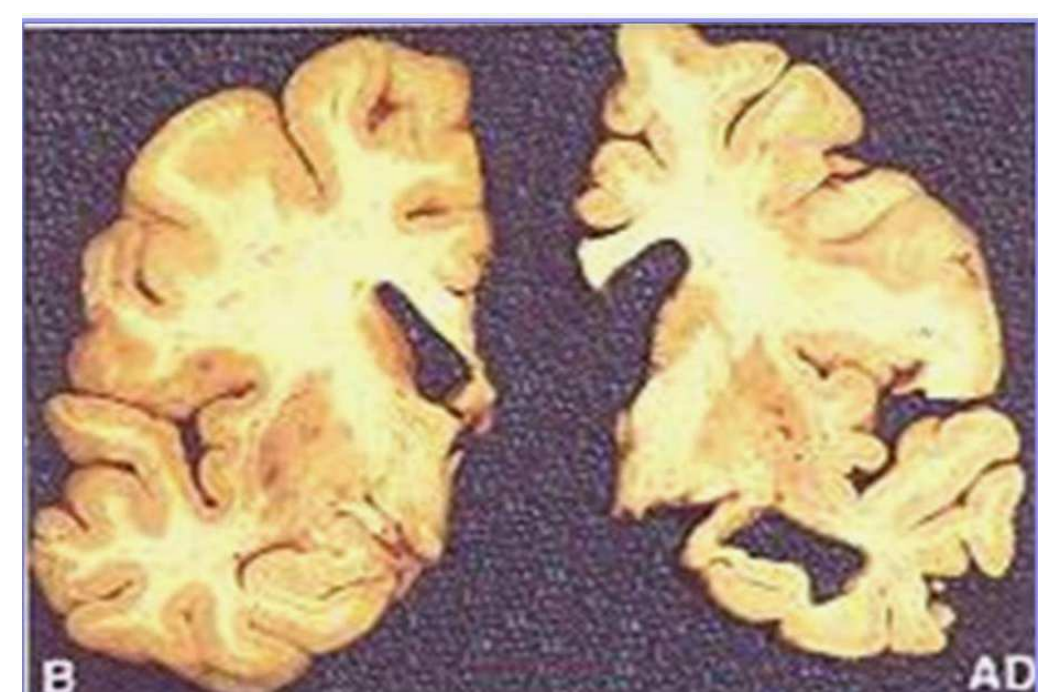

Figura 1.4.1. No lado esquerdo, podemos verificar um cérebro relativo a um idoso sem demência e no lado direito, um cérebro de um paciente com doença de Alzheimer.

Fonte: www.neurocienciasnaweb.com.br/palestras.asp?pagR=4

Para diagnóstico clínico, são usados os critérios NINDCS-ADRDA (MCKHANN, 1984), do DSM-IV (APA, 1994) ou da Classificação Internacional de Doenças, na sua $10^{\mathrm{a}}$ edição (OMS, 1993). Tais critérios clínicos têm aproximadamente 85\% de correlação com os achados neuropatológicos. Em pesquisas, alguns diagnósticos estruturados são usados, podendo-se citar o ADAS-cog e o CAMDEX. Este último será utilizado para a avaliação diagnóstica dos pacientes com doença de Alzheimer que irão participar do presente estudo.

O processo neurodegenerativo na DA leva à deficiência em diversos sistemas de neurotransmissores, entretanto, a deficiência do sistema colinérgico é a mais consistente e apresenta o maior significado quantitativo. A acetilcolina é um neurotransmissor presente no SNC que é degradada pela acetilcolinesterase, presente nos terminais dos neurônios colinérgicos. Os grupamentos de neurônios colinérgicos do SNC são encontrados no tronco cerebral e no prosencéfalo basal. A via septo-hipocampal (dos núcleos septal medial e da banda diagonal de Broca para o hipocampo) e a via Meynertcortical (do núcleo basal de Meynert para a amígdala e neocórtex) são as vias mais importantes que se originam no prosencéfalo basal (MESULAM, 2000). O papel das vias colinérgicas nos mecanismos de memória e de atenção tem sido demonstrado em humanos e em animais (SARTER; PARITH, 2005; SARTER et al., 2005). A diminuição acentuada da atividade colinérgica mostra nítida correlação com o declínio cognitivo. Assim, as estratégias que visam aumentar a quantidade de acetilcolina nas fendas sinápticas, tais como os inibidores da acetilcolinesterase, são tratamentos 
eficazes na melhora cognitiva dos pacientes com DA e têm ação na melhora dos escores em provas que exigem atenção espacial (SARTER; PARITH, 2005).

Foster, Behrmann e Stuss (1999) e Parasuraman e Haxby (1993) mostraram que apesar da evolução heterogênea do quadro, a memória é a função cognitiva que apresenta deterioração em primeiro lugar. Segue-se a deterioração da atenção e posteriormente, a linguagem e as funções visuoespaciais são acometidas. Só na fase avançada da doença há alteração da psicomotricidade.

\subsubsection{Atenção na doença de Alzheimer}

No estudo da atenção, sempre utilizamos uma via sensorial a fim de estudar o efeito atencional na formação do percepto. Assim, como a DA é uma doença progressiva, é importante avaliar se as disfunções cognitivas são provenientes de deficiências sensoriais ou atencionais. Esta questão foi abordada em um estudo elegante realizado por Rizzo e Anderson (2000), no qual foram avaliadas as funções sensoriais visuais, incluindo a acuidade visual estática, percepção de cor, estereoscopia, percepção de movimento e acuidade visual dinâmica. Os pacientes com DA de grau leve foram comparados com idosos normais e houve pareamento por idade. Foram encontradas alterações leves na discriminação de cor e da freqüência espacial nos pacientes com DA em relação aos idosos normais, confirmando os dados clínicos que indicam que a percepção na DA está preservada. De forma diferente, provas que avaliaram a atenção dividida e a atenção sustentada mostraram escores sensivelmente piores em pacientes com DA e mostraram correlação com o desempenho em testes neuropsicológicos.

Há um esforço de caracterizar os déficits de atenção na doença de Alzheimer. Perry e Hodges (1999), em uma revisão da literatura, asseveram que a atenção dividida (relacionada ao focar da atenção em mais que um estímulo ou tarefa, ao mesmo tempo) e a atenção seletiva (capacidade de manter o foco da atenção em um alvo e ignorar distratores) estariam alteradas em estágios iniciais da doença, enquanto a atenção sustentada (capacidade de manter o foco atencional por períodos maiores de tempo) só estaria alterada em estágios mais avançados da doença.

Foster, Behrmann e Stuss (1999) mostraram que pacientes com DA leve têm dificuldades em tarefas de busca visual, quando o alvo é parecido com os distratores. $\mathrm{O}$ estudou mostrou que o tempo de reação é proporcional ao número de estímulo. Ao 
contrário de pacientes com DA moderada, os pacientes com quadro leve não mostraram diferenças em relação ao controle, na busca visual simples (alvo é bem diferente do distrator). Tal resultado foi interpretado com uma dificuldade em mudar o foco atencional voluntariamente, nas fases leves da DA. O trabalho de Danckert et al. (1998) enfatizou a dificuldade de inibir distratores que aparecem abruptamente na tela, asseverando que na DA leve há problemas com a atenção voluntária ou endógena, mas não com a atenção automática ou exógena.

Outra característica observada em estudos de busca visual é a dificuldade de ajustar o tamanho do foco atencional (GREENWOOD; PARASURAMAN; ALEXANDER, 1997), pacientes com DA leve se beneficiam pouco de pistas válidas que indiquem uma região mais ampla na qual o alvo pode ser apresentado (PARASURAMAN; GREENWOOD; ALEXANDER, 2000).

Usando o modelo de Posner (POSNER; PETERSEN, 1990) no qual a atenção seletiva é divida em três fases (liberação, mudança e engajamento), alguns trabalhos sugerem que, na DA leve, haveria uma dificuldade de liberação e mudança do foco atencional (PARASURAMAN; HAXBY, 1993; MARUFF; CURRIE, 1995; PERRY; HODGES, 1999). Tal alteração estaria vinculada a uma diminuição da função do córtex parietal posterior, achado freqüente nos exames de SPECT e PET, e a uma deficiência colinérgica (NOBILIE; SANNITA, 1997).

Outro fato importante a ser salientado é que o padrão de alterações da atenção não é homogêneo nas fases leves da DA. Alguns pacientes apresentam desempenho prejudicado em tarefas que requeiram atenção seletiva bilateralmente e outros apresentam déficits unilaterais, apenas (MARUFF; MALONE; CURRIER, 1995).

\subsubsection{Percepção de tempo na doença de Alzheimer}

Como pudemos observar na sessão prévia, os estudos dos déficits atencionais na DA têm enfocado a distribuição e o alocar da atenção no espaço. Poucos estudos avaliaram a atenção dos pacientes com DA na percepção de tempo. Igualmente, a percepção de tempo tem sido pouco avaliada a despeito do fato dos pacientes com DA exibirem precocemente desorientação temporal (antes da espacial) avaliada pela dificuldade de saber qual a data, dia da semana, horário e período em que permaneceu realizando uma atividade (MESULAM, 2000). 
O trabalho de Nichelli et al. (1993) foi um dos primeiros trabalhos a estudar a relação entre a percepção de tempo e DA. As tarefas consistiam em produção do tempo de um intervalo de 1 segundo e de estimativa de tempo de intervalos de 1 segundo. Os resultados mostram uma grande variabilidade para pacientes com DA e uma tendência de superestimar em relação aos idosos e jovens.

Levy e Dreier (1997) estudaram a compreensão mais geral sobre o tempo em pacientes com DA leve, que apesar de mostrarem mais desorientados em relação ao tempo (a data que se encontravam), não apresentavam dificuldades de dizer quantos segundos há em um minuto e outras questões referentes ao conhecimento cultural que temos a respeito do tempo. Tal resultado evidencia que o desempenho prejudicado dos pacientes com DA leve nas tarefas de percepção de tempo não se deve a uma alteração da capacidade de compreender o que significam as unidades de tempo usadas no cotidiano. Também, realizaram uma tarefa de estimativa verbal de tempo (intervalos 12 , 24, 60 e 120 segundos) e não foram encontradas diferenças. Todavia, o estudo de Carrasco, Guillem e Redolat (2000) avaliou a estimativa de tempo em pacientes com DA empregando, da mesma forma, uma tarefa de estimativa de tempo para intervalos de 5, 10 e 25 segundos. Encontraram diferença significativa no erro absoluto e na variabilidade em todos os intervalos e sugeriram que sua diferença em relação ao trabalho de Levy e Dreier (1997) se devia às diferenças na análise, particularmente, ao fato de Levy e Dreier usarem apenas o tempo estimado e não o erro absoluto como medida do desempenho, uma vez que usando a primeira medida, Carrasco e al, também não encontraram diferenças para a duração de 10 e 25 segundos.

Os artigos avaliados previamente enfocaram apenas a avaliação da percepção de tempo e não estudaram condições que a influenciassem, tais com a atenção e a memória. O único estudo do qual temos conhecimento que abordou a questão foi conduzido por Papagno, Allegra e Cardaci (2004) e avaliou a estimativa de tempo de intervalos de 15 e 50 segundos em duas condições distintas: maior demanda atencional e necessidade de maior capacidade de armazenamento da memória operacional. Tomando como medida de desempenho porcentagem de acertos, mostraram um pior desempenho nas duas condições, mas este foi particularmente pior para condição que requeria maior demanda atencional.

Pacientes com DA também mostram dificuldades de ordenar eventos no tempo (STORANDT; KASKIE; VON DRAS, 1998) que já aparece em pacientes que apresentam CDR de 0,5 em comparação com idosos sem demência e esta dificuldade 
piora com a evolução do quadro (CDR 1). Apesar disto, pacientes mantém o evento da primazia e do estímulo posterior, que se referem ao fato de haver melhor rememoração para o primeiro e o último estímulo de uma lista.

Resumindo, os estudos referentes à percepção de tempo em pacientes com Alzheimer são poucos em quantidade e não contemplam vários aspectos desta percepção de tempo. Não temos estudos que avaliaram, por exemplo, a reprodução de tempo, a discriminação de tempo, bem como estudo sistemático dos fatores que modulam a percepção temporal.

Dos resultados acima descritos, podemos verificar que há um pior desempenho em pacientes com DA em tarefas de estimativa verbal, que são mais bem avaliadas por porcentagem de acertos ou erro absoluto, uma vez que a variabilidade é consideravelmente maior neste grupo. Outra evidência que corrobora uma alteração na capacidade de avaliar o tempo é que pacientes com DA, pelo menos nas fases iniciais, mantém preservados conceitos relativos ao tempo, culturalmente aprendidos. Isto mostra que o problema não está no entendimento da tarefa, mas capacidade perceptiva.

\subsection{Justificativa do Trabalho}

O estudo da percepção de tempo tem crescido nas duas últimas décadas, particularmente com relação ao uso de novas formas de análise, à avaliação do efeito do envelhecimento nas capacidades cognitivas e à comparação do desempenho de como os pacientes com lesões cerebrais percebem o tempo.

Com a finalidade de abordar estas questões, nosso trabalho é constituído de 4 experimentos, divididos em dois grupos. O primeiro grupo de dois experimentos avalia a percepção de tempo e sua modulação atencional, em jovens. O segundo grupo de experimentos tem por finalidade comparar o desempenho de jovens, idosos e pacientes com DA.

Isto posto, nosso trabalho faz uma avaliação sistemática das tarefas de reprodução e discriminação de tempo, modulando os recursos atencionais através de variáveis do próprio experimento, não usando tarefas concorrentes que habitualmente são utilizadas para modular a demanda atencional. Poucos estudos usaram a primeira alternativa de modulação da atenção, cita-se o estudo de Vanneste e Pouthas (1999). 
Acreditamos que tal procedimento permite avaliar, usando a metáfora atencional da lente zoom, como a distribuição da atenção interfere na percepção de tempo. Além disto, quando realizamos duas tarefas concomitantemente, há uma competição tanto por recursos atencionais como por memória, sendo muitas vezes difícil discriminar qual fator tem maior relevância.

Além disto, não foram encontrados trabalhos, na literatura a respeito da percepção de tempo em idosos e pacientes com DA, utilizando a teoria de detecção de sinais com a finalidade de diferenciar atenção de outros fatores. Deve-se ainda citar a escassez de estudos sobre a percepção de tempo em pacientes com DA. Com isto, acreditamos que o presente trabalho traga contribuições originais para compreensão da percepção de lapso de tempo e da importância da atenção nesta percepção, discriminando a ação da atenção de outros fatores como a memória e a estratégia usada pelo indivíduo na realização das tarefas. 


\section{OBJETIVOS}

\subsection{Objetivos Gerais}

Temos por objetivo avaliar a modulação atencional da percepção de tempo nos jovens, idosos saudáveis e pacientes com doença de Alzheimer, considerando os aspectos psicofísicos desta percepção de tempo e sua modulação atencional.

\subsection{Objetivos Específicos}

- Avaliar o efeito da demanda atencional na percepção de tempo em tarefas de reprodução de tempo e de discriminação temporal, modificando as variáveis número de distratores e conhecimento (a priori ou a posteriori) do alvo.

- Discriminar os efeitos da modulação atencional daqueles relativos à memória e à estratégia dos participantes.

- Verificar a lei de Vierordt para os três grupos (jovens, idosos e pacientes com DA) e avaliar em quais durações o efeito da atenção é mais pronunciado.

- Determinar os pontos de igualdade (PI) em jovens, idosos e pacientes com DA.

- Comparar o desempenho de idosos e pacientes com doença de Alzheimer em testes cognitivos e nas tarefas psicofísicas (reprodução de tempo e discriminação temporal).

- Comparar a percepção de tempo entre jovens, idosos saudáveis e pacientes com DA, enfocando o papel da atenção e seus possíveis mecanismos neurofisiológicos. 


\section{MÉTODOS GERAIS}

\subsection{Participantes}

Neste estudo, participaram jovens voluntários saudáveis, com idades entre 19 a 32 anos que cursavam a Faculdade de Odontologia da Universidade de São Paulo e o Instituto de Física da Universidade de São Paulo.

Houve a participação de idosos saudáveis com idade maior ou igual a 65 anos, que não estivessem utilizando medicações psicoativas. Foram avaliados quanto a sua acuidade visual, utilizando-se a própria tela de experimento. Os critérios de exclusão empregados foram:

1) pontuação menor que 23 no exame do estado mental - mini-mental (FOLSTEIN; FOLSTEIN; MC HUCH, 1975).

2) história de glaucoma, catarata ou descolamento de retina.

3) medicação em uso: benzodiazepínicos, anticonvulsivantes, antidepressivos e antipsicóticos.

4) presença de transtornos afetivos, transtornos ansiosos, quadros psicóticos, epilepsia, acidentes cerebrais isquêmicos ou hemorrágicos, doença de Parkinson, síndrome amnéstica, quadro demencial ou transtorno cognitivo leve.

5) incapacidade de ler as instruções mostradas na tela do experimento ou dificuldade de nomear as figuras apresentadas.

6) analfabetos ou indivíduos com escolaridade menor que 2 anos.

Devemos salientar que os critérios de exclusão acima listados foram integralmente utilizados para os idosos saudáveis. Para o grupo de jovens, não foram realizadas avaliações cognitivas em virtude do fato de manterem atividades acadêmicas, o que tornaria desnecessária uma avaliação cognitiva com testes de rastreio para demências, portanto, o primeiro critério de exclusão não foi usado para o grupo em questão.

O grupo de pacientes com demência era oriundo do PROTER (Projeto Terceira Idade), ambulatório de psiquiatria geriátrica do Instituto de Psiquiatria do Hospital das Clínicas da Faculdade de Medicina da Universidade de São Paulo. Todos os indivíduos deveriam apresentar idade maior ou igual a 65 anos. Todos deveriam ter diagnóstico de 
doença de Alzheimer (DA) em estágio leve (CDR de 0,5 ou 1). O diagnóstico deveria ser obtido pela avaliação clínica, através da entrevista estruturada CAMDEX (o escore no CAMCOG deveria ser menor ou igual a 80), exames sanguíneos (glicemia de jejum, TSH, T3, T4, hemograma completo, sódio, potássio, uréia, creatinina, TGO, TGP, VDRL, dosagem de vitamina B12 e de ácido fólico) e exames de imagem (tomografia de crânio ou ressonância magnética de encéfalo e se necessário SPECT). Além disto, foram aplicadas, aos pacientes com DA, a escala de ansiedade de Hamilton (HAM-A), a escala de depressão de Montgomery (MADRAS) e a escala CDR (Clinical Dementia Rating), com a finalidade de avaliar a gravidade do quadro demencial.

Os critérios de exclusão foram:

1) pontuação menor que 18 no enxame do estado mental - mini-mental (FOLSTEIN; FOLSTEIN; MC HUCH, 1975) ou pontuação maior que 80 no CAMCOG.

2) história de glaucoma, catarata ou descolamento de retina.

3) medicação em uso: benzodiazepínicos e anticonvulsivantes. Dosagens baixas de antidepressivos e antipsicóticos eram permitidas.

4) presença, no momento da avaliação, de transtornos afetivos, transtornos ansiosos, quadros psicóticos, epilepsia, acidentes cerebrais isquêmicos ou hemorrágicos, doença de Parkinson ou quadro demencial cujo diagnóstico não era doença de Alzheimer.

5) incapacidade de ler as instruções mostradas na tela do experimento ou dificuldade de nomear as figuras apresentadas.

6) analfabetos ou indivíduos com escolaridade menor que 2 anos.

Para indivíduos que realizaram experimentos nos quais foi empregado registro eletroencefalográfico, um critério de exclusão adicional era a presença de contração muscular involuntária durante o estado vigil, que não pudesse ser reduzida por manobras de relaxamento e que produzisse interferência significativa no traçado de EEG.

Os experimentos 1 e 2 foram realizados exclusivamente por jovens que estavam freqüentando um curso universitário na Universidade de São Paulo. O experimento 1 foi realizado por 35 voluntários jovens, com média de idade de 21,2 $\pm 0,5$ anos, sendo 7 participantes do sexo masculino e 28 participantes do sexo feminino. $\mathrm{O}$ experimento 2 foi realizado por 20 voluntários jovens, com média de idade de 21,5 0,5 anos, sendo 9 participantes do sexo masculino e 11 participantes do sexo feminino. 
Os experimentos 3 e 4 foram realizados pelos três grupos: jovens saudáveis (grupo de jovens), idosos saudáveis (grupo de idosos) e pacientes com doença de Alzheimer (grupo de pacientes com DA). As características dos participantes dos grupos são descritas a seguir. $\mathrm{O}$ grupo de jovens era formado por 9 sujeitos, com idade média de 23,44 \pm 0,97 anos, sendo 4 participantes do sexo masculino e 5 participantes do sexo feminino. Todos estavam cursando um curso universitário na Universidade de São Paulo e a sua escolaridade, dada pelo número de anos completos de estudo formal, foi de 14,00 \pm 0,17 anos. No grupo de idosos saudáveis, o número de participantes foi de 11, com idade média de 69,5 $\pm 1,1$ anos, com 6 participantes do sexo masculino e 5 participantes do sexo feminino. A escolaridade foi de $6,4 \pm 1,3$ anos. No grupo de pacientes com DA, o número de participantes foi de 4 , com idade média de 80,0 $\pm 3,4$ anos, com 3 participantes do sexo feminino e 1 participante do sexo masculino. A escolaridade foi de 7,75 $\pm 3,15$ anos.

Os experimentos foram integralmente realizados no Instituto de Ciências Biomédicas da Universidade de São Paulo.

Todos os sujeitos que participaram deste experimento assinaram o Termo de Consentimento Livre e Esclarecido (Anexo A). No caso de tratar-se de um paciente com doença de Alzheimer, era necessária a assinatura de um responsável.

Este projeto foi aprovado pela Comissão de Ética em Pesquisas Envolvendo Seres Humanos do Instituto de Ciências Biomédicas da USP.

\subsection{Materiais}

Os experimentos foram realizados em uma sala com pouca luminosidade, baixos níveis de ruído e de temperatura agradável, conforme as necessidades dos sujeitos.

O sujeito se sentava em cadeira confortável e os estímulos eram projetados em uma parede branca, que distava $344 \pm 1 \mathrm{~cm}$ do sujeito. A tela projetada tinha $238 \pm 1$ por $238 \pm 1 \mathrm{~cm}$.

O programa utilizado para confeccionar os testes psicofísicos foi o "E-Prime 1.0". O computador utilizado para gerar os estímulos era um Pentium 4, com velocidade de CPU de 3,60 GHz, $512 \mathrm{Mb}$ de memória RAM. O projetor era da marca SONY SV60 VPL - EST e utilizamos a freqüência de $60 \mathrm{~Hz}$, na vertical. 
O registro eletroencefalográfico foi obtido em um aparelho BrainNet BNT-36, de trinta e seis canais, com frequiência amostral de 600 pontos/s e constante de tempo de 0,16 segundos. Usamos 21 eletrodos Ag/AgCl (Fp1/Fp2, F7/F8, T3/T4, T5/T6, F3/F4, $\mathrm{C} 3 / \mathrm{C} 4, \mathrm{P} 3 / \mathrm{P} 4, \mathrm{O} 1 / \mathrm{O} 2, \mathrm{FZ}, \mathrm{CZ}, \mathrm{PZ}$ e OZ, A1/A2) e o eletrodo terra foi posicionado no násio (ponto na região frontal na base do nariz entre as duas sobrancelhas), conforme o sistema international 10-20, preconizado pela Sociedade Brasileira de Neurofisiologia Clínica (LUCCAS et al., 1996) e pela American EEG Society (LESSER, 1994). Foram utilizadas as seguintes faixas de freqüência disponíveis no referido equipamento, em Hz: delta: de 0,3 a 3,9 Hz; teta: 4,0 a 7,9 Hz; alfa: de 8,0 a 12,5 Hz; beta 1: 12,6 a 19,9 Hz; beta 2: 20,0 a 26,0; e beta 3: 26,1 a $33 \mathrm{~Hz}$.

O aparelho de "trigger", cuja finalidade era sincronizar os eventos que ocorriam nas tarefas psicofísicas com o registro eletroencefalográfico, foi feito segundo as especificações do diretor da EMSA, empresa responsável pelo suporte técnico do equipamento de eletroencefalografia (anexo B). O computador usado para registrar os sinais eletroencefalográficos tinha as especificações: Pentium 4, CPU com velocidade de 2,40 GHz, 256 Mb de memória RAM.

\subsection{Metodologia Geral}

Após a avaliação inicial, com a finalidade de avaliar o sujeito quanto aos critérios de inclusão e exclusão, os sujeitos realizavam sessões de treinamento para avaliar se haviam entendido a tarefa. O número de sessões dependia do aprendizado do sujeito. Habitualmente, era necessária apenas uma sessão para jovens. Todavia, alguns sujeitos do grupo de idosos e do grupo de pacientes com DA tinham a necessidade de mais sessões (duas ou três). Além disto, antes de cada bloco, os sujeitos realizavam um pequeno treinamento, no qual relembravam aspectos da tarefa a ser realizada.

Realizamos tarefas psicofísicas de duas naturezas: reprodução de tempo e discriminação temporal.

A tarefa de reprodução de tempo, empregada nos experimentos 1 e 3 , consiste em reproduzir a duração de um estímulo. O sujeito deve atentar para a duração do estímulo (fase de codificação) e depois, pressionar uma tecla pelo tempo que julga ter durado o estímulo (fase de reprodução). 
A tarefa de discriminação temporal, empregada nos experimentos 2 e 4, consiste em julgar se a duração de um dado estímulo foi maior ou menor do que a duração do estímulo padrão. Em cada apresentação, o estímulo padrão é mostrado previamente. Segue-se o alvo, estímulo cuja duração será comparada com a duração do estímulo padrão. O sujeito deve indicar, através da utilização de uma tecla, qual estímulo apresentou maior duração: o alvo ou o estímulo padrão.

Os experimento de número 1 e 2 são experimentos unicamente psicofísicos e os experimentos de número 3 e 4, além das tarefas psicofísicas, foram realizados com registro eletroencefalográfico concomitante.

Em todos os experimentos, os participantes foram orientados a fixarem o olhar em uma cruz localizada no centro da tela (ponto de fixação). Também, eram orientados a não usar qualquer tipo de contagem, isto é, não deveriam transformar a duração de tempo em um número de determinadas unidades. Eram, também, desaconselhados a usar alguma parte do corpo para empreender esta contagem.

Em nenhum experimento havia informação a respeito desempenho do indivíduo.

Nos experimentos 3 e 4, os participantes eram orientados a não mover a cabeça ou partes do corpo, não mover os olhos, não piscar e não contrair musculatura da face durante a apresentação dos estímulos e a consecução da tarefa. Após cada apresentação, havia um período de descanso, no qual o sujeito era orientado a piscar e poderia movimentar os segmentos corpóreos que desejasse. Este período de descanso era finalizado, quando o sujeito apertava uma tecla que iniciava a apresentação dos estímulos. Após cada apresentação, o sujeito era informado se houve contração, movimentação ocular ou piscamento.

Os idosos e pacientes com DA realizaram testes cognitivos para avaliar o perfil de déficits dos grupos. Os testes realizados foram: mini-exame do estado mental, FOME, teste de trilhas (Trail Making A e B), teste da figura complexa de Rey, dígitos diretos, dígitos reversos e fluência verbal, tais teste são descritos no anexo C.

Consideramos como nível de significância $\alpha<0,05$, para todos os experimentos do presente trabalho. 


\section{EXPERIMENTO 1}

\subsection{Objetivo}

A finalidade deste experimento é avaliar a percepção de tempo, considerando a duração de um estímulo, o número de distratores e o conhecimento do alvo (os dois últimos supostamente, mediriam os recursos atencionais empregados).

Portanto, o objetivo principal é avaliar a influência da demanda atencional na percepção de tempo, considerando a relação entre o tempo objetivo (medido fisicamente) e o tempo subjetivo (experienciado pelo participante), isto é, se há superestimação ou subestimação do tempo objetivo. Deve-se, ainda, caracterizar em quais durações o efeito atencional ocorre prioritariamente.

Outro objetivo é determinar as durações de maior acurácia, na quais o tempo percebido, no caso reproduzido, seria similar ao tempo objetivo.

\subsection{Arranjo Experimental}

A tarefa utilizada é de reprodução de duração, que consiste em reproduzir a duração de um estímulo, pressionando uma tecla a duração que o indivíduo percebeu.

$\mathrm{Na}$ tarefa, utilizamos quatro figuras geométricas diferentes (círculo, quadrado, triângulo e elipse), isoecêntricas e de área equivalente a um quadrado de $3,29 \pm 0,08^{\circ} \mathrm{x}$ $3,29 \pm 0,08^{\circ}$ (ângulo visual). A excentricidade era de $13,72 \pm 0,09^{\circ}$, sendo que o centro da figura se situava nos vértices de um quadrado invisível, cujo centro é o ponto de fixação. O fundo era branco e as figuras eram pretas, tal como mostrada na figura 4.2.1. 


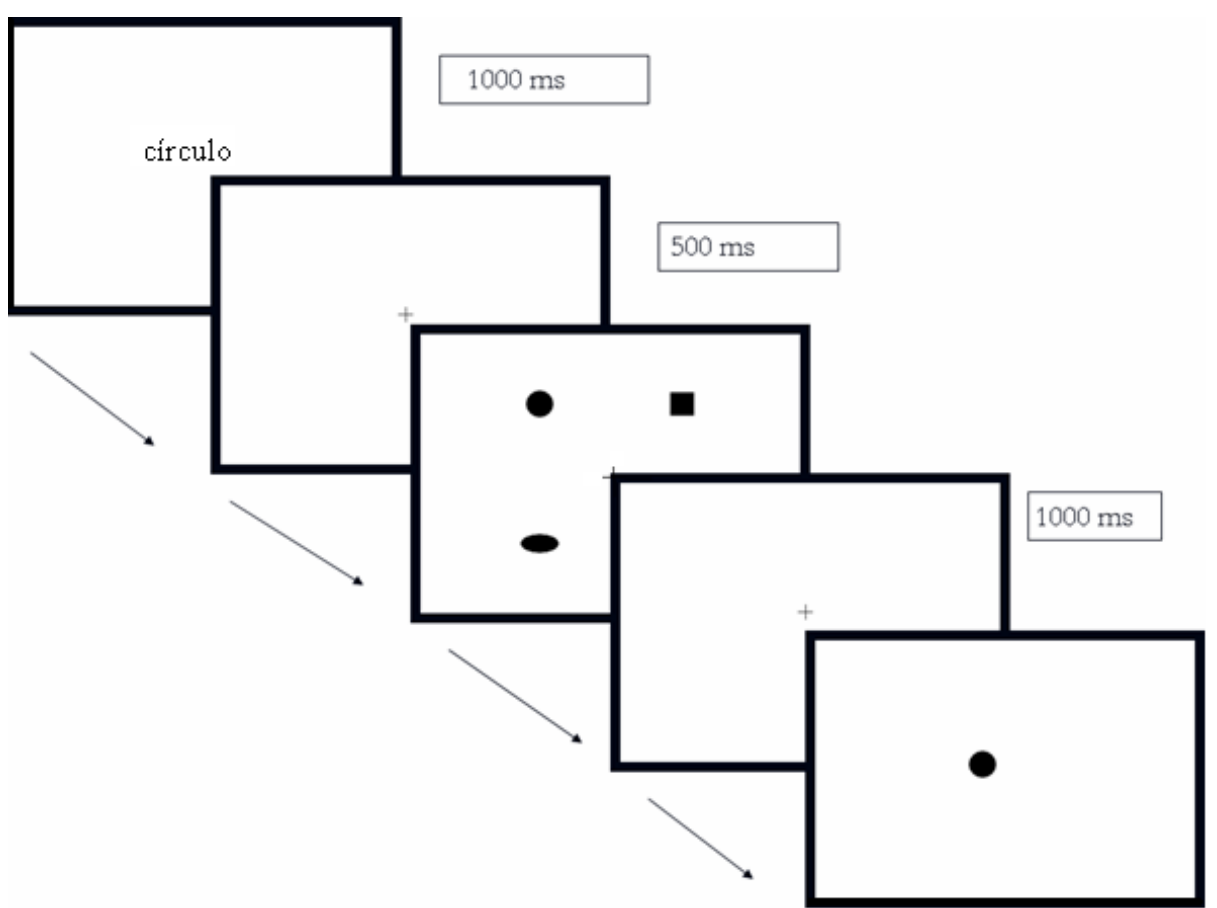

Figura 4.2.1. Figura ilustrativa de uma apresentação típica de um bloco 4 estímulos prospectivo. O círculo apresentado na tela final corresponde ao período no qual o participante reproduzia a duração do alvo.

A instrução dada aos participantes era de que deveriam prestar atenção na duração das figuras. $\mathrm{O}$ sujeito era orientado a manter seus olhos direcionados ao ponto de fixação e a não utilizar estratégia cognitiva que envolvesse contagem.

Utilizamos três parâmetros a fím de avaliarmos a percepção de tempo. O primeiro parâmetro era o conhecimento do alvo, isto é, na condição prospectiva, o indivíduo sabia previamente qual era o alvo (o nome da figura geométrica indicava qual figura seria o alvo, tal como mostrado na figura 4.2.1). Na condição retrospectiva, eram apresentadas as figuras e, posteriormente à apresentação destas figuras, o alvo era indicado. Nesta condição, o sujeito era orientado a prestar atenção em todas as figuras, visto que não sabia qual delas seria o alvo a ser reproduzido.

O segundo parâmetro era o número de figuras apresentadas, que poderia ser 1, 2 ou 4 estímulos. Havia apenas um alvo, independentemente do número de estímulos.

O terceiro parâmetro eram as durações dos estímulos: 0,$5 ; 1,0 ; 1,5 ; 2,0 ; 2,5 ; 3,0$; 3,$5 ; 4,0 ; 4,5 ; 5,0$ segundos, com incerteza total de $22,8 \mathrm{~ms}$ (incerteza referente à varredura vertical $\sigma=16,7 \mathrm{~ms}$, à varredura do teclado $\sigma=15 \mathrm{~ms}$ e ao programa usado na confecção dos estímulos visuais com $\sigma=4 \mathrm{~ms}$ ). 
O experimento apresentava cinco blocos, cuja ordem de apresentação foi aleatoriazada. Cada bloco consistia em sessenta apresentações e cada duração era apresentada 6 vezes, de forma pseudo-randômica ${ }^{2}$.

No bloco $1 \mathrm{C}^{3}$, o indivíduo deveria prestar atenção na duração do único estímulo que aparecesse na tela a fim de reproduzi-lo, apertando uma tecla. Deve-se salientar que no bloco $1 \mathrm{C}$, como apenas um estímulo é apresentado, não faz sentido classificá-lo em retrospectivo ou prospectivo.

No bloco 2P, antes da apresentação dos estímulos, era mencionada qual figura seria o alvo. A seguir, eram apresentados dois estímulos e a tarefa do indivíduo seria reproduzir a duração percebida do alvo. Deve-se ressaltar que os estímulos não apareciam em tempos iguais e nem terminavam em tempos iguais, pois a latência de aparecimento e as durações eram aleatorizadas. Note que, neste caso, havia um distrator.

No bloco 4P, o mesmo se sucedia: primeiramente, a informação sobre qual estímulo seria o alvo, seguindo-se a apresentação de quatro estímulos (um sendo o alvo e três distratores).

No bloco 2R, o sujeito não sabia qual estímulo seria o estímulo alvo, portanto deveria prestar atenção nos dois estímulos apresentados e, posteriormente com a indicação de qual figura era o alvo, era solicitado que reproduzisse um destes dois estímulos.

No bloco 4R, de forma idêntica, o sujeito não era informado sobre qual seria o alvo, entretanto quatro estímulos eram apresentados, ao fim dos quais, era solicitada a reprodução de um destes estímulos.

\subsection{Análise e Resultados}

A medida empregada para avaliar o desempenho dos sujeitos foi a diferença relativa porcentual da média de todos os sujeitos (resultados semelhantes foram encontrados utilizando-se a mediana), que pode ser obtida pela diferença entre a média

\footnotetext{
2 Chama-se de pseudo-randômico o processo no qual os resultados de apresentações anteriores influenciam a probabilidade de aparecimento de estímulos em apresentações posteriores. Note que em um processo randômico verdadeiro, o aparecimento de estímulos é independente das apresentações anteriores, portanto, não há um número fixo de apresentações para um dado parâmetro.

${ }^{3} \mathrm{C}$ se refere ao fato de que o bloco 1 é concomitantemente prospectivo e retrospectivo.
} 
da duração reproduzida (Drep) e a média da duração objetiva do estímulo (Dob), dividida pela média da duração objetiva do estímulo:

$$
\text { Diferença relativa }(\%)=100 \times(\text { Drep }- \text { Dob)/Dob (eq. 1) }
$$

Com relação a esta medida de desempenho devemos fazer algumas considerações. A primeira se refere ao fato da diferença relativa ser uma medida possivelmente assimétrica. A Diferença relativa (\%) é derivada, através de uma transformação linear, de uma medida denominada de acurácia ou razão. Tal medida de desempenho é dada por:

$$
\text { Acurácia (\%) = } 100 \times \text { (Drep/ Dob) (eq. 2) }
$$

Tal medida é uma variável definida como de razão, isto é, expressa o quociente


verificar que:

$$
\text { Diferença relativa }(\%)=\text { acurácia }(\%)-100 \quad \text { (eq. 3) }
$$

Destarte, há apenas uma transformação linear no domínio referente à diferença relativa ([-100, $\infty[)$. Neste caso, podemos depreender que não há uma assimetria real desta medida de desempenho, uma vez não há uma limitação da região dos valores negativas (tal região compreende os valores no quais se verifica Drep $<$ Dob).

A segunda consideração se refere ao fato da diferença relativa (\%) ser uma porcentagem e requerer uma transformação do tipo arcosseno, para que análises como ANOVA sejam utilizadas. Mediante a análise da equação (eq. 1), devemos observar que a diferença relativa é dada em porcentagem, mas não se refere a uma probabilidade cujo domínio é dado por [0,100] e cuja distribuição é binomial (ZAR, 1996).

Isso posto, quando a diferença relativa é positiva, encontramos uma superestimação da duração objetiva de um estímulo, isto é, o indivíduo reproduz o estímulo como tendo uma duração maior do que a duração realmente apresentada pelo estímulo. Por outro lado, quando a diferença é negativa, temos uma subestimação da duração objetiva do estímulo, ou seja, a duração percebida e reproduzida é menor que a duração objetiva do estímulo.

Devemos salientar que, neste experimento, não temos como distinguir claramente a duração percebida da duração reproduzida, apenas podemos conjeturar sobre a fase na qual o efeito atencional ocorre predominantemente. Não podemos, portanto, definir em que nível cognitivo se situa a distorção em relação à duração objetiva do estímulo. Assim, utilizaremos apenas o termo duração reproduzida, para o tempo avaliado pelo sujeito. 
Com a finalidade de avaliar a variabilidade, realizamos a medida do coeficiente de variação $(\mathrm{CV})$, que consiste na razão entre o desvio padrão e média da duração reproduzida:

$$
\left.\mathrm{CV}=S_{\text {Drep }} / \bar{X}_{\text {Drep }} \text { (eq. } 4\right)
$$

As análises estatísticas, com exceção das regressões, de todos os experimentos apresentados neste trabalho foram realizadas utilizando-se o programa STATISTICA 7.0 .

Tomamos a média da diferença relativa para cada duração do alvo, considerando o tipo de experimento e o número de estímulos e realizamos uma análise paramétrica de variância de medidas repetitivas (ANOVA $2 \times 3 \times 10$ ). ${ }^{4}$ Os fatores são, respectivamente: tipo de experimento (prospectivo e retrospectivo), número de estímulos (1, 2 e 4 estímulos) e duração do alvo (0,5 a 5 segundos). Fizemos o teste de normalidade de Kolmogorov-Smirnov que não mostrou diferenças significativas da distribuição normal.

Obtivemos significância estatística para todos os fatores principais: tipo de experimento $(\mathrm{F}(1,34)=5,9$ e $\mathrm{p}=0,021)$, número de estímulos $(\mathrm{F}(2,68)=24,8$ e $\mathrm{p}<$ $0,001)$ e duração $(\mathrm{F}(9,306)=141,5$ e $\mathrm{p}<0,001)$.

Todas as interações foram significativas: interação dos fatores duração e número de estímulos $(\mathrm{F}(18,612)=30,1$ e $\mathrm{p}<0,001)$, tipo de experimento e duração $(\mathrm{F}(9,306)=$ 43,4 e p < 0,001) e tipo de experimento e número de estímulos $(\mathrm{F}(2,68)=3,4$ e $\mathrm{p}=$ 0,040). A interação dos três fatores $(\mathrm{F}(18,612)=17,38)$ e $\mathrm{p}<0,001)$ também foi significativa (Figura 4.3.2).

Realizamos o teste post-hoc de Newman-Keuls, comparando tipo de experimento e número de estímulos. Para o tipo prospectivo, a presença de um estímulo é diferente, significativamente $(\mathrm{p}<0,001$ para as comparações entre 1 e 2 estímulos e entre 1 e 4 estímulos), em relação à presença de dois e quatro estímulos. Entretanto, dois ou quatro estímulos não foram diferentes entre si. Para o tipo retrospectivo, há diferença significativa entre 1, 2 e 4 estímulos ( $p<0,001$ entre comparações entre 1 e 2 estímulos; entre 1 e 4 estímulos e entre 2 e 4 estímulos). A figura 4.3.1 apresenta graficamente tais diferenças.

Comparando a condição $2 \mathrm{P} \operatorname{com} 2 \mathrm{R}$, encontramos diferenças, no teste post hoc, para as durações do alvo: $0,5 \mathrm{~s}(\mathrm{p}<0,001)$ e $1,0 \mathrm{~s}(\mathrm{p}=0,002)$. Comparando a condição

\footnotetext{
${ }^{4} \mathrm{Na}$ ANOVA, usamos o bloco $1 \mathrm{C}$ tanto na divisão prospectiva quanto retrospectiva. Isto foi feito para manter a simetria da análise, ainda que com este procedimento poderíamos perder poder estatístico.
} 
4P com 4R, houve diferenças significativas para as durações: 0,5 s ( $\mathrm{p}<0,001), 1,0 \mathrm{~s}(\mathrm{p}$ $<0,001)$ e $1,5 \mathrm{~s}(\mathrm{p}=0,003)$. A tabela 4.3.1. apresenta outros resultados do post hoc.

Tabela 4.3.1. Valores de p do post hoc (Newman-Keuls) para as durações do alvo, considerando os blocos experimentais.

\begin{tabular}{lllll}
\hline DURAÇÃO & $1 \mathrm{C} \neq 2 \mathrm{P} \quad 1 \mathrm{C} \neq 4 \mathrm{P} \quad 2 \mathrm{P} \neq 4 \mathrm{P} \quad 1 \mathrm{C} \neq 2 \mathrm{R} \quad 1 \mathrm{C} \neq 4 \mathrm{R} \quad 2 \mathrm{R} \neq 4 \mathrm{R}$ \\
\hline
\end{tabular}

\begin{tabular}{ccccccc}
0,5 & $<0,001$ & $<0,001$ & $<0,001$ & $<0,001$ & $<0,001$ & $<0,001$ \\
\hline 1,0 & $<0,001$ & $<0,001$ & n.s & $<0,001$ & $<0,001$ & $<0,001$ \\
\hline 1,5 & $<0,001$ & $<0,001$ & n.s & $<0,001$ & $<0,001$ & $<0,001$ \\
\hline 2,0 & $<0,001$ & 0,001 & n.s & $<0,001$ & $<0,001$ & $<0,001$ \\
\hline 2,5 & 0,027 & 0,002 & n.s & n.s & n.s & n.s
\end{tabular}

Notas: 1C (1 estímulo), 2P (2 estímulos, tipo prospectivo), 4P (4 estímulos, tipo prospectivo), $2 \mathrm{R}$ (2 estímulos, tipo retrospectivo), 4R (4 estímulos, tipo retrospectivo) e n.s. (não significante estatisticamente)

Para avaliar se a distribuição era simétrica, também empregamos as diferenças relativas da mediana de cada duração, considerando o tipo e o número de estímulos. Realizamos uma ANOVA 2x3x10, com os mesmos fatores. Os resultados foram semelhantes, apenas não encontramos significância para a interação de segunda ordem entre tipo e número de estímulos, o que ratifica o fato de que a distribuição das Drep era simétrica (pressuposto este que é necessário, mas não suficiente para determinar a normalidade de uma distribuição).



Figura 4.3.1. Mostra a média da diferença relativa dos sujeitos em função da quantidade de estímulos apresentados na tela, permitindo a avaliação da interação tipo e caso. Com um estímulo, não faz sentido classificá-lo em prospectivo ou retrospectivo. As barras de erro correspondem ao erro padrão da média (e.p.m). 



1 ESTÍMULO 2 ESTÍMULOS RETROSPECTIVO

Figura 4.3.2. Mostra diferença relativa da média de todos os sujeitos em função da duração do alvo, considerando o tipo de experimento e o número de estímulos. A barra de incerteza refere-se ao intervalo de confiança de 0,95 .

Com a finalidade de avaliar a existência de intervalo de tempo onde a duração reproduzida pelo sujeito é semelhante à duração real (ponto de igualdade - PI), isto é, ponto no qual se verifica maior acurácia, realizamos uma regressão exponencial do tipo:

$$
y(x)=y_{0}+A_{1} \exp \left[-(x-0,5) / t_{1}\right](\text { eq. 5) }
$$

Os parâmetros encontrados, usando o software de análise ORIGIN 5.0, são mostrados na tabela 4.3.2. Trata-se de uma regressão não linear de primeira ordem, usando o método dos mínimos quadrados.

Tabela 4.3.2. Parâmetros encontrados pela regressão exponencial para cada curva da figura 4.3.2., bem como a respectivas incertezas.

\begin{tabular}{|c|c|c|c|c|c|}
\hline Parâmetros & $1 \mathrm{C}$ & $2 \mathrm{P}$ & $4 \mathrm{P}$ & $2 \mathrm{R}$ & $4 \mathrm{R}$ \\
\hline Y0 & $-31,80 \pm 0,92$ & $-27,13 \pm 1,3$ & $-21,1 \pm 2,1$ & $-27,49 \pm 1,4$ & $-29,8 \pm 2,5$ \\
\hline $\mathrm{A} 1$ & $38,9 \pm 1,6$ & $67,4 \pm 1,4$ & $71,5 \pm 3,1$ & $109,6 \pm 2,4$ & $177,7 \pm 5,1$ \\
\hline T1 & $0,96 \pm 0,19$ & $1,50 \pm 0,18$ & $1,10 \pm 0,25$ & $0,91 \pm 0,10$ & $0,75 \pm 0,10$ \\
\hline
\end{tabular}


Com tais parâmetros, calculamos o ponto onde a diferença relativa é igual a zero, que corresponderia ao ponto de igualdade (PI).

Tabela 4.3.3. O ponto de igualdade das cinco exponenciais ajustadas e as incertezas correspondentes.

\begin{tabular}{cccc}
\hline Blocos & PI & incerteza & Adj. $\mathrm{R}^{2}$ \\
\hline 1C & 0,70 & 0,1 & 0,96902 \\
\hline 2P & 1,87 & 0,22 & 0,99534 \\
\hline 2R & 1,84 & 0,39 & 0,95771 \\
\hline 4P & 1,75 & 0,16 & 0,98359 \\
\hline 4R & 1,85 & 0,22 & 0,98249 \\
\hline
\end{tabular}

Nota: As incertezas foram obtidas por propagação de incertezas ${ }^{5}$. Adj. $R^{2}$ se refere ao coeficiente de ajustamento que é proporcional à variabilidade dos dados em relação a um modelo matemático.

Com relação ao coeficiente de variação, encontramos como efeitos principais: tipo de experimento $(\mathrm{F}(1,34)=72,6$ e p $<0,001)$, número de estímulos $(\mathrm{F}(2,68)=6,7$ e $\mathrm{p}=0,002)$ e duração do alvo $(\mathrm{F}(9,306)=27,1$ e $\mathrm{p}<0,001)$. Nas interações obtivemos significância para os fatores duração e número de estímulos $(\mathrm{F}(18,612)=8,8$ e p < $0,001)$ e entre tipo de experimento e número de estímulos $(\mathrm{F}(2,68)=42,7$ e $\mathrm{p}<0,001)$.

Com relação ao número de estímulos, no teste post hoc, 1 estímulo foi diferente 2 estímulo $(\mathrm{p}=0,003)$ e de 4 estímulos $(\mathrm{p}=0,006)$, mas estes não foram diferentes entre si. A figura 4.3.3 apresenta a relação entre o número de estímulos e o tipo de experimento: $2 \mathrm{P}$ foi diferente de $2 \mathrm{R}(\mathrm{p}<0,001)$ e $4 \mathrm{P}$ foi diferente de $4 \mathrm{R}(\mathrm{p}<0,001)$.

$$
\begin{aligned}
& \sigma_{F(x, y, z)}=\sqrt{\left(\frac{\partial F(x, y, z)}{\partial x}\right)^{2} \sigma_{x}^{2}+\left(\frac{\partial F(x, y, z)}{\partial y}\right)^{2} \sigma_{y}^{2}+\left(\frac{\partial F(x, y, z)}{\partial z}\right)^{2} \sigma_{z}^{2}}
\end{aligned}
$$






Figura 4.3.3. Coeficiente de variação em função do número de estímulo, discriminado o tipo de experimento. As barras de erro correspondem ao intervalo de confiança de $95 \%$.

As durações de $0,5 \mathrm{~s}, 1,0 \mathrm{~s}$ e 1,5 s apresentaram diferenças na comparação entre $1 \mathrm{C}$ e $2 \mathrm{R}$ (com $\mathrm{p}<0,001$ para as comparações) e entre $1 \mathrm{C}$ e $4 \mathrm{R}$ (com $\mathrm{p}<0,001$ para as comparações). Houve diferença entre $2 \mathrm{R}$ e $4 \mathrm{R}$ para as durações $0,5 \mathrm{~s}(\mathrm{p}=0,006)$ e $1,0 \mathrm{~s}$ $(\mathrm{p}<0,001)$.

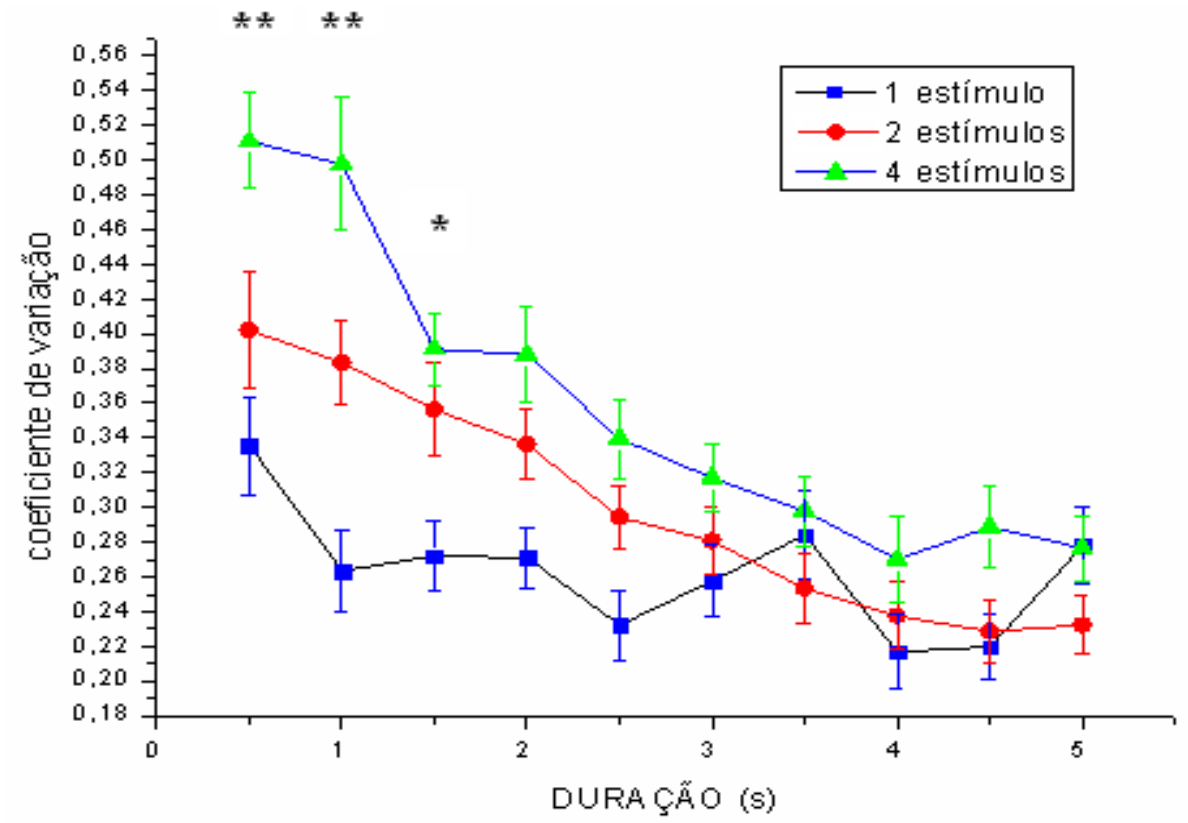

Figura 4.3.4. Coeficiente de variação em função da duração do alvo, apenas para o tipo retrospectivo. As barras de erro correspondem ao erro padrão da média.* se refere $1 C \neq 2 R$ e $1 C \neq 4 R$ e ** inclui estas diferenças e também $2 \mathrm{R} \neq 4 \mathrm{R}$, obtidas no teste post hoc. A barra de erro corresponde ao erro padrão da média. 


\subsection{Discussão do Experimento 1}

$\mathrm{Na}$ figura 4.3.2., podemos visualizar curvas que apresentam a forma de exponenciais vinculada à superestimação do tempo reproduzido para durações curtas (menores ou iguais 1,5 segundos) e à subestimação para durações longas (maiores ou iguais 3,0 segundos). Este efeito tem sido descrito na literatura de forma consistente (VANNESTE; POUTHAS, 1999) e é conhecida com lei de Vierordt. Como resultado, não há uma relação linear entre o tempo objetivo ou físico e o tempo reproduzido. A compreensão dos mecanismos neurofisiológicos deste fenômeno ainda é insuficiente (WEARDEN; LEJEUNE, 2008), a despeito dos avanços recentes da área.

A lei de Vierordt viola os pressupostos da teoria escalar do relógio interno (GIBBON; CHURCH; WARREN, 1984), apesar disto, há uma tentativa de explicar a subestimação e a superestimação como associada à freqüência do oscilador. Neste caso, se apresento uma duração menor que a freqüência do oscilador, haveria uma tendência de superestimar, pois haveria uma tendência de reproduzir o tempo mais próximo da freqüência do oscilador. O mesmo ocorreria com durações maiores, mas neste caso, haveria uma tendência em subestimar, uma vez que a freqüência do oscilador seria menor que a duração a ser reproduzida.

Há vários problemas não solucionados, considerando-se esta explicação: outras tarefas como bissecção, generalização e estimativa temporal apresentam uma relação linear com tempo objetivo (WEARDEN; LEJEUNE, 2008) e teoricamente, empregariam o mesmo oscilador. Outro problema se vincula ao fato de haver vários PIs e ainda que a frequiência do oscilador possa ser mudada por psicotrópicos $(\mathrm{CHURCH}$, 1984), não estão claros quais fatores, associados às tarefas psicofísicas, poderiam alterar o ritmo do relógio interno.

Nossos resultados, por outro lado, sugerem que a atenção tenha implicação na superestimação de durações curtas e seja um fator importante na compreensão da relação entre o tempo reproduzido e o tempo objetivo. A superestimação mostra-se mais pronunciada quanto maior a quantidade de estímulos na tela, ou seja, verifica-se que quanto maior o número de distratores, maior a superestimação para durações curtas. Esta superestimação é ainda maior nos blocos retrospectivos, isto é, quando o conhecimento do alvo é a posteriori. 
Tal achado poderia ser interpretado como efeito de alguns fatores cognitivos: memória e atenção (ZACKAY; BLOCK, 1997; MECK, 1984) ou vinculado a uma estratégia empreendida pelos participantes. No modelo do relógio interno, a atenção e a memória teriam papeis diferentes, com base nesta ação diferencial podemos tentar compreender qual fator cognitivo estaria mais implicado nas diferenças encontradas no experimento 1 .

Se a memória fosse o fator que pudesse explicar os resultados obtidos no experimento, não deveríamos encontrar diferenças nas reproduções dos blocos cujo tipo fosse prospectivo, tal como podemos observar na figura 4.3.1. Neste caso, o indivíduo sabe qual é o alvo e não há problemas para diferenciá-lo dos distratores. Uma vez percebida a duração do alvo, a informação sobre a duração do estímulo não deveria sofrer alterações, visto que o indivíduo não precisa guardar nenhuma outra informação adicional. Nenhuma tarefa adicional e simultânea é requerida.

Parece haver um efeito vinculado à ação dos distratores na percepção de tempo, mais precisamente, nas durações curtas. Tal ação poderia ser interpretada como de origem atencional e estaria associada ao fato de que o aparecimento e o desaparecimento dos distratores requererem atenção, ao menos, para evitar a interferência. Assim, nas durações curtas, os distratores interfeririam na atenção dispensada ao alvo e os participantes deveriam inibir o direcionamento da atenção aos distratores, o que requer maior demanda atencional. A inibição de informações irrelevantes é um processo essencialmente atencional, uma vez que permite a eleição de informações consideradas importantes (PASHLER, 1999).

Uma importante questão a ser esclarecida é que tanto no bloco $1 \mathrm{C}$ como nos demais blocos $(2 \mathrm{P}, 2 \mathrm{R}, 4 \mathrm{P}$ e $4 \mathrm{R})$ a latência entre a apresentação do alvo e reprodução efetuada pelos voluntários era, em média, semelhante. Isto permite afastar a hipótese de que a latência de reprodução e, desta forma, a memória pudesse explicar nossos resultados.

Com relação aos blocos retrospectivos, a princípio, não poderíamos diferenciar o efeito de manter uma maior quantidade de informação na memória do efeito de ter que distribuir a atenção no campo visual a fim de perceber a duração dos estímulos apresentados.

Devemos destacar que, na percepção de tempo, tanto memória quanto atenção são fundamentais para que o processo perceptivo possa ocorrer, nossa discussão se 
destina a interpretar qual fator teria maior preponderância nos resultados experimentais de reprodução de tempo, apresentados no presente trabalho.

Neste sentido, é importante notar que, nas durações longas, há uma subestimação que não depende da quantidade de estímulos e do tipo da tarefa (prospectiva ou retrospectiva). Um fato experimental digno de nota é que a porcentagem de subestimação mantém-se quase constante (-25 a -30\%) para durações maiores que 4 segundos, podendo ser descrita pela lei de Weber (GESHEIDER, 1997).

Se a memória fosse um fator importante, esperaríamos que houvesse um aumento da subestimação do tempo, que fosse proporcional ao número de estímulos, particularmente nos blocos retrospectivos e para as durações longas, uma vez que haveria maior demanda por memória nas durações longas (admitindo que os indivíduos não tenham transformado em um número a duração, através de um processo de contagem).

Por outro lado, o achado de que durações longas são independentes do número de estímulos para os blocos prospectivos, pode ser explicado pelo fato de que a percepção de duração de um estímulo longo sofre menor influência de distratores. Isto seria esperado, visto que o desaparecimento e aparecimento são circunstâncias que poderiam desviar a atenção do alvo e tais eventos são rápidos. No caso das durações longas, há pouca interferência, pois o direcionamento da atenção para os distratores é rápido e não é crítico na percepção de uma duração mais longa. Assim, o achado de que nas durações curtas há efeito do número de distratores e do tipo de experimento favorece a hipótese de que a atenção e não a memória seja o principal fator cognitivo envolvido neste experimento.

O experimento 1, por usar a atenção dispensada aos estímulos apresentados, variando não só o número de estímulos apresentados mas também o conhecimento do alvo, pode ser considerado um experimento mais simples, em termos de análise, do que aqueles que usam tarefas concomitantes. Nestes experimentos, a necessidade de realizar simultaneamente duas tarefas não apenas aumenta a demanda atencional, mas também por memória e pode haver maior necessidade de utilizar funções executivas, o que torna os resultados mais difíceis de serem interpretados.

Neste sentido, nossos resultados trazem contribuições á compreensão da percepção de tempo, pois permitem uma maior separação do que seria devido á atenção em relação a outros fatores cognitivos envolvidos na apreensão do lapso. 
Todavia, o experimento 1 não permite excluir a influência da estratégia nos resultados. Por este motivo, o experimento 2 tem por finalidade avaliar a influência deste fator na percepção de tempo.

Quanto maior atenção dispensada a outras tarefas ou estímulos, menores os recursos atencionais direcionados à avaliação da duração do alvo, admitindo que os recursos atencionais sejam limitados (PASHLER, 1999).

Entretanto, em uma tarefa de reprodução, há duas fases, nas quais a atenção pode interferir. Quanto menores forem os recursos atencionais dispensadas à fase perceptiva, segundo a teoria do relógio interno, menor seria a quantidade de pulsos que chegariam ao acumulador, uma vez que o interruptor permaneceria por mais tempo fechado. De forma semelhante, na fase de reprodução, como alguns pulsos não chegariam ao acumulador, o indivíduo manteria a tecla apertada por mais tempo a fim de obter a duração pretendida, ou seja, para que o número de pulsos fosse comparável àquele encontrado na memória (proveniente da fase perceptiva) é necessário que o indivíduo superestime o tempo em sua reprodução, pois o interruptor está parcialmente fechado, em virtude da alocação de menores recursos atencionais.

O último processo explica os resultados encontrados em durações menores (superestimação), em nosso trabalho. Devemos salientar que os sujeitos não podiam transformar as durações percebidas em um número, assim, o alvo deveria permanecer na memória e na fase de reprodução, esta memória seria transformada em tempo, através do ato motor de pressionar a tecla. Corroboram esta interpretação, estudos que obtiveram resultados semelhantes, usando uma segunda tarefa concomitantemente à fase de reprodução (FORTIN; ROSSEAU, 1998).

Há trabalhos que obtiveram um aumento da subestimação com o aumento do número de estímulos (BROWN; WEST, 1990), entretanto usaram durações significativamente maiores que 5 segundos, o que dificulta a comparação de resultados.

Os PI são pontos de maior acurácia e se encontram entre durações que são superestimada e durações que são subestimadas. Verificamos que, na presença de 1 estímulo, o PI foi de $0,70 \pm 0,10$ segundos, tal valor concorda com o valor em torno de 1 segundo, obtido por Nichelli (1993) e de 0,6 a 0,9 segundos, em trabalhos antigos como os de Wundt e seus contemporâneos (JAMES, 1952). Para os blocos com 2 ou 4 estímulos, os valores dos PIs foram próximos independentemente do tipo de experimento (vide Tabela 4.3.2). A média ponderada encontrada foi $1,83 \pm 0,28$ 
segundos. O valor de cerca de 2 a 3 segundos foi obtido nos trabalhos de Pöppel (2004) e Fontin e Couture (2002).

É curioso notar que os trabalhos vinculados à percepção de tempo que tinham por objetivo avaliar as durações de maior acurácia tendem a se organizar nestes dois PIs, principalmente se admitirmos que os PIs se refiram à frequiência do oscilador. Em nosso estudo, encontramos estes dois valores e nossa interpretação se alinharia com a proposta de Ivry e Spencer (2004) da existência de múltiplos osciladores, que seriam utilizados conforme a duração a ser percebida e características das tarefas empregadas. Outra hipótese alternativa seria de que a freqüência do oscilador sofreria a influência de fatores vinculados à tarefa. Ainda que nosso desenho experimental não tenha por escopo avaliar estas hipóteses, nossos resultados favorecem a proposta de Ivry e Spencer (2004), uma vez que os PIs encontrados podem ser agrupados em torno de dois valores, o que não seria esperado se a freqüência do oscilador pudesse ser modificada por algum fator vinculado à tarefa, implicando em alguma relação de proporcionalidade entre os fatores da tarefa e os PIs.

Nossos dados mostram efeito do número de estímulos e do tipo de experimento no coeficiente de variação. Isto sugere que uma maior demanda atencional levaria a um aumento na variabilidade, uma vez que os fatores que levam a piora do tempo reproduzido, também levam a uma piora da variabilidade. Tais resultados se alinham com aqueles obtidos por Ulbrich et al. (2007) e Brown e West (1990) e não estão de acordo com as previsões da teoria escalar, na qual o coeficiente de variação seria constante (GIBBON et al., 1997).

A melhor interpretação para a ação da atenção na variabilidade, considerando o modelo de osciladores internos, seria de que, ao aumentar a demanda atencional, haveria uma maior variabilidade na abertura do interruptor, o que levaria a uma piora da precisão do comportamento.

Deve-se citar que o coeficiente de variação também foi influenciado pela duração, o que implica que a atenção não seja o único fator a determiná-lo, aliás, o achado de que há um aumento do CV em durações curtas é frequentemente encontrado nas tarefas de reprodução de tempo e ainda não apresenta explicação satisfatória (WEARDEN; LEJEUNE, 2008).

Ainda que não seja nosso objetivo, nem nossos experimentos tenham sido engendrados com o escopo de avaliar os modelos vigentes de percepção de tempo, nossa discussão é centrada no modelo do oscilador, ainda que tenhamos encontrado 
resultados que divergem das previsões da teoria escalar (uma formulação teórica que utiliza o relógio interno para explicar a apreensão do tempo em humanos e animais). Outros modelos, tais como o modelo de Block e Zackay (2004), não foram utilizados na interpretação de nossos resultados, por apresentarem previsões difíceis de serem quantificadas e cotejadas com estes resultados experimentais.

\section{EXPERIMENTO 2}

\subsection{Objetivo}

A finalidade deste experimento é avaliar a percepção de tempo e a modulação atencional desta percepção, usando uma tarefa de discriminação de tempo. Para tanto, variaram-se a duração, o número de distratores e o conhecimento sobre o estímulo alvo, sendo que, por hipótese, os dois últimos parâmetros estariam relacionados à demanda atencional, permitindo estudar a modulação atencional da percepção de tempo, tal como discutido no primeiro experimento.

Esta tarefa complementa o experimento prévio, uma vez que permite avaliar a percepção de tempo usando uma tarefa puramente perceptiva, permitindo, assim, a avaliação da modulação da atenção. Neste sentido pode-se avaliar, através da teoria de detecção de sinais, a discriminabilidade (associada, entre outros fatores, à atenção) e o critério (associado, entre outros fatores, à decisão e estratégia do indivíduo), visto que esta abordagem não foi possível no experimento 1 .

\subsection{Arranjo Experimental}

A tarefa utilizada é de discriminação de tempo, que consiste em comparar a duração de um alvo com a duração do estímulo padrão, classificando-a como maior ou menor em relação à duração deste estímulo padrão. Tal resposta deveria ser realizada através da escolha de uma tecla apropriada, que poderia ser pressionada após a apresentação dos estímulos.

$\mathrm{Na}$ tarefa, utilizamos cinco figuras geométricas diferentes (retângulo, círculo, quadrado, triângulo e elipse). As figuras usadas como alvo e distratrores (círculo, quadrado, triângulo e elipse), tal como no primeiro experimento, eram isoecêntricas 
$\left(13,72 \pm 0,09^{\circ}\right)$ e de área equivalente a um quadrado de 3,29 $\pm 0,08 \times 3,29 \pm 0,08^{\circ}$ (ângulo visual). O retângulo sempre era apresentado no centro da tela e sempre vinha antes da apresentação das outras figuras, independentemente do tipo de experimento, número de estímulos e da duração do padrão. Este retângulo era o estímulo padrão e tinha a mesma duração em cada bloco, o que era declarado aos participantes.

Tal como o primeiro experimento, o fundo era branco e as figuras eram pretas, tal como mostrada na figura 5.2.1. Tais características são semelhantes àquelas empregadas no experimento 1, a fim de que possamos comparar os resultados experimentais.

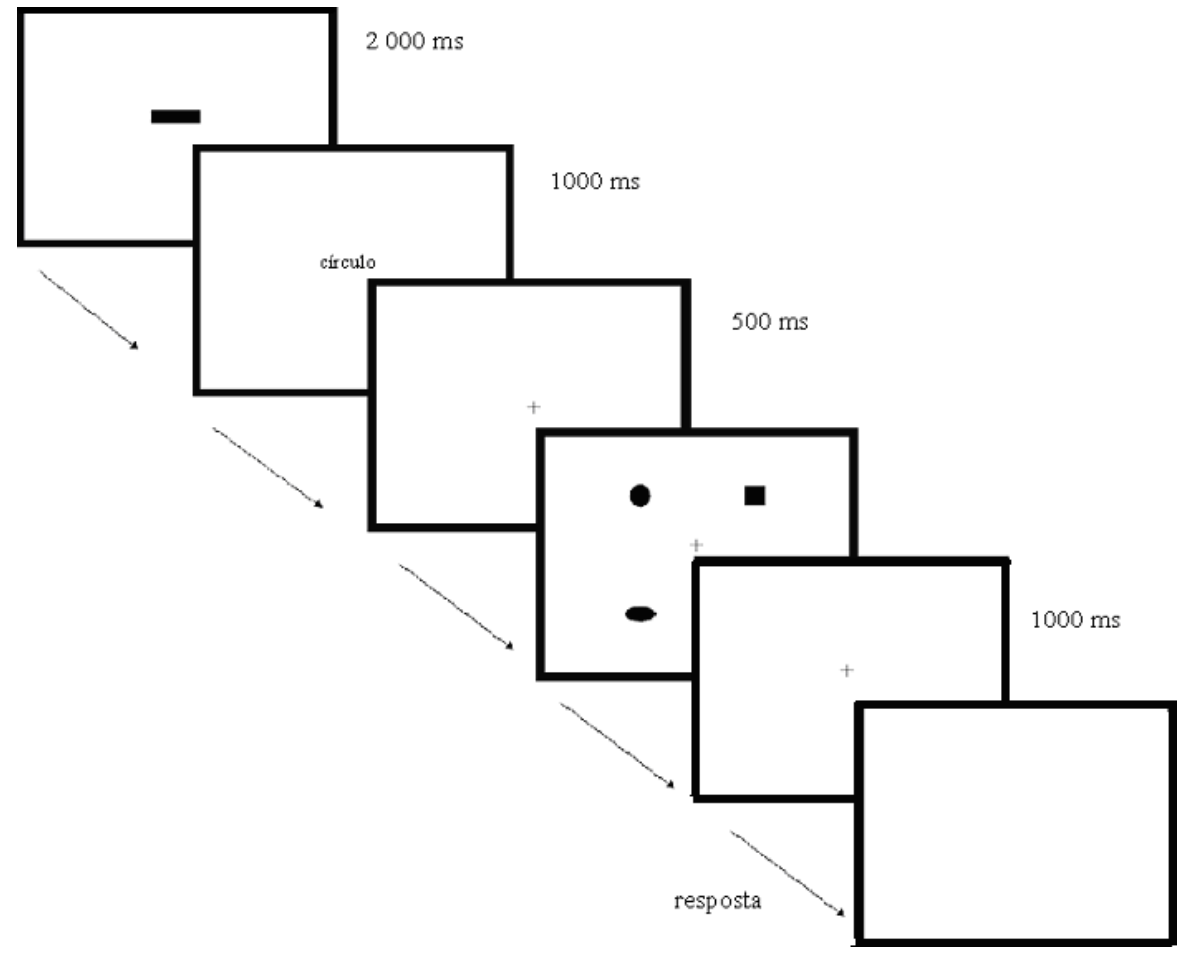

Figura 5.2.1. Ordem de apresentação dos estímulos, no experimento 2. Esta ordem se refere ao bloco 4P com duração do padrão de 1750 ms.

O estímulo padrão poderia apresentar a duração de $1750 \pm 23$ ms ou $3250 \pm 23$ ms. Estas durações eram constantes em cada bloco e tal informação era fornecida aos sujeitos. Também, era solicitado aos sujeitos que mantivessem seus olhos direcionados ao ponto de fixação e que não utilizassem estratégia cognitiva que envolvesse contagem.

O experimento apresentava cinco blocos para cada duração padrão, cuja ordem de apresentação era aleatória. Cada bloco consistia em 36 apresentações, com estímulos que apresentavam diferenças de durações $(\Delta \mathrm{t})$ de $\pm 250 \mathrm{~ms}, \pm 750 \mathrm{~ms}$ e $\pm 1250 \mathrm{~ms}$ em relação à duração do estímulo padrão. Por exemplo, se o estímulo padrão tivesse 
duração de $1750 \mathrm{~ms}$, as durações possíveis do alvo e dos distratores seriam de $500 \mathrm{~ms}$ $(\Delta \mathrm{t}=-1250 \mathrm{~ms}), 1000 \mathrm{~ms}(\Delta \mathrm{t}=-750 \mathrm{~ms}), 1500 \mathrm{~ms}(\Delta \mathrm{t}=-250 \mathrm{~ms}), 2000 \mathrm{~ms}(\Delta \mathrm{t}=+250$ $\mathrm{ms}), 2500 \mathrm{~ms}(\Delta \mathrm{t}=+750 \mathrm{~ms}), 3000 \mathrm{~ms}(\Delta \mathrm{t}=+1250 \mathrm{~ms})$. Se o estímulo padrão tivesse duração de $3250 \mathrm{~ms}$, as durações possíveis dos estímulos seriam: $2000 \mathrm{~ms}(\Delta \mathrm{t}=-1250$ $\mathrm{ms}), 2500 \mathrm{~ms}(\Delta \mathrm{t}=-750 \mathrm{~ms}), 3000 \mathrm{~ms}(\Delta \mathrm{t}=-250 \mathrm{~ms}), 3500 \mathrm{~ms}(\Delta \mathrm{t}=+250 \mathrm{~ms}), 4000$ $\mathrm{ms}(\Delta \mathrm{t}=+750 \mathrm{~ms}), 4500 \mathrm{~ms}(\Delta \mathrm{t}=+1250 \mathrm{~ms})$. Cada duração, em cada bloco, era apresentada 6 vezes, de forma pseudo-randômica.

No bloco 1, o indivíduo deveria prestar atenção na duração do único estímulo que aparecesse na tela a fim de reportar, através da escolha de uma tecla, se o alvo era mais longo ou mais curto que o estímulo padrão.

No bloco 2P, antes da apresentação dos estímulos, era mencionado qual seria o estímulo alvo. A seguir, eram apresentados dois estímulos e a tarefa do indivíduo seria reportar se a duração do alvo era maior ou menor do que a duração percebida do estímulo padrão. Deve-se ressaltar que os estímulos não apareciam em tempos iguais e nem terminavam em tempos iguais, pois a latência de aparecimento e as durações eram aleatoriazadas. Note que, neste caso, havia um distrator. No bloco 4P, o mesmo se sucedia: primeiramente, a informação sobre qual estímulo seria o alvo, seguindo-se a apresentação de quatro estímulos (sendo um alvo e três distratores).

No bloco 2R, o sujeito não sabia, previamente, qual estímulo seria o alvo, portanto, deveria prestar atenção nos dois estímulos apresentados e, posteriormente, era indicado qual seria o alvo a ser comparado com o estímulo padrão. No bloco 4R, de forma idêntica, o sujeito não era informado sobre qual seria o estímulo alvo, entretanto quatro estímulos eram apresentados, ao fim dos quais, era indicado o estímulo alvo.

Tal como ocorreu no experimento 1 , denominamos de prospectiva a condição em que o indivíduo é informado previamente sobre o estímulo alvo, ou seja, sabe em qual estímulo deverá prestar atenção. Denominamos de retrospectiva a condição em que o indivíduo não sabe, antes da apresentação dos estímulos, qual estímulo é o alvo. Deve-se salientar que no bloco 1, como apenas um estímulo é apresentado, não faz sentido classificá-lo em retrospectivo ou prospectivo.

Utilizamos quatro variáveis dependentes a fim de avaliarmos, neste experimento, a percepção de tempo. A primeira variável era a duração do estímulo padrão (1750 ms e $3250 \mathrm{~ms}$ ), tais durações foram empregadas para permitir o estudo mais pormenorizado do PI encontrados no experimento 1. A segunda variável se referia ao conhecimento do alvo, isto é, na condição prospectiva, o indivíduo sabia previamente qual era o alvo, 
visto que uma palavra indicando a figura alvo aparecia antes que as figuras fossem apresentadas. Na condição retrospectiva, eram apresentadas as figuras e posteriormente, era indicado quem era o alvo. Nesta condição, o sujeito era orientado a prestar atenção em todas as figuras, visto que não sabia qual delas seria o alvo a ser reproduzido.

A terceira variável era o número de figuras apresentadas, que poderia ser 1,2 ou 4 estímulos. Havia apenas um alvo, independentemente do número de estímulos.

A quarta variável se referia à diferença de duração $(\Delta \mathrm{t})$, seis possíveis $\Delta \mathrm{t}$ para cada duração do estímulo padrão.

\subsection{Análise e Resultados}

Um modo profícuo de avaliar os dados da discriminação de ordem temporal é a utilização da teoria de detecção de sinais (GREEN; SWETS, 1966). Com este método podemos avaliar o efeito da atenção de uma forma mais sistemática, visto que a alteração da discriminabilidade (d') está relacionada, na literatura, a uma modulação atencional e uma modificação do critério $(\beta)$ a um padrão de resposta influenciado por outros fatores, tais como a estratégia dos indivíduos (BROWN; NEWCOMB; KAHRL, 1995; MACMILLAN; CREELMAN, 2004).

Com a finalidade de calcular a discriminabilidade e o critério, considerando cada $|\Delta \mathrm{t}|$, foi obtida uma matriz com as respostas dadas por cada participante (vide tabela 5.3.1), considerando o tipo de experimento, a duração do estímulo padrão e o número de estímulos.

Tabela 5.3.1. Mostra o cálculo da tabela usada na teoria de detecção de sinais.

\begin{tabular}{l|l|l}
\hline & \multicolumn{2}{|l}{ Duração Real } \\
\hline Resposta & maior & menor \\
\hline maior & acerto & F.A \\
\hline menor & erro & R. C \\
\hline
\end{tabular}

Nota: Resposta significa a resposta dada pelo sujeito e Duração Real é relação física entre a duração do alvo e a duração do estímulo padrão. Acerto significa que o sujeito respondeu que era maior quando realmente era maior. R.C (rejeição correta) significa que o sujeito respondeu que era menor quando realmente menor. Erro significa que o sujeito respondeu que era menor quando era maior e F.A. (falso alarme) significa que sujeito respondeu que era maior, quando era menor, na realidade. Os termos empregados são vocábulos clássicos da teoria de detecção de sinais. 
Para o cálculo da discriminabilidade e critério usamos as relações abaixo ( $\mathrm{Z}$ significa escore z de uma probabilidade, com relação a uma distribuição normal):

$$
\begin{aligned}
& d^{\prime}=Z(\text { acerto })-Z(\text { F.A.)_ (eq. 6) } \\
& \beta=-0,5[Z(\text { acerto })+Z(F . A)] \_ \text {(7) }
\end{aligned}
$$

$\mathrm{O}$ escore $\mathrm{z}$ pode ser mais bem entendido como a abscissa da figura abaixo. Considerando uma curva gaussiana normalizada (cuja integral de - infinito a + infinito é 1), há uma relação bem estabelecida entre o escore z e a probabilidade de um evento. Se integrarmos de - infinito até um determinado $\mathrm{z}(]-\infty, \mathrm{z}])$, encontraremos uma probabilidade. Em nosso caso, realizamos o caminho inverso, ou seja, encontramos o escore $\mathrm{z}$ correspondente a uma dada probabilidade, que foi calculado usando-se tabela 5.3.1.

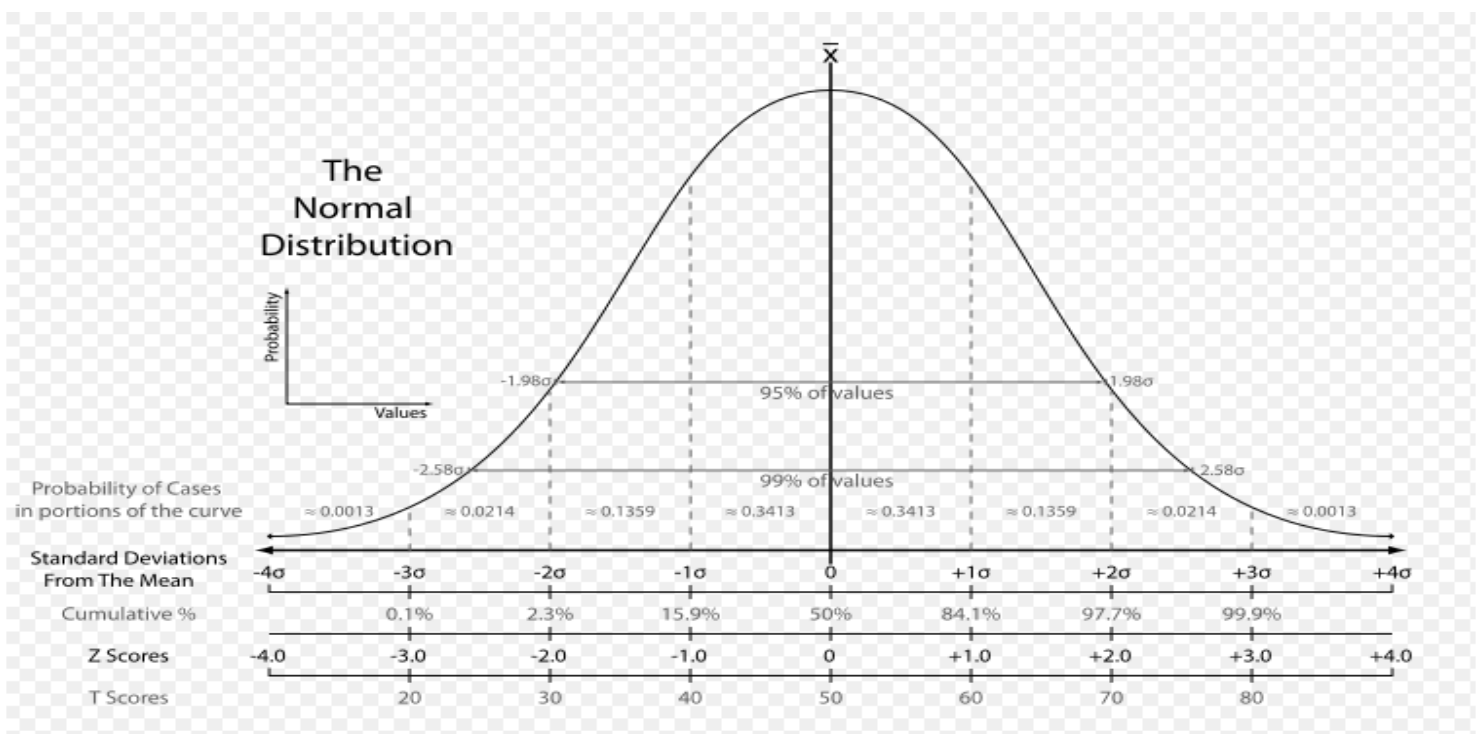

Figura 5.3.1. Mostra uma gaussiana em função da densidade de probabilidade. Fonte: http://en.wikipedia.org/wiki/Standard_score.

Considerando os resultados do primeiro experimento, temos como hipótese que o aumento do número de estímulos afeta a atenção aumentando a chance de que o indivíduo se distraia e assim, tenha menor acurácia na avaliação da duração de tempo de um dado objeto em seu campo visual. Além disto, o conhecimento do alvo interferira na distribuição da atenção e levaria a uma piora no desempenho nos casos em que o sujeito deveria prestar atenção em um número maior de estímulos, sem saber qual destes estímulos é o alvo.

Usamos uma ANOVA $2 \times 2 \times 3 \times 3$ tomando como fatores: duração do estímulo padrão (1750 ou $3250 \mathrm{~ms}$ ), tipo de experimento (prospectivo ou retrospectivo), número 
de estímulos (1, 2 ou 4 estímulos) e $|\Delta \mathrm{t}|( \pm 250 \mathrm{~ms}, \pm 750 \mathrm{~ms}$ e $\pm 1250 \mathrm{~ms})$. As durações, pela teoria de detecção de sinais, só podem ser avaliadas com sendo: diferença pequena $( \pm 250 \mathrm{~ms})$, diferença intermediária $( \pm 750 \mathrm{~ms})$ e diferença grande $( \pm$ $1250 \mathrm{~ms}$ ) entre duração do estímulo padrão e duração do alvo. Chamamos tal fator de módulo da diferença de duração ou $|\Delta \mathrm{t}|$.

O teste de Kolmogorov-Smirnov foi realizado na variável d' e $\beta$. Não foram encontrados desvios significativos da normalidade, o que, aliado ao fato da ANOVA ser um método robusto mesmo com pequenos desvios da homocedacidade e normalidade (ZAR, 1996), permite a eleição de tal método paramétrico na análise estatística.

Tomando a análise da discriminabilidade (d'), encontramos significância estatística para todos os principais fatores: duração padrão $(\mathrm{F}(1,19)=18,3$ e p < 0,001), tipo de experimento $(\mathrm{F}(1,19)=44,7$ e p $<0,001)$, número de estímulos $(\mathrm{F}(2,38)=7,6$ e $\mathrm{p}=0,002)$ e $|\Delta \mathrm{t}|(\mathrm{F}(2,38)=235,9$ e $\mathrm{p}<0,001)$.

Encontramos interação de segunda ordem para os fatores tipo de experimento e número de estímulos $(\mathrm{F}(2,38)=18,7$ e $\mathrm{p}<0,001)$, que pode ser avaliada na figura 5.3.2. As demais interações não foram significativas.

Realizamos o teste post-hoc para número de estímulos e encontramos diferença significativa entre 1 e 4 estímulos $(\mathrm{p}<0,001)$. Todos os $|\Delta \mathrm{t}|$ foram diferentes estatisticamente ( $\mathrm{p}<0,001$ para todas as comparações), vide figura 5.3.1.

Realizamos uma regressão linear para o tipo de experimento retrospectivo, cujos valores foram: coeficiente angular $=-0,341 \pm 0,025$ e coeficiente linear $=3,149 \pm 0,074$ (com $\mathrm{R}=-0,997$ e $\mathrm{p}=0,047$ ), que se mostrou significativa. Para o tipo prospectivo, a regressão linear não se mostrou significativa (coeficiente angular $=0,012 \pm 0,010$; coeficiente linear $=2,823 \pm 0,029 ; \mathrm{R}=0,768$ e $\mathrm{p}=0,443$ ). 


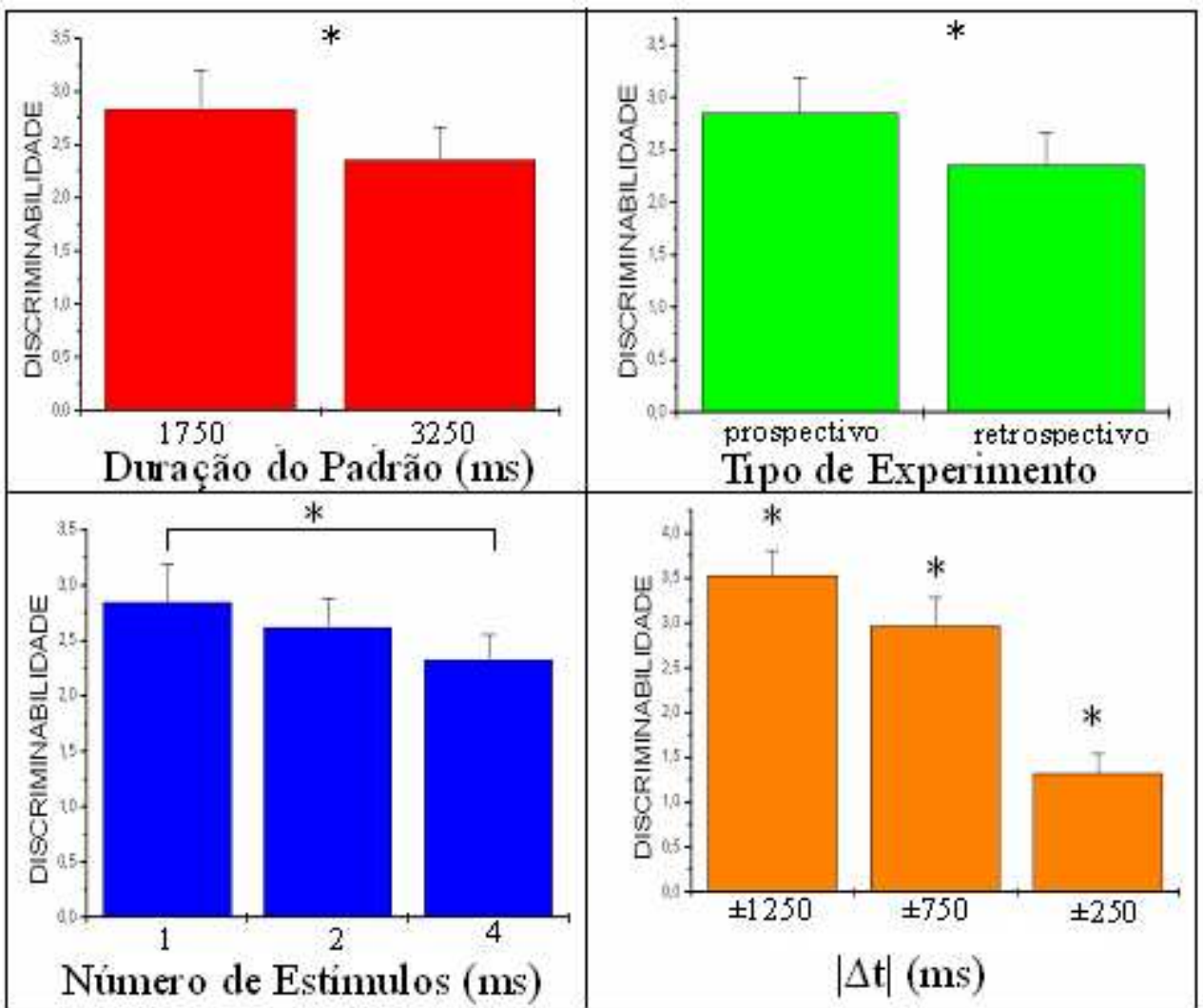

Figura 5.3.2. Os gráficos apresentam os principais fatores em função da discriminabilidade (d'), cuja unidade é em escore z: Duração padrão (superior esquerdo), tipo de experimento (superior direito), número de estímulos (inferior esquerdo) e diferença de duração ou $|\Delta \mathrm{t}|$ (inferior direito). As barras de erro correspondem ao erro padrão da média.
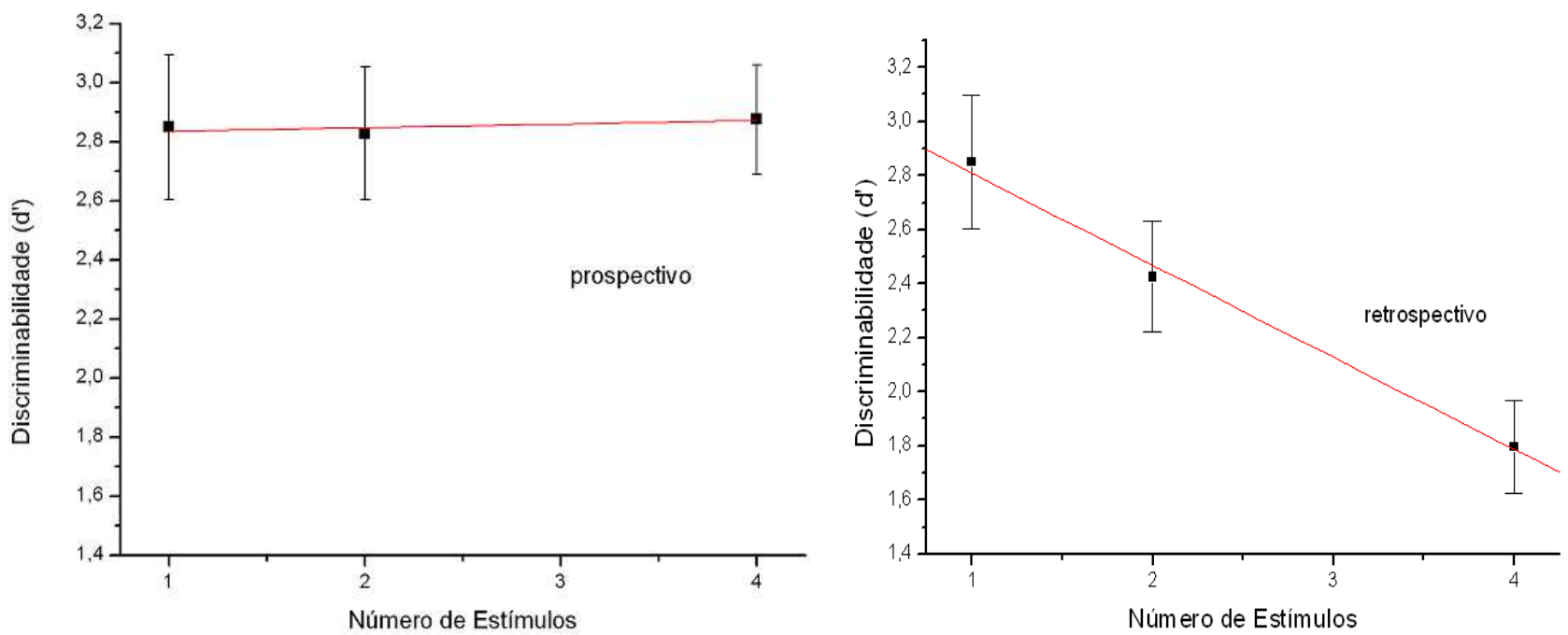

Figura 5.3.3. Número de estímulos em função da discriminabilidade (d'). À esquerda, regressão linear para o tipo prospectivo. À direita, a regressão linear para o tipo de experimento retrospectivo. As barras de erro correspondem ao erro padrão da média.

Realizamos o teste post-hoc: para o tipo prospectivo não encontramos diferenças entre a quantidade de estímulos apresentadas. No caso do tipo retrospectivo, encontramos diferenças significativas $(p=0,020$ para comparação $1 \mathrm{C}$ e $2 \mathrm{R}, \mathrm{p}<0,001$ 
para comparação $1 \mathrm{C}$ e $4 \mathrm{R}$ e $\mathrm{p}<0,001$ para $2 \mathrm{R}$ e $4 \mathrm{R}$ ). Tais dados ratificam os dados encontrados nas regressões lineares.

Comparando o tipo retrospectivo com o tipo prospectivo, encontramos diferenças para $|\Delta t|= \pm 250 \mathrm{~ms}(\mathrm{p}=0,004)$ e $|\Delta \mathrm{t}|= \pm 750 \mathrm{~ms}(\mathrm{p}=0,003)$, o que mostra que para $|\Delta \mathrm{t}|= \pm 1250 \mathrm{~ms}$, por representar grande diferença entre a duração do padrão e a duração do alvo, é uma tarefa discriminativa fácil e o desempenho é bom tanto nos blocos reprospectivos como prospectivos.


Encontramos significância estatística para o fator principal número de estímulos $(\mathrm{F}(2,38)=5,2$ e $\mathrm{p}=0,010)$.



Figura 5.3.4. Critério em função do número de estímulos. A linha contínua em zero se refere ao fato do indivíduo não apresentar tendência de resposta, isto é, estratégia que privilegie uma tecla. A barra de erro corresponde ao erro padrão da média.

Ao utilizarmos o d', não foi possível avaliar $\Delta \mathrm{t}$ e sim o módulo desta variável $(|\Delta \mathrm{t}|)$. Com a finalidade de avaliar o efeito da duração na percepção de tempo, comparando os resultados advindos da reprodução de tempo (com regiões de maior acurácia, o PI) com aqueles relativo à discriminação de tempo, utilizamos como medida de desempenho a porcentagem de acertos. Esta variável é definida pela porcentagem de vezes que os participantes acertaram se a duração do estímulo padrão foi maior ou menor do que a duração do alvo. Tal medida, por ser uma porcentagem apresenta uma distribuição binomial e não normal, sendo necessário uma transformação de p em p', dada pela relação abaixo:

$$
\mathrm{p}^{\prime}=\operatorname{arcsen}\left(\mathrm{p}^{1 / 2}\right)
$$


Para a análise estatística utilizamos um ANOVA 2x2x3x6 com os seguintes fatores: duração do estímulo padrão (1750 ms ou $3250 \mathrm{~ms}$ ), tipo do experimento (prospectivo ou retrospectivo), número de estímulos (1, 2 ou 4 estímulos) e diferença de duração $(\Delta \mathrm{t})$.

Devemos salientar que a utilização de porcentagem de acertos como medida do desempenho não permite separar o componente atencional dos demais componentes, tais com a estratégia do indivíduo.

Encontramos significância estatística para os fatores principais: duração do padrão $(F(1,19)=26,6$ e $p<0,001)$, tipo de experimento $(F(1,19)=39,2$ e $p<0,001)$, número de estímulos $(\mathrm{F}(2,38)=25,4$ e p < 0,001) e $\Delta \mathrm{t}(\mathrm{F}(5,95)=44,5$ e $\mathrm{p}<0,001)$.

Encontramos uma interação de segunda ordem para os fatores número de estímulos e tipo do experimento com significância estatística $(F(2,38)=16,7$ e p < 0,001). Da mesma forma como o descrito para d', o teste post-hoc mostra diferenças estatísticas apenas para o tipo retrospectivo, com relação ao número de estímulos: entre $1 C$ e $2 R(p=0,013)$, entre $1 C$ e $4 R(p<0,001)$ e entre $2 R$ e $4 R(p<0,001)$.

Também foi obtido, no teste post-hoc, uma diferença significativa entre $\Delta \mathrm{t}=$ $250 \mathrm{~ms}$ e $+250 \mathrm{~ms}$ para a duração do padrão de $1750 \mathrm{~ms}$, tanto para o tipo prospectivo $(\mathrm{p}<0,001)$ quanto retrospectivo ( $\mathrm{p}<0,001)$, como é mostrado na figura 5.3.4. Na tabela 5.3.2 apresentamos os valores do teste post hoc comparando os $\Delta \mathrm{t}$ de $-250 \mathrm{~ms}$ com 250 ms, diferenciando a duração do padrão e o número de estímulos.

Também avaliamos a assimetria da curva. Verifica-se uma assimetria na curva, o que pode ser avaliado pelo teste de avaliação da simetria $(\zeta=2,15$ para $1750 \mathrm{~ms}$ de padrão e $\zeta=2,01$ para $3250 \mathrm{~ms}$, para $\mathrm{p}=0,05)$, teste que é descrito no anexo D. 


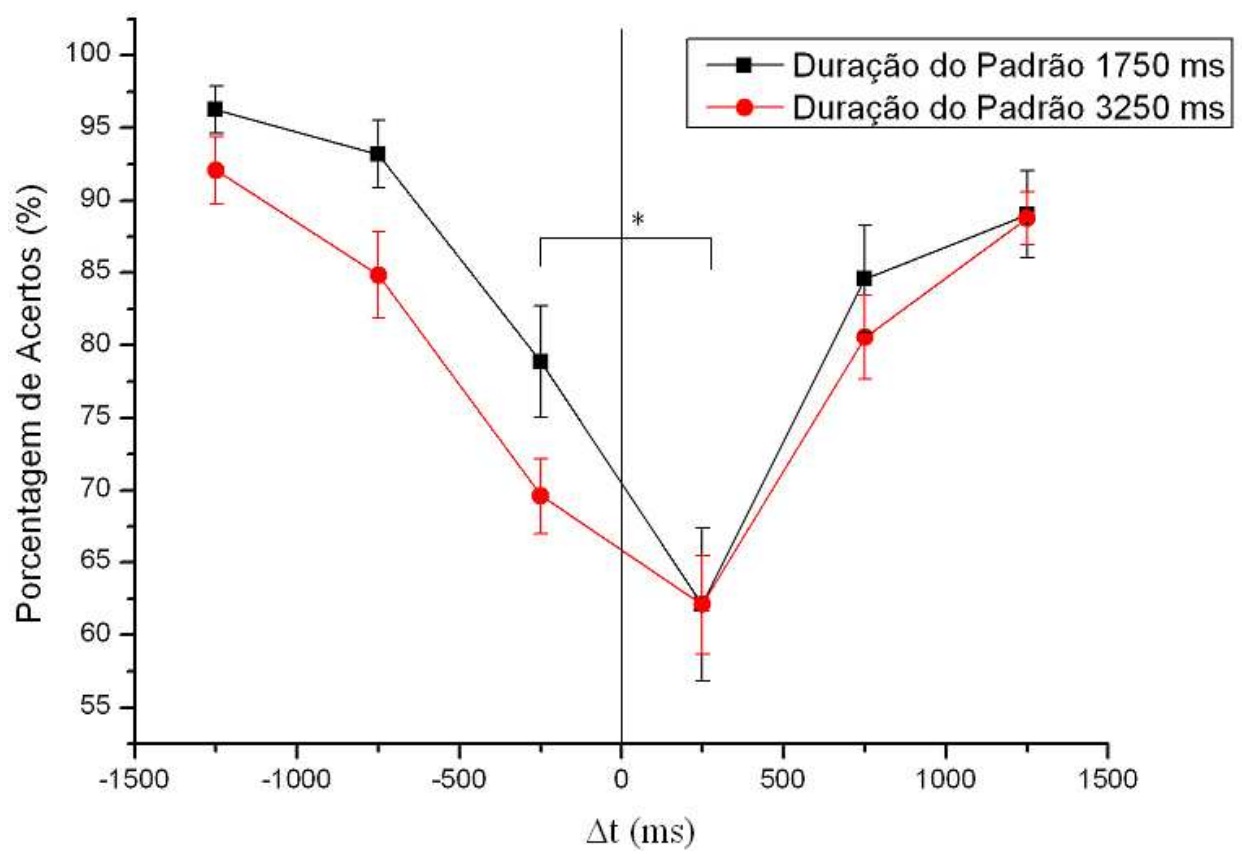

Figura 5.3.5. Relação entre porcentagem de acertos e a diferença entre duração do alvo e duração do estímulo padrão. A barra de erro corresponde ao erro padrão da média.

Tabela 5.3.2. Resultados do post hoc para $\Delta \mathrm{t}$. Apresenta os resultados de p do teste post hoc nas comparações entre $\Delta \mathrm{t}=-250 \mathrm{~ms}$ e $\Delta \mathrm{t}=+250 \mathrm{~ms}$, em função da duração padrão e do número de estímulos.

\begin{tabular}{ccc}
\hline $\begin{array}{c}\text { Número de } \\
\text { Estímulos }\end{array}$ & \multicolumn{1}{c}{ Duração do Padrão } \\
\hline & $1750 \mathrm{~ms}$ & $3250 \mathrm{~ms}$ \\
1 & n.s & n.s \\
\hline 2 & $<0,001$ & n.s \\
\hline 4 & $<0,001$ & n.s \\
\hline
\end{tabular}

Nota: Apresenta os resultados de p do teste post hoc nas comparações entre $\Delta \mathrm{t}=-250 \mathrm{~ms}$ e $\Delta \mathrm{t}=$ +250 ms, em função da duração padrão e do número de estímulos.

\subsection{Discussão do Experimento 2}

Este experimento tende a complementar os resultados encontrados no primeiro experimento, uma vez que os experimentos foram construídos de tal forma que se assemelhassem quanto às características dos estímulos, latências dos estímulos e durações do alvo.

O gráfico 5.3.1. apresenta as diferenças encontradas para tipo de experimento e número de estímulos. A diferença entre o tipo retrospectivo e prospectivo era esperada, em virtude dos resultados encontrados no primeiro experimento. Com a necessidade de 
avaliar estímulos sem o conhecimento prévio de qual estímulo era o alvo, a tarefa se torna mais difícil e o resultado é uma menor porcentagem de acertos e uma menor discriminabilidade.

Quanto maior o número de estímulos maior é a dificuldade da tarefa, com consequiente queda do d'. Contudo, esta asserção só é válida para o tipo retrospectivo (vide Figura 5.3.2.). Além disto, nossos resultados mostram uma relação linear entre o número de estímulos e discriminabilidade, de forma similar aos achados clássicos de busca visual (PASHLER, 1999).

O d' permite separar os efeitos oriundos de estratégias utilizadas pelos participantes dos efeitos atencionais, o que não era possível ser avaliado no primeiro experimento. Frequentemente, o d' tem sido associado com a atenção (BROWN; NEWCOMB; KAHRL, 1995). Entretanto, a discriminabilidade se modifica também em função de características puramente perceptivas da tarefa e de outros fatores como a memória. Um exemplo da relação entre d' e características dos estímulos é o apresentado na figura 5.3.1, no quadrante inferior direito (d' em função de $\Delta$ t). Há uma queda da discriminabilidade quanto menor o $|\Delta t|$, o que mostra que quanto menor for a diferença absoluta entre a duração alvo e a duração do estímulo padrão, maior é a dificuldade da tarefa e menor é o d'.

Desta forma, d' permite a separação entre a estratégia e atenção, mas há necessidade de avaliarmos fatores puramente perceptivos da tarefa, bem como outros fatores como memória e funções executivas.

As tarefas empregadas tanto no tipo prospectivo, quanto retrospectivo, são semelhantes, uma vez que a única diferença é conhecimento do alvo. Por conseguinte, as diferenças com relação ao d' não podem ser associadas a fatores puramente perceptivos. Argumentação semelhante pode ser usada como argumento que contraria a suposição de que fatores puramente perceptivos possam explicar o efeito do número de estímulos, nas tarefas retrospectivas.

Como já asseverado anteriormente, o fato de não usarmos tarefas concomitantes para modular a atenção torna improvável que uma maior demanda por funções executivas interfira no d'.

A diferenciação da modulação atencional e da ação associada à memória é mais sutil. Há dois argumentos que favorecem a hipótese de que os resultados do segundo experimento possam ser interpretados com relativos a uma modulação atencional. $\mathrm{O}$ primeiro argumento se refere ao fato de que, no primeiro experimento, podem-se 
separar, ao menos parcialmente, os efeitos da atenção e da memória. Como ambos os experimentos compartilham semelhanças, à exceção da tarefa, pode-se inferir que a atenção tenha papel mais proeminente nos resultado do segundo experimento.

$\mathrm{O}$ segundo argumento se refere à economia de recursos. No caso da discriminação realizada pelo sujeito, este deve comparar a duração de um estímulo padrão com o alvo. Como a duração do estímulo padrão é a mesma em um dado bloco e o sujeito é informado disto, podemos supor que a memória desta duração se mostre bem consolidada e não seja fácil modificá-la, isto é, é improvável que ocorra uma interferência de distratores nesta memória. Apóia tal suposição o fato de que, durante os experimentos de discriminação, era freqüente a consideração, feita pelos sujeitos que realizavam o teste, de que o estímulo padrão era geralmente ignorado, após algumas apresentações.

Neste caso, duas possibilidades ocorreriam nos blocos retrospectivos: ou o participante julgaria se os estímulos eram maiores ou menores que o padrão durante a fase perceptiva da tarefa, ou julgariam os estímulos na fase de resposta, quando era fornecido o conhecimento do alvo. Na última possibilidade, os participantes manteriam as durações em sua memória até que fosse apresentado qual dos estímulos seria o alvo. Com isto, haveria uma sobrecarga no armazenamento das durações do estímulo (note que os sujeitos não podiam transformar a duração em um número através da contagem). Seria mais econômico, entretanto, comparar os estímulos, na fase perceptiva da tarefa. Neste caso, não há sobrecarga da memória, mas sim uma maior demanda atencional e tal demanda seria, supostamente, menor do que manter a duração dos estímulos na memória para só, na fase de resposta, comparar a duração do alvo com a duração do estímulo padrão.

É evidente que, com tais argumentos, não se pretende excluir a participação da memória e dos efeitos relativos ao armazenamento de informações no cérebro. A finalidade é argumentar no sentido de que a modulação atencional tenha um papel mais destacado na percepção de tempo, nos experimentos apresentados neste trabalho.

Diferentemente do que aconteceu no primeiro experimento, nos blocos prospectivos, o número de estímulos não teve papel significativo, mostrando que mecanismos atencionais vinculados à captura involuntária da atenção não foram importantes neste experimento. Uma possível explicação para este resultado é que, no primeiro experimento, o efeito atencional dos distratores ocorreu em durações curtas (0,5 s e 1,0 s). No entanto, considerando a menor duração do estímulo padrão (1750 
ms), há uma diferença expressiva entre as durações curtas do alvo e a duração do padrão. Portanto, o fato das durações curtas, onde o efeito dos distratores foi mais pronunciado, serem facilmente diferenciados da duração do estímulo padrão (vide Figura 5.3.4), impediu a avaliação, no segundo experimento, dos resultados encontrados nos blocos prospectivos do primeiro experimento.

Com relação ao critério, encontramos poucos achados significativos, o que afasta a hipótese de que a estratégia fosse responsável pelos principais resultados, tanto nas tarefas de discriminação como de reprodução. O resultado mostrado na figura 5.3.3 (critério diferente de zero para a apresentação de dois e quatro estímulos) pode ser explicado pelo fato de que mantivemos sempre as mesmas teclas se referindo a resposta da tarefa de discriminação. Assim, em situações mais difíceis, isto é, com maior número de estímulos sendo apresentados, o sujeito tinha a tendência de apertar o botão direito. Apesar desta falha no desenho do estudo, as alterações no critério foram de pouca magnitude, embora estatisticamente significativas para o fator número de estímulos.

Para tarefas de discriminação temporal, geralmente, não é possível obter os PIs, a menos que sejam usadas muitas durações padrões, o que obrigaria a um aumento sensível do número de sessões e levaria a uma dificuldade expressiva de analisar os dados.

Entretanto, podemos observar uma assimetria, estatisticamente significativa, na curva relativa à duração padrão de 1750 ms (ver Figura 5.3.3). Particularmente, o teste post-hoc mostrou que há uma diferença significativa entre $\Delta \mathrm{t}=-250 \mathrm{~ms}$ e $+250 \mathrm{~ms}$ com número de estímulos de 2 e 4 . Isto mostra que há durações nas quais há um maior d', portanto, a percepção de tempo é mais acurada. A região de maior assimetria é aquela situada entre $1,25 \mathrm{~s}$ e 1,75 s e, próximo deste intervalo, se encontra o PI de 1,83 $\pm 0,28 \mathrm{~s}$, calculado para 2 e 4 estímulos, no primeiro experimento. Tal como esperado, não foi encontrado assimetria com 1 estímulo (Tabela 5.3.2), uma vez que o PI de 0,7 \pm 0,10 s estaria situado em uma região onde a tarefa de discriminação seria fácil, não sendo possível verificar o efeito relativo à uma maior acurácia no julgamento do lapso de tempo.

Deve-se ainda ressaltar que o fato dos participantes terem respondido, com maior freqüência, que a duração do alvo era maior do que a duração do estímulo padrão (Figura 5.3.3.) não é responsável pela assimetria encontrada na figura 5.3.4. O evento de responder mais vezes que a duração do alvo foi maior não leva a uma modificação do 
d', uma vez que a probabilidade da duração do alvo ser maior que a duração do estímulo padrão é $50 \%$ e isto não interfere na equação 6.

\section{EXPERIMENTO 3}

\subsection{Objetivo}

Este experimento é semelhante ao primeiro experimento, entretanto avaliamos jovens, idosos e pacientes com DA, com concomitante registro eletroencefalográfico. Houve, ainda, uma simplificação do desenho experimental, em virtude das limitações inerentes à condição médica dos pacientes com DA.

O objetivo deste experimento é comparar a percepção de tempo e a influência da atenção nesta percepção em idosos, atentando para os aspectos relativos ao envelhecimento, e em pacientes com DA, considerando suas deficiências atencionais oriundas do quadro demencial.

\subsection{Arranjo Experimental}

A tarefa utilizada é de reprodução de tempo, já descrita no primeiro experimento. Entretanto, algumas simplificações foram efetuadas.

O tamanho, disposição, excentricidade e seqüência eram idênticos àquelas descritas no primeiro experimento, com a exceção de uma tela de descanso no final de cada apresentação. Esta tela permitia ao indivíduo se preparar para a apresentação que era iniciada quando este quisesse, bastando apertar uma tecla.

As instruções consistiam em não utilizar estratégia cognitiva que envolvesse contagem, manter os olhos direcionados ao ponto de fixação, não piscar, não movimentar cabeça e manter o máximo grau de relaxamento muscular possível. Tais instruções só se aplicavam à apresentação dos estímulos e não a tela de descanso.

Houve treinamento extensivo para diminuir o número de piscamentos e quando terminavam as apresentações, o sujeito era informado se havia piscado ou havia artefatos de contração muscular no registro eletroencefalográfico.

O sujeito era cônscio de que havia uma hierarquia: o principal era realizar o melhor possível a tarefa psicofísica e era secundário, porém muito desejável, não contrair, nem piscar durante as apresentações. 
Os grupos de jovens e idosos saudáveis realizaram duas sessões de três blocos cada, tendo cada bloco 24 apresentações. Em relação aos pacientes com DA, algumas modificações foram feitas no experimento. Realizamos apenas uma sessão, dadas as dificuldades de locomoção dos pacientes com DA até o local onde os experimentos eram realizados. Além disto, em cada apresentação havia uma tela que solicitava ao sujeito que reproduzisse a duração do alvo. Era freqüente, nos períodos de descanso, lembrar o paciente do que deveria fazer. Tais modificações se deviam às limitações de memória e aprendizado que os pacientes com DA apresentavam.

Utilizamos três variáveis. A primeira era o grupos (jovens, idosos ou pacientes com DA). Classificamos a segunda variável como tipo de experimento e envolvia as condições: apresentação de 1 estímulo (1C), apresentação de 4 estímulos com conhecimento prévio do alvo ou prospectiva (4P) e apresentação de 4 estímulos sem conhecimento prévio do alvo, dita retrospectiva (4R).

A terceira variável se referia às possíveis durações do alvo: 0,$5 ; 1,0 ; 1,5 ; 2,0$; 2,5; 3,0 segundos, com incerteza máxima de $23 \mathrm{~ms}$. Para o grupo de jovens e de idosos, havia uma quarta variável que consistia na sessão (primeira ou segunda sessão).

Os idosos e pacientes com DA realizaram testes cognitivos para avaliar o perfil de déficits dos grupos. Os testes realizados foram: exame do estado mental (MEEM), FOME, teste de trilhas (Trail Making A e B), teste da figura complexa de Rey, dígitos diretos, dígitos reversos e fluência verbal. Uma descrição mais completa destes testes cognitivos e do CAMDEX se encontra no anexo C.

O CAMDEX (Cambrigde Examination for Mental Disorder) completo foi aplicado aos pacientes com DA, além da escala de ansiedade de Hamilton (HAM-A), a escala de depressão de Montgomery (MADRAS) e CDR (Clinical Dementia Rating). As medicações utilizadas pelos pacientes se encontram na tabela 6.2.1 e os escores do CAMCOG e das escalas são apresentados na tabela 6.2.2.

Tabela 6.2.1. Apresenta os pacientes (representados pelas iniciais do nomes) e a medicação utilizada. PACIENTES MEDICAÇÃO

\begin{tabular}{cc}
\hline H. S. R & $9 \mathrm{mg}$ rivastigmina e $200 \mathrm{mg}$ de sertralina \\
\hline L. . & $9 \mathrm{mg}$ rivastigmina \\
\hline C. G. Z. & $10 \mathrm{mg}$ dopezila \\
\hline A. G. F. & $12 \mathrm{mg}$ rivastigmina e $1 \mathrm{mg}$ risperidona \\
\hline
\end{tabular}


Tabela 6.2.2. $\quad$ Escores dos testes cognitivos. Mostra a média, mediana e erro padrão da média (E. P. M) dos escores das escalas neuropsiquiátricas e do CAMCOG (pontuação total e seus subtestes), instrumentos estes aplicados para a avaliação dos pacientes com DA.

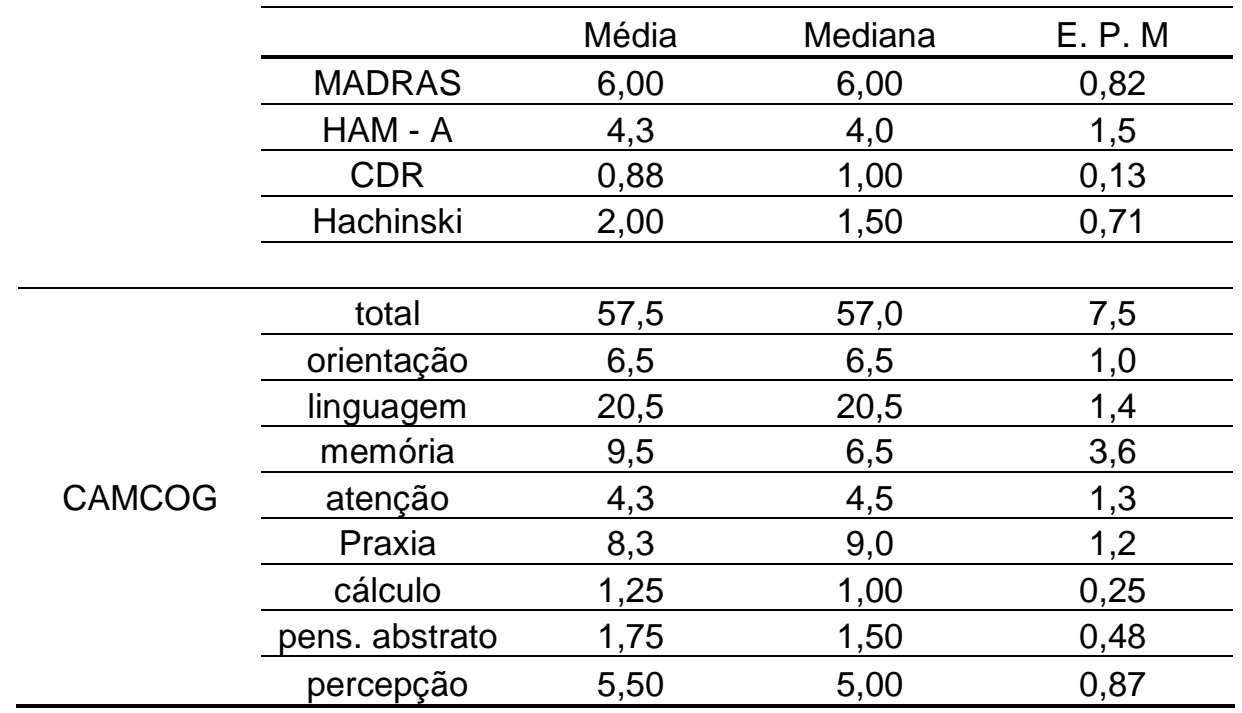

Nota: Mostra a média, mediana e erro padrão da média (E. P. M) dos escores das escalas neuropsiquiátricas e do CAMCOG (pontuação total e seus subtestes), instrumentos estes aplicados para a avaliação dos pacientes com DA.

\subsection{Análise e Resultados}

Tal como realizado no primeiro experimento, utilizamos como medida do desempenho a diferença relativa (\%) e o coeficiente de variação (CV). Em virtude da presença realização de duas sessões para os grupos de jovens e idosos, iremos realizar, primeiramente, uma análise dos dados relativos ao grupo de jovens e de idosos saudáveis. Posteriormente, procederemos à análise dos três grupos (jovens, idosos e pacientes com DA)

Foi realizada uma ANOVA de quatro fatores $(2 \times 3 \times 6 \times 2)$ nas médias da diferença relativa e no $\mathrm{CV}$, com a finalidade de avaliar o efeito da sessão na reprodução de tempo. $\mathrm{O}$ primeiro fator era a idade, sendo dividido em jovens e idosos. $\mathrm{O}$ segundo fator se referia ao tipo de experimento: 1 estímulo (1C), 4 estímulos prospectivo (4P) e 4 estímulos retrospectivo (4R). O terceiro fator era a duração e o quarto era a sessão (sessão 1 e 2), para avaliar o efeito do aprendizado.

Como resultados da análise, encontramos um efeito principal para o tipo de experimento $(\mathrm{F}(2,36)=5,5$ e $\mathrm{p}=0,008)$ e para a duração $(\mathrm{F}(5,90)=29,4$ e p $<0,001)$. As interações encontradas foram: duração e idade $(F(5,90)=4,3$, e p = 0,002), duração e tipo de experimento $(F(10,180)=9,6$ e p < 0,001) e duração e sessão $(F(5,90)=2,7$ e $\mathrm{p}=0,026)$. Realizamos o teste post-hoc e encontramos diferença entre o tipo de 
experimento $1 \mathrm{C}$ e $4 \mathrm{P}(\mathrm{p}=0,009)$ e $1 \mathrm{C}$ e $4 \mathrm{R}(\mathrm{p}=0,011)$. A reprodução da duração de 0,5 segundo é diferente para os três tipos de experimento $(\mathrm{p}<0,001$ para as três comparações).

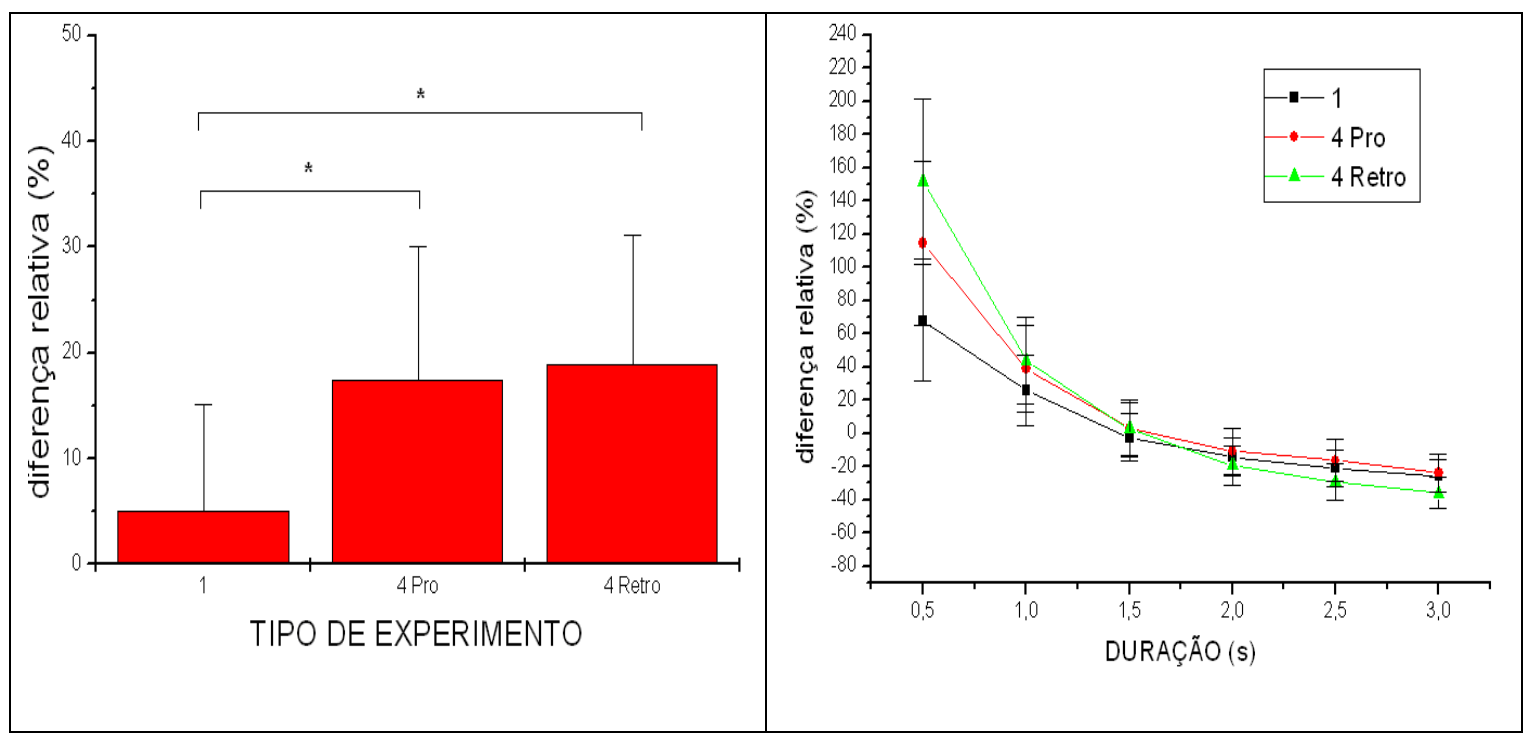

Figura 6.3.1. O gráfico mostra a média das diferenças relativas (\%) em função do tipo de experimento (esquerda). A duração em função da diferença relativa, considerando o tipo de experimento (direita). As barras de erro se referem ao erro padrão.

Devemos ressaltar que a medida de desempenho "diferença relativa", geralmente, apresenta distribuição normal (BUHUSI; MECK, 2005; WEARDEN; LEJEUNE, 2008) e, por isso, os métodos paramétricos têm sido usados para avaliar os dados da reprodução de tempo. Contudo, é necessário conhecer a distribuição de nossos dados, para tanto, procedeu-se à avaliação da normalidade, usando o teste de Kolmogorov-Smirnov. A distribuição da diferença relativa não foi significativamente diferente da distribuição normal para a maior parte das variáveis. Com relação à avaliação da homocedascidade, utilizamos o teste de Levene e não houve desvios significativos da homogeneidade considerando os grupos jovens, idosos e pacientes com DA.

Nem todas as variáveis apresentaram distribuições homogêneas, entretanto, como argumenta Zar (1996), a ANOVA é suficientemente robusta, mesmo quando há pequenos desvios da homogeneidade. Prova disto é que tanto as transformações logarítmicas e que envolvem raiz quadrada, que levaram a um diminuição no número de variáveis com distribuição não homogêneas, apresentaram resultados semelhantes aos obtidos usando-se os dados sem transformação (os fatores principais e as interações 
estatisticamente significantes foram os mesmos). Portanto, com a finalidade de comparar os grupos de jovens, idosos saudáveis e pacientes com DA, apresentaremos os resultados da ANOVA dos dados sem qualquer transformação. Foi considerada apenas a primeira sessão do grupo de jovens e de idosos, uma vez que pacientes realizaram apenas uma sessão.

Realizamos uma ANOVA de três fatores $(3 \times 3 \times 6)$ no conjunto de variáveis de diferença relativa. O primeiro fator era o grupo, sendo dividido em jovens, idosos e pacientes com DA. O segundo fator se referia ao tipo de experimento: 1 estímulo (1C), 4 estímulos prospectivo (4P) e 4 estímulos retrospectivo (4R) e o terceiro fator era a duração do alvo $(0,5 ; 1,0 ; 1,5 ; 2,0 ; 2,5 ; 3,0)$.

Como resultados da análise, encontramos um efeito principal para a duração $(\mathrm{F}(5,105)=27,9$ e $\mathrm{p}<0,001)$. O teste post hoc mostra que as durações 0,5 e 1,0 segundos são diferentes entre si $(\mathrm{p}=0,001)$ e das demais durações. Particularmente, para a duração de 0,5 segundos, $1 \mathrm{C}$ foi diferente de $4 \mathrm{P}(\mathrm{p}<0,001)$ e de $4 \mathrm{R}(\mathrm{p}<0,001)$ e também 4P foi diferente de 4R ( $\mathrm{p}=0,009)$.

Houve interação com os fatores grupo e duração $(F(10,105)=2,5$ e $p=0,011)$ e a interação de terceira ordem entre grupo, duração e tipo de experimento $(F(20,210)=$ $3,6$ e $\mathrm{p}<0,001)$.
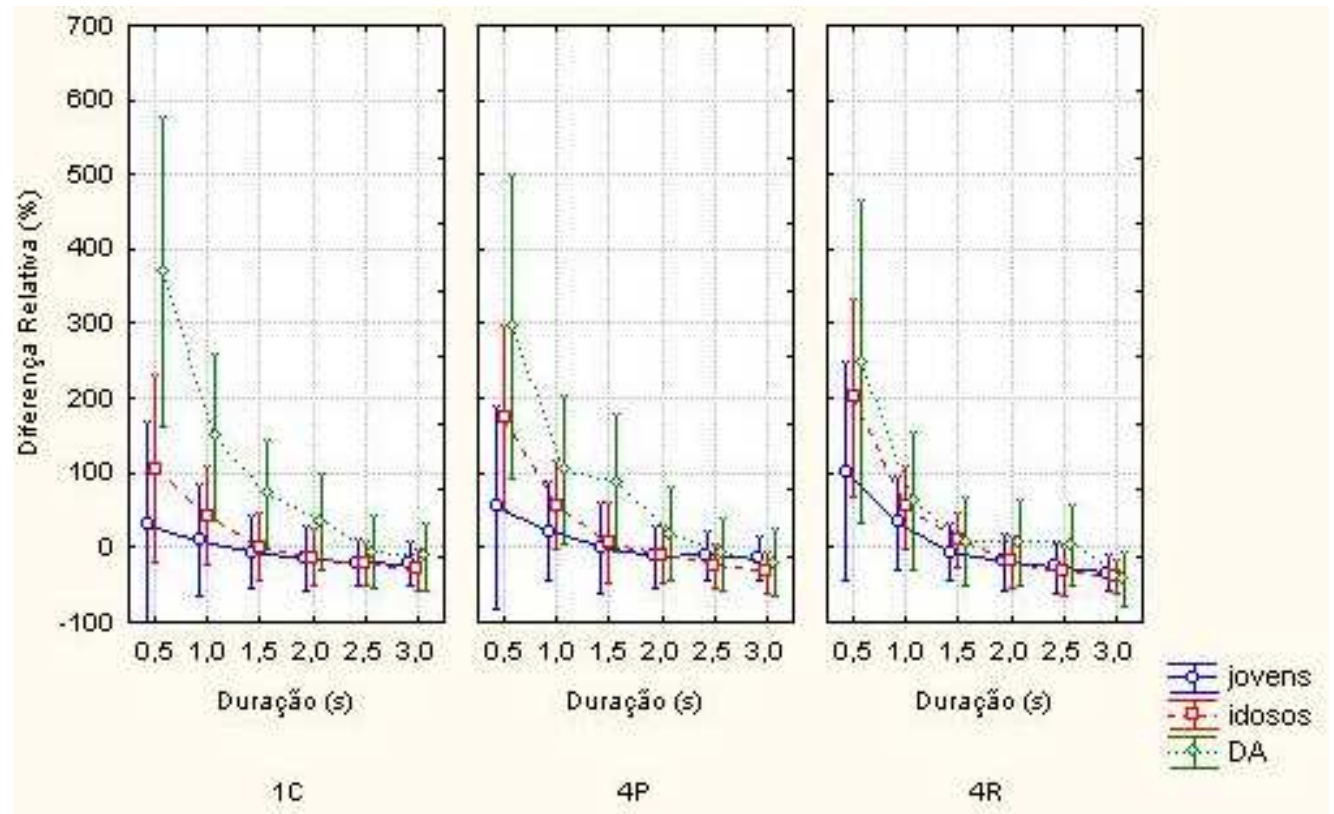

Figura 6.3.2. Diferença Relativa em função da duração do alvo. Na parte inferior discrimina-se o tipo de experimento e as linhas se referem aos grupos experimentais. A barra de erro corresponde ao intervalo de confiança de $95 \%$. 
Analisamos também a mediana, usando uma ANOVA $3 \times 3 \times 6$ e obtivemos resultados similares: efeito principal na duração $(F(5,105)=27,2$ e p $<0,001)$, interação com os fatores duração e grupo $(\mathrm{F}(10,105)=2,6$ e $\mathrm{p}=0,008)$ e interação de terceira ordem (grupo x tipo de experimento x duração do alvo) com $\mathrm{F}(20,210)=2,5$ e p < 0,001. Isto mostra que as distribuições das variáveis envolvidas são simétricas.

Realizamos uma regressão exponencial da diferença relativa em função da duração, considerando o grupo e o tipo de experimento, o que consiste, na prática, em calcular a regressão exponencial dos pontos experimentais apresentados na figura 6.3.2., procedimento descrito na seção 4.3. Os coeficientes da regressão exponencial e os PI (ponto de igualdade) são apresentados na tabela 6.3.1. e tabela 6.3.2, respectivamente. Com isto, podem-se obter as durações nas quais há maior acurácia para cada grupo.

Tabela 6.3.1. Apresenta os coeficientes da regressão exponencial obtidos para cada tipo de experimento, considerando cada grupo estudado.

\begin{tabular}{|c|c|c|c|c|}
\hline & & $1 \mathrm{C}$ & $4 \mathrm{P}$ & $4 \mathrm{R}$ \\
\hline \multirow{3}{*}{ JOVENS } & y0 & $-28,3 \pm 4,1$ & $-14,9 \pm 3,7$ & $-37,8 \pm 2,9$ \\
\hline & $\mathrm{A} 1$ & $53,1 \pm 4,5$ & $79,4 \pm 6,6$ & $159,2 \pm 3,8$ \\
\hline & $\mathrm{t} 1$ & $0,85 \pm 0,39$ & $0,41 \pm 0,19$ & $0,66 \pm 0,08$ \\
\hline \multirow{3}{*}{ IDOSOS } & y0 & $-31,8 \pm 5,1$ & $-24,7 \pm 3,7$ & $-43,24 \pm 4,7$ \\
\hline & $\mathrm{A} 1$ & $168,87 \pm 5,9$ & $250,7 \pm 5,7$ & $215,0 \pm 6,8$ \\
\hline & $\mathrm{t} 1$ & $0,79 \pm 0,15$ & $0,54 \pm 007$ & $0,58 \pm 0,10$ \\
\hline \multirow{3}{*}{ DA } & y0 & $-11,8 \pm 6,1$ & $-19,63 \pm 0,50$ & $-41,55 \pm 0,50$ \\
\hline & A1 & $369 \pm 13$ & $310 \pm 22$ & $284 \pm 23$ \\
\hline & $\mathrm{t} 1$ & $0,57 \pm 0,08$ & $0,70 \pm 0,19$ & $0,61 \pm 0,21$ \\
\hline
\end{tabular}

Tabela 6.3.2. Mostra os PIs, para cada tipo de experimento e grupo estudado. Adj. $\mathrm{R}^{2}$ se refere ao coeficiente de determinação ajustado.

\begin{tabular}{|c|c|c|c|c|}
\hline Grupo & Tipo & $\mathrm{PI}$ & incerteza & Adj. $R^{2}$ \\
\hline \multirow{3}{*}{ JOVENS } & $1 \mathrm{C}$ & 1,03 & 0,37 & 0,87 \\
\hline & $4 \mathrm{P}$ & 1,18 & 0,38 & 0,81 \\
\hline & $4 \mathrm{R}$ & 1,45 & 0,16 & 0,99 \\
\hline \multirow{3}{*}{ IDOSOS } & $1 \mathrm{C}$ & 1,83 & 0,36 & 0,99 \\
\hline & $4 \mathrm{P}$ & 1,75 & 0,22 & 0,98 \\
\hline & $4 \mathrm{R}$ & 1,44 & 0,2 & 0,98 \\
\hline \multirow{3}{*}{ DA } & $1 \mathrm{C}$ & 2,45 & 0,66 & 0,98 \\
\hline & $4 \mathrm{P}$ & 2,42 & 0,55 & 0,91 \\
\hline & $4 \mathrm{R}$ & 1,66 & 0,41 & 0,74 \\
\hline
\end{tabular}


Com relação ao coeficiente de variação $(\mathrm{CV})$, realizamos a ANOVA 3x3x6 e só encontramos interação entre tipo e duração $(F(10,210)=2,2$ e $p=0,019)$, que não obedece qualquer padrão evidente.

Uma questão importante é se a escolaridade ou o fator idade tiveram importância na explicação dos resultados, uma vez que o grupo de pacientes com DA apresenta maior idade em relação o grupo de idosos saudáveis. Com este intuito realizamos uma análise de covariância (ANCOVA) e não encontramos significância para as variáveis escolaridade e idade em relação às médias das diferenças relativas, o que sugere que a tais variáveis não são responsáveis pelos resultados obtidos.

As figuras 6.3 .4 e 6.3 .5 mostram as diferenças, estatisticamente significativas, entre o desempenho de idosos e pacientes com DA, usando o teste U de Mann-Whitney (um teste não paramétrico, uma vez que os escores dos testes cognitivos não necessariamente apresentam distribuições normais). Também incluímos na análise os subtestes do MEEM que avaliam a atenção (prova dos sete) e a memória (evocação tardia). As seguintes diferenças entre os escores obtidos pelo grupo de idosos e de pacientes com DA foram encontradas: mini-mental $(Z=2,55$ e $p=0,011)$, evocação tardia $(Z=2,47$ e $p=0,013)$, cópia imediata $(Z=2,82$ e $p=0,005)$ e recuperação em 30 minutos $(Z=2,82$ e $p=0,005)$ da figura de Rey, Teste de trilhas parte $A(Z=-2,47$ e $p$ $=0,013)$ e parte $\mathrm{B}(\mathrm{Z}=-2,82$ e $\mathrm{p}=0,005)$, FOME $(Z=2,82$ e $\mathrm{p}=0,005)$ e fluência verbal $(Z=2,84$ e $p=0,005)$.

Utilizamos a correlação de Spearman para avaliar a relação entre as médias da diferença relativa, particularmente para as durações do alvo de 0,5 e 1,0 segundos, durações nas quais o efeito atencional é mais pronunciado. Usando $\alpha$ de 0,05 , encontramos uma correlação $\rho=-0,53$ (ordem de correlação de Spearman) entre a duração de 0,5 segundos para o tipo $1 \mathrm{C}$ e os escores do teste de trilhas parte $\mathrm{B}$ (a correlação é negativa, pois quanto maior o escore no teste, pior é concentração do sujeito). Entre os testes houve várias correlações, citamos apenas as que se referem aos testes que estariam vinculados à atenção: correlação do teste de trilhas parte B com a prova dos sete, sub-teste do mini exame do estado mental $(\rho=-0,54)$. Outra correlação é do teste de trilhas parte A com o teste de trilhas parte B $(\rho=0,72)$. 


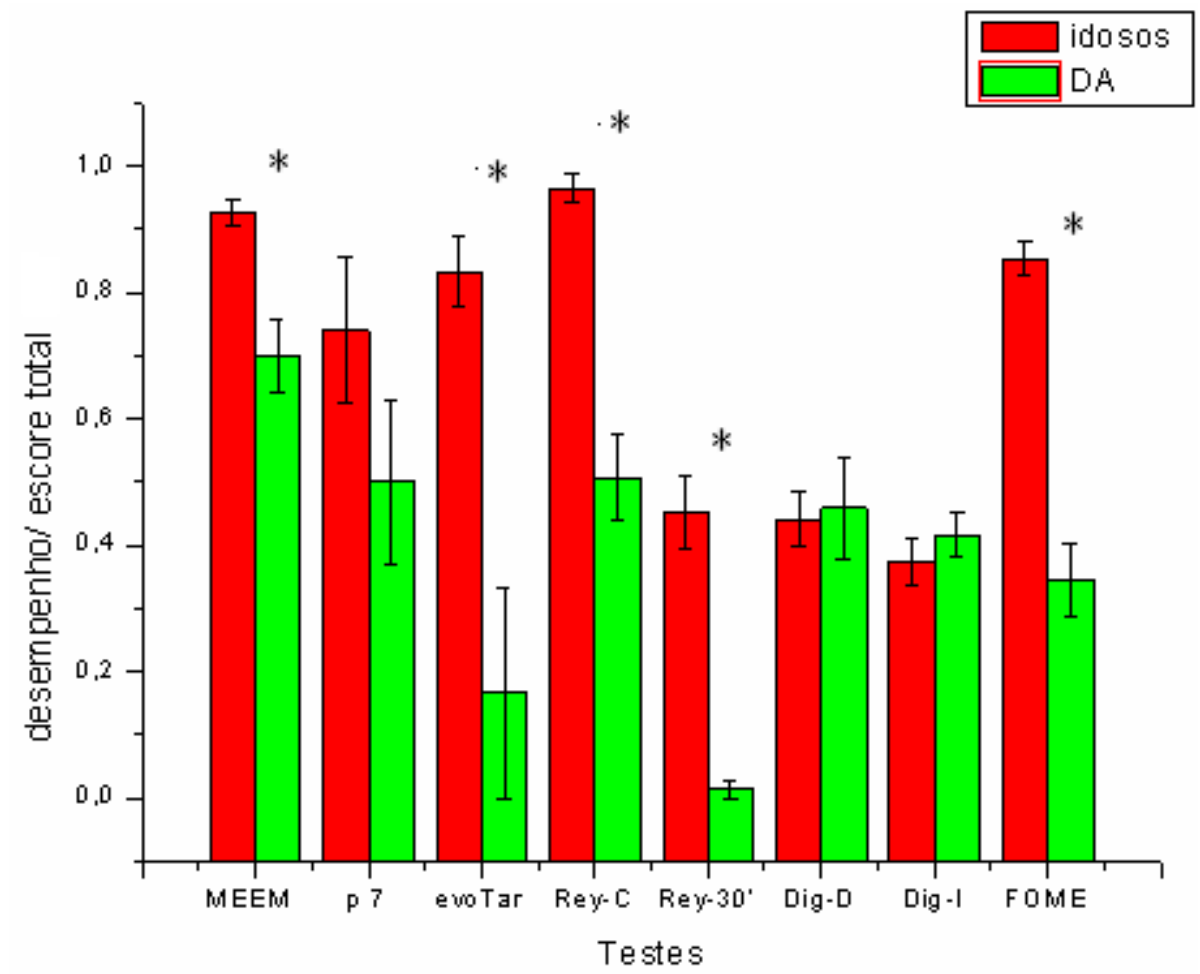

Figura 6.3.4. A figura mostra o desempenho relativo (desempenho / escore total do teste) dos grupos de idosos e pacientes com DA. p7: prova dos sete; evoTar: evocação tardia; REY-C: cópia da figura complexa de Rey; REY-30': reprodução da figura complexa após 30 mimutos; Dig-D: dígitos diretos; Dig-I: dígitos inversos ${ }^{6}$. As barras de erro se referem ao erro padrão da média.

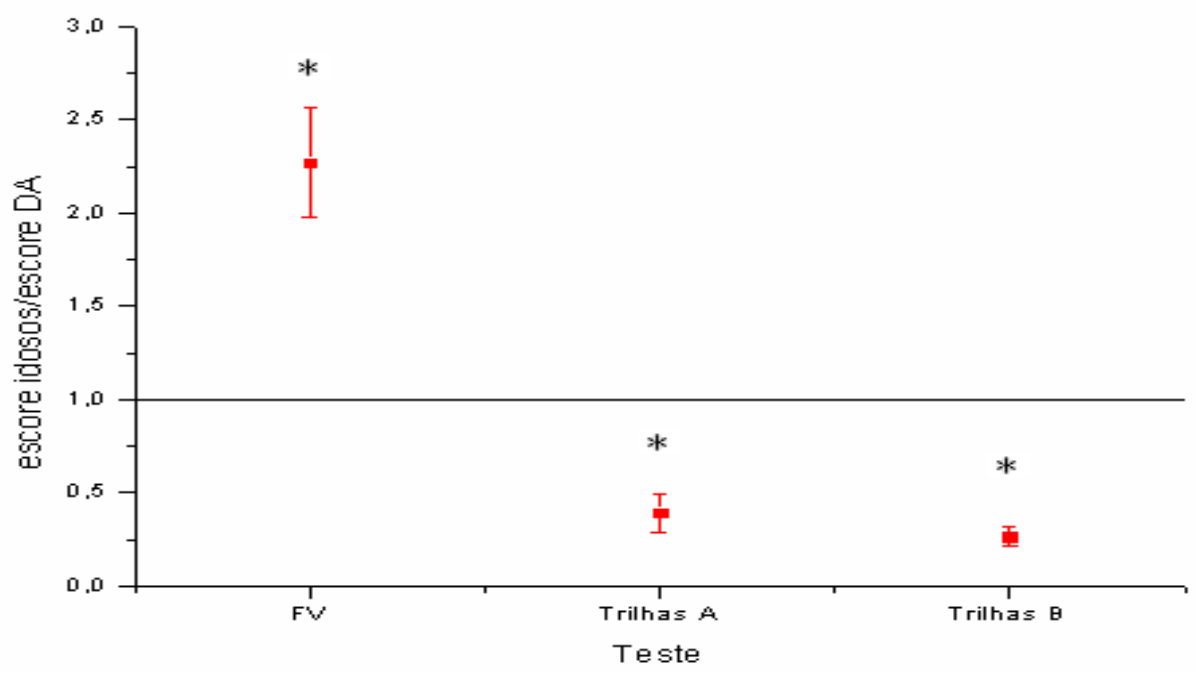

Figura 6.3.5. O escore de idosos/ escore de pacientes com DA. Note que quanto maior o escore no FV melhor o desempenho, quanto menor o escore no teste de trilhas, tanto na versão A quanto $\mathrm{B}$, melhor o desempenho. FV: teste de fluência verbal. As barras de erro se referem ao erro padrão da média.

${ }^{6}$. Os escores do FOME levam em conta apenas o número de acertos, isto é, o número de evocações dos objetos efetuadas pelos indivíduos. 


\subsection{Discussão do experimento 3}

Os resultados apresentados devem ser cotejados com o primeiro experimento e sua interpretação depende das argumentações desenvolvidas na seção 4.4. Neste sentido, o número de estímulos e conhecimento prévio ou posterior do alvo estão associados com a demanda atencional.

Os resultados referentes à comparação entre o grupo de jovens e de idosos saudáveis mostram o efeito significante do tipo de experimento (1C foi diferente de $4 \mathrm{P}$ e 4R, como apresentado na figura 6.3.1.). Curiosamente, não encontramos diferença entre os blocos 4P e 4R, tal como havia acontecido no primeiro experimento. Possíveis fatores que tenham interferido na replicação parcial dos resultados do primeiro experimento são o número de participantes ser menor e o fato de que o indivíduo deveria manter-se atento quanto à contração muscular e ao piscamento, em virtude do registro eletroencefalográfico concomitante. Com isto, o participante era submetido a uma maior demanda atencional, pois necessitava prestar atenção na apresentação dos estímulos e também controlar relaxamento muscular e a freqüência de piscamentos. Neste sentido, há uma tendência de apresentar uma maior superestimação nos resultados do terceiro experimento (Figura 6.3.2.) em relação ao primeiro experimento (Figura 4.3.2), particularmente na apresentação de um estímulo. Podemos entender tal situação com similar àquela na qual se empregam tarefas concomitantemente. Apesar do treinamento prévio ao qual cada participante era submetido, não foi possível eliminar completamente o efeito atencional desta necessidade de monitorar a atividade muscular, ainda que o treinamento, sabidamente, diminua a demanda atencional em experimentos que empregaram duas tarefas concomitantemente (BROWN, 2008). Mesmo assim, encontramos uma interação com os fatores duração e tipo de experimento. A duração de 0,5 segundo é diferente para todos os tipos de experimento e há uma superestimação maior para esta duração quanto maior a complexidade da tarefa, que baseado nos dados do primeiro experimento, supomos ser de origem atencional.

Outro resultado importante é que grupo de idosos tende a superestimar mais jovens em durações curtas. Consoante a discussão realizada no primeiro experimento, interpretamos tal achado como associado a uma limitação dos recursos atencionais vinculada ao envelhecimento.

Todavia, Vanneste e Pouthas (1999) e Carrasco, Guillem e Redolat (2001) encontraram uma subestimação para os idosos, mas as durações empregadas eram 
diferentes (maiores que 5 segundos), durações estas que não foram avaliadas nem no primeiro, tampouco no terceiro experimento.

Ulbrich et al. (2007) sustentam a hipótese formulada por Fraisse (1984) de que há fatores, cuja preponderância é diferente para a percepção de tempo de durações até 3 segundos da percepção de tempo para durações maiores que 3 segundos. Para a percepção de tempo de durações maiores que 3 segundos a memória tem um importante papel. De fato, uma maior demanda associada à memória deve apresentar papel importante nos resultados obtidos por Vanneste e Pouthas (1999), considerando o desenho do experimento, no qual o sujeito deveria reproduzir sequencialmente a duração dos três estímulos apresentados previamente.

No desenho de nosso experimento, além de utilizarmos durações menores que 3 segundos, tentamos diminuir a demanda vinculada à memória, com a finalidade de ressaltar o papel da atenção nos resultados obtidos. Além disto, nossos resultados se alinham com experimentos nos quais foram empregadas tarefas concomitantes à fase de reprodução (FORTIN; ROUSSEAU, 1998).

Com relação à percepção de tempo em pacientes com DA, verificamos um aumento da superestimação, particularmente, de durações de 0,5 e 1,0 segundos, apesar de não termos encontrado um efeito completo da dificuldade da tarefa nesta superestimação (1C é diferente de $4 \mathrm{P}$ e $4 \mathrm{R}$ ), isto é, o efeito seria completo se 4P fosse diferente de 4R. A figura 6.3.2. mostra, com clareza, que o efeito do tipo de experimento é mais pronunciado em jovens e se faz de forma intermediária no grupo de idosos saudáveis. Uma explicação é que a facilitação do conhecimento prévio do alvo seria diminuída em idosos e mais intensamente em pacientes com DA, sendo que tal deficiência estaria associada a uma diminuição dos recursos atencionais. Nestes dois grupos é sabido que há uma capacidade diminuída de inibir a percepção de estímulos irrelevantes (MADDEN, 2007; DANCKETT et al., 1998). Outro fato importante, em especial nos pacientes com DA, é a dificuldade de focar e alocar voluntariamente a atenção em um objeto ou região do espaço (FOSTER; BEHRMANN; STUSS, 1999). Para pacientes com DA, a alteração da atenção seria tão grande, que não conseguiriam atentar para um estímulo, em especial se fosse rápido. Isto se coaduna com a afirmação, por parte de alguns pacientes, de que não conseguiam ver alguns estímulos, pois eram muito rápidos.

Naturalmente, tal consideração só pode ser feita considerando que passaram por uma avaliação da acuidade visual e que conseguiam avaliar, relativamente melhor, o 
tempo de figuras, cujas durações eram maiores que 2 segundos. Deve-se enfatizar que pacientes com DA leve não apresentam alterações nas áreas corticais sensoriais primárias e sua percepção de características básicas está preservada (RIZZO; ANDERSON, 2000).

Um resultado que se alinha à hipótese que a atenção esteja envolvida, de forma preponderante, no desempenho de idosos e pacientes com DA, é a correlação do desempenho com um teste cognitivo que avalia atenção (teste de trilhas parte B) e a ausência de correlações com tarefas de memória. Um fator importante para não termos encontrado mais correlações pode ter sido o número pequeno de indivíduos. Além disto, alguns testes, tais como o exame do estado mental, apresentavam um efeito teto para idosos. Outro possível fator relaciona-se a não utilizar testes que avaliem a atenção dividida, que se encontra alterada tanto em idosos como pacientes com DA (STUARTHAMILTON, 2002; PERRY; HODGES, 1999).

Ainda que discutir ou apoiar-se sobre resultados não significantes seja temerário, o fato de não termos encontrado covariância entre o desempenho na reprodução de tempo e a escolaridade ou a idade sugere que os resultados relativos aos pacientes com DA não podem ser explicados pela idade, nem tampouco a escolaridade interferiu significativamente em nosso experimento.

É interessante notar que há uma tendência, nos PIs, de aumentar conforme há um pior desempenho na percepção de tempo para durações curtas. Em média o PI do grupo jovem foi de $1,22 \pm 0,37 \mathrm{~s}$, do grupo de idosos $1,67 \pm 0,33 \mathrm{~s}$ e do grupo de pacientes com DA foi de 2,18 $\pm 0,56 \mathrm{~s}$. Este fato não era inteiramente esperado, uma vez que, pelo modelo do oscilador, não haveria modificação da freqüência do oscilador relacionada a menores recursos atencionais. Uma hipótese é de que a diminuição do metabolismo cerebral leve a uma diminuição da freqüência do oscilador, tal como foi descrito com a temperatura corporal (WEARDEN; PENTON-VOAK, 1995). Os experimentos apresentados neste trabalho, a rigor, não permitem uma avaliação sistemática do oscilador. Para avaliar tal questão, seria importante avaliar a estimativa verbal ou produção de tempo, uma vez que, nestas tarefas, haveria uma transformação do tempo percebido (usando o relógio interno) em unidades objetivas de tempo (segundos, minutos, horas). Na reprodução de tempo o indivíduo usaria o mesmo marca-passo para perceber e para reproduzir. De forma semelhante, na discriminação temporal, o mesmo oscilador estaria envolvido em julgar a duração do estímulo padrão e do alvo. Portanto, nestas duas tarefas, seria difícil avaliar o oscilador diretamente, pois tanto na resposta 
como na fase perceptiva do lapso de tempo o mesmo relógio interno seria empregado. $\mathrm{Na}$ literatura, há alguns trabalhos que sugerem que o marca-passo esteja acelerado no envelhecimento (BLOCK; ZAKAY; HANCOCK, 1998), ainda que haja considerável controvérsia sobre o tema (WEARDEN; WEARDEN; RABBITT, 1997). Em relação à freqüência do oscilador em pacientes com DA, não foram encontrados trabalhos que avaliassem o assunto.

Outra hipótese seria de que haveria outros fatores envolvidos no PI e que este não fosse determinado exclusivamente pela freqüência do oscilador, como sugerem alguns autores (PÖPPEL, 1997). Zackay e Block (2004) advogam que a atenção teria um papel estrutural na percepção de tempo e nos PIs, por conseguinte, não seria apenas um fator que modularia a percepção, mas sim determinaria a relação entre tempo objetivo e tempo percebido. Com esta formulação, não é possível usar o modelo do relógio interno, ao menos aquele proposto por Gibbon, Church e Meck (1984).

\section{EXPERIMENTO 4}

\subsection{Objetivo}

Este experimento é semelhante ao experimento 2, entretanto avaliamos jovens, idosos e pacientes com DA com concomitante registro eletroencefalográfico. Houve, ainda, uma simplificação do desenho experimental, em virtude das limitações inerentes à condição médica dos pacientes com DA.

Nosso objetivo é avaliar a discriminação de tempo em idosos e em pacientes com DA cotejando com o desempenho de jovens, complementando o experimento 3.

\subsection{Arranjo Experimental}

A tarefa utilizada é de discriminação de tempo, já descrita no experimento 2.

O grupo de sujeitos que realizou o experimento 3 também realizou o experimento 4. Este experimento apresentava os mesmos estímulos e a mesma localização empregada no experimento 2.

Contudo, algumas modificações foram realizadas. Havia uma tela de descanso no final de cada apresentação que permitia ao sujeito preparar-se para estas 
apresentações. Outra modificação foi a utilização de apenas uma duração para o estímulo padrão (1750 ms)

As instruções consistiam em não utilizar estratégia cognitiva que envolvesse contagem, manter os olhos direcionados ao ponto de fixação, não piscar, não movimentar cabeça e manter o máximo grau de relaxamento muscular possível. Tais instruções só se aplicavam à apresentação dos estímulos e não a tela de descanso.

Houve treinamento extensivo para diminuir o número de piscamentos e quando terminavam as apresentações, o sujeito era informado se havia piscado ou havia artefatos de contração muscular no registro eletroencefalográfico.

O sujeito era cônscio de que o havia uma hierarquia: o principal era realizar o melhor possível a tarefa psicofísica e era secundário, porém muito desejável, não contrair, nem piscar durante as apresentações.

Os grupos de jovens e idosos saudáveis realizaram duas sessões de três blocos cada, tendo cada bloco 24 apresentações.

Utilizamos três parâmetros. O primeiro era o grupo (jovens, idosos ou pacientes com DA). Classificamos o segundo parâmetro como tipo de experimento e envolvia as condições: apresentação de 1 estímulo (1C), apresentação de 4 estímulos com conhecimento prévio do alvo ou prospectiva (4P) e apresentação de 4 estímulos sem conhecimento prévio do alvo, dita retrospectiva (4R).

O terceiro parâmetro se referia à diferença entre duração do alvo e duração do estímulo padrão $(\Delta \mathrm{t})$ : $-1250 \mathrm{~ms},-250 \mathrm{~ms},+250 \mathrm{~ms}$ e $+1250 \mathrm{~ms}$. Um quarto parâmetro se referia à sessão, sendo que apenas os grupos de jovens e de idosos realizaram duas sessões.

Tal como ocorreu no terceiro experimento, algumas modificações foram feitas para o grupo de pacientes com DA. Além de realizarem apenas uma sessão, em cada apresentação havia uma tela que solicitava ao sujeito que respondesse qual estímulo tinha durado mais (alvo ou estímulo padrão). Também havia uma indicação sobre o que significavam as teclas de resposta, uma vez que os pacientes tinham dificuldade, mesmo após treino, de memorizar o significado das duas teclas.

\subsection{Análise e Resultados}

As medidas de desempenho empregadas para a avaliação da discriminação de tempo foram a discriminabilidade (d'), o critério $(\beta)$ e a porcentagem de erros. 
Considerando que os grupos de jovens e de idosos realizaram duas sessões, foi utilizada uma ANOVA $2 \times 3 \times 2 \times 2$. O primeiro fator era o grupo (jovens e idosos), o segundo fator é o tipo de experimento (1C, 4P e 4R). O terceiro fator era o módulo da diferença entre a duração do alvo e a duração do estímulo padrão, podendo apresentar os valores: $|\Delta \mathrm{t}|= \pm 1250 \mathrm{~ms}$ ou $\pm 250 \mathrm{~ms}$. O quarto fator se refere às sessões, sendo que com este fator pretendemos avaliar a relevância do aprendizado no decorrer do experimento.

Com relação à discriminabilidade (d') encontramos efeitos principais no grupo $(\mathrm{F}(1,18)=34,4$ e $\mathrm{p}<0,001),|\Delta \mathrm{t}|(\mathrm{F}(1,18)=42,1$ e $\mathrm{p}<0,001)$ e tipo de experimento $(\mathrm{F}(2,36)=4,9$ e $\mathrm{p}=0,013)$, que pode ser visualizado na figura 7.3.1. Houve interação significativa com os fatores $|\Delta \mathrm{t}|$ e idade $(\mathrm{F}(1,18)=16,1$ e $\mathrm{p}<0,001)$.

O teste post-hoc mostra uma diferença significativa entre $1 \mathrm{C}$ e $4 \mathrm{R}(\mathrm{p}=0,019) \mathrm{e}$ entre 4P e 4R ( $\mathrm{p}=0,013)$. Na comparação entre jovens e idosos, houve diferenças para $1 \mathrm{C}(\mathrm{p}=0,019), 4 \mathrm{P}(\mathrm{p}=0,037)$ e $4 \mathrm{R}(\mathrm{p}=0,024)$, considerando $|\Delta \mathrm{t}|= \pm 1250 \mathrm{~ms}$ (ver Figura 7.3.2). No grupo de jovens, houve diferença entre $1 \mathrm{C}$ e $4 \mathrm{R}(\mathrm{p}=0,044)$. No grupo de idosos saudáveis, houve diferença entre $4 \mathrm{P}$ e $4 \mathrm{R}(\mathrm{p}=0,021)$, como pode ser observado na figura 7.3.2.

Não houve significância estatística para nenhum efeito principal e interação, considerando o critério como medida de desempenho.

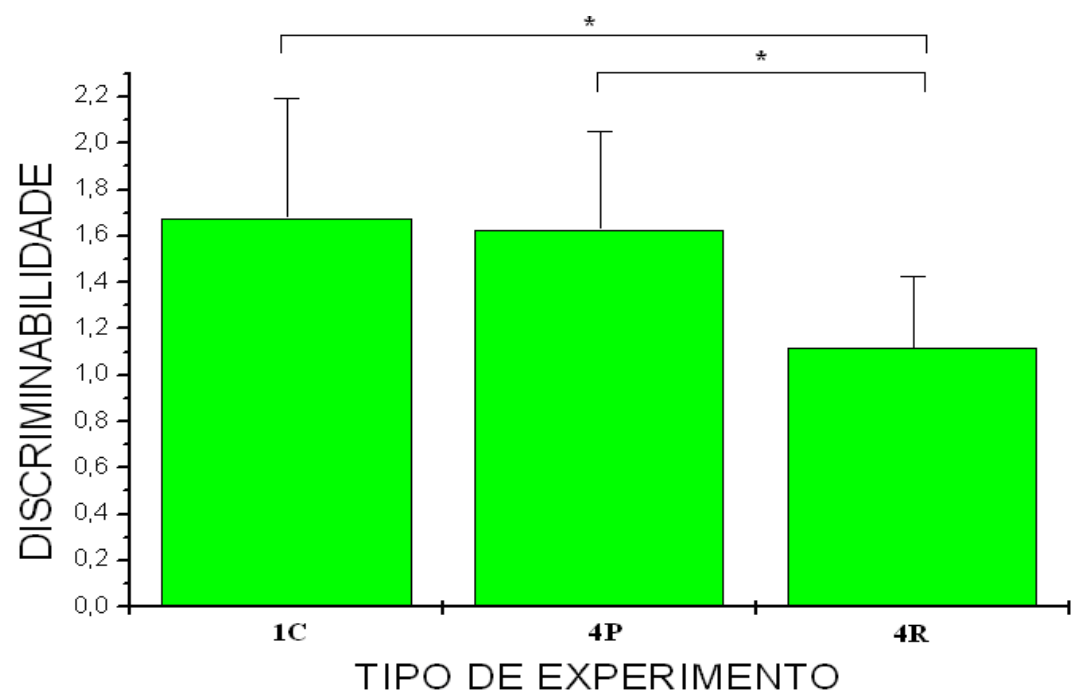

Figura 7.3.1. A diferença entre os tipos de experimento, considerando d'. As barras de erro se referem ao erro padrão da média. 

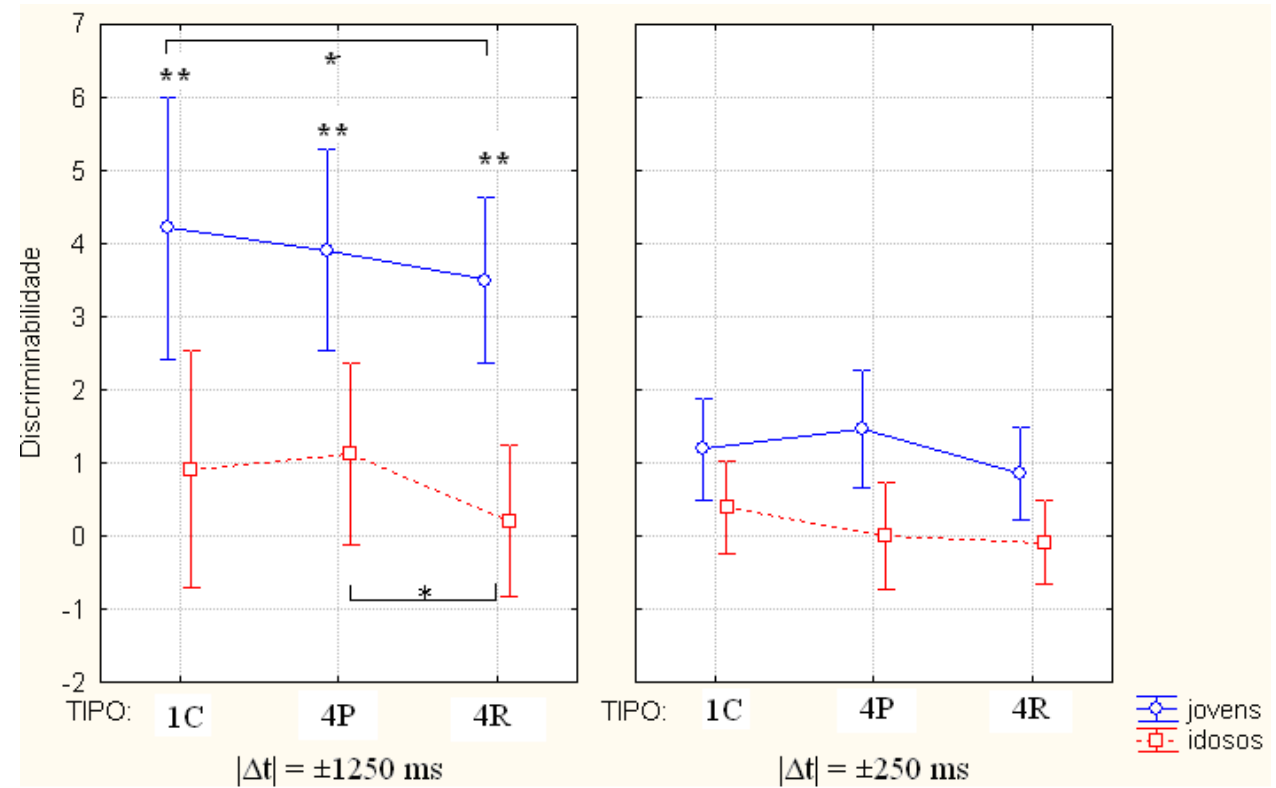

Figura 7.3.2. Discriminabilidade em função do tipo de experimento, considerando o grupo e $|\Delta t|$. A barra de erro se refere ao intervalo de confiança de $95 \%$. ** se refere a diferenças entre o grupo de jovens e idosos e* se refere a diferenças em um dado grupo.

Avaliamos a homogeneidade do d' e de $\beta$ através do teste de Levene e não encontramos transgressões significativas da homogeneidade, considerando os três grupos (jovens, idosos e pacientes com DA). Todas as variáveis mostraram distribuição que não foi diferente da normal, pelo teste de Kolmogorov-Smirnov.

Com a finalidade de analisar e comparar os dados de pacientes com DA com os demais grupos experimentais, consideramos apenas a primeira sessão dos grupos de jovens e idosos. Empregou-se uma ANOVA 3x3x2, cujo primeiro fator era o grupo (jovens, idosos, pacientes com DA). O segundo fator era o tipo de experimento (1C, 4P e 4R) e o terceiro fator era $|\Delta t|$, que apresentava os valores de $\pm 1250 \mathrm{~ms}$ e $\pm 250 \mathrm{~ms}$.

Com relação à discriminabilidade (d') encontramos efeitos principais no grupo $(\mathrm{F}(2,21)=31,3$ e $\mathrm{p}<0,001)$ e $|\Delta \mathrm{t}|(\mathrm{F}(1,21)=25,4$ e $\mathrm{p}<0,001)$. Obtivemos interação com os fatores duração e grupo $(\mathrm{F}(2,21)=8,7$ e $\mathrm{p}=0,002)$. 


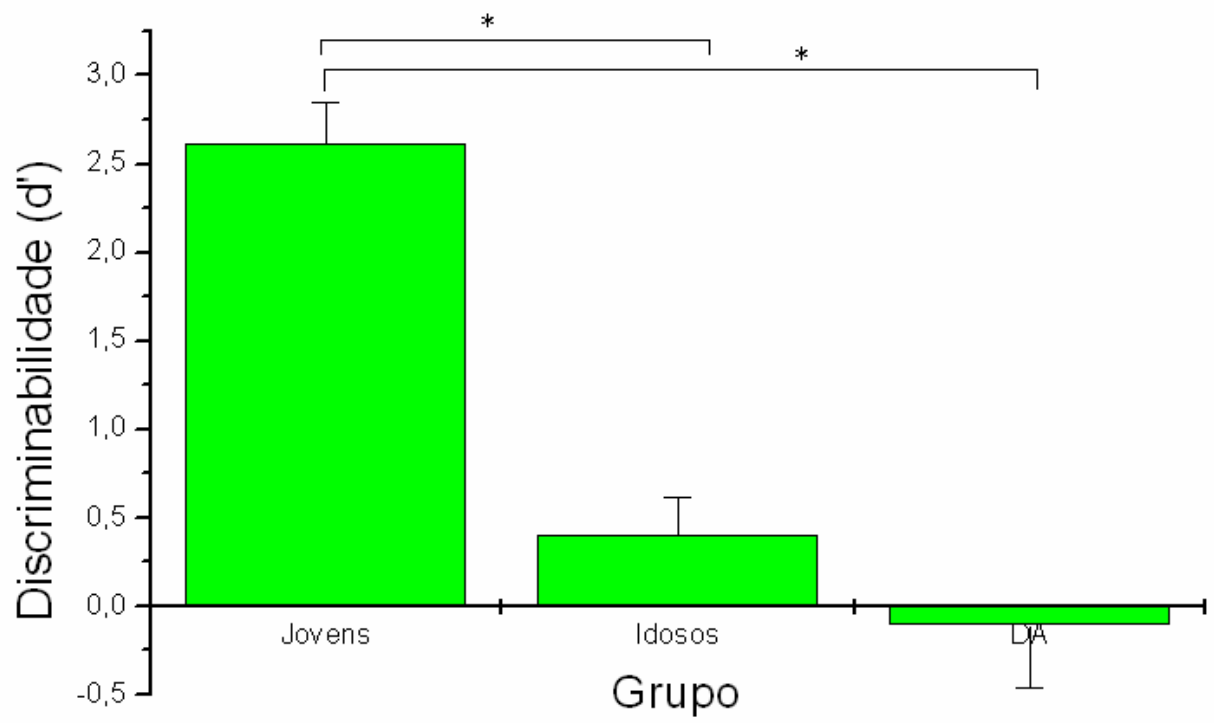

Figura 7.3.3. Diferenças entre os grupos, considerando o d'. As barras de erro se referem ao erro padrão da média.

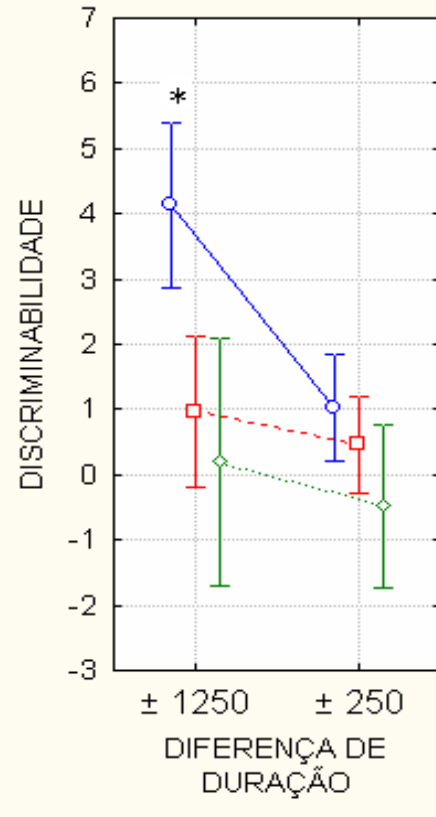

1 ESTÍMULO

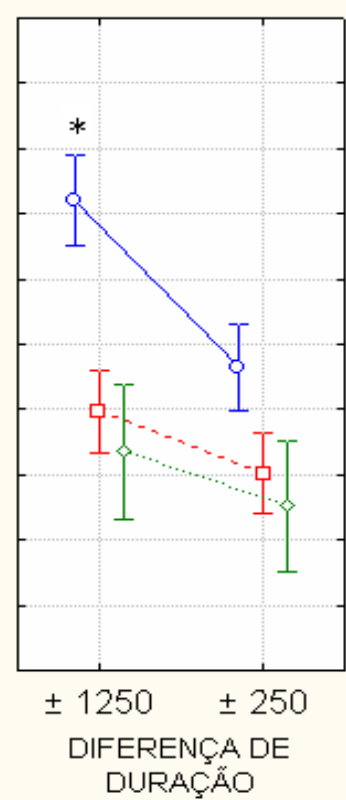

4 PROSPECTIVO

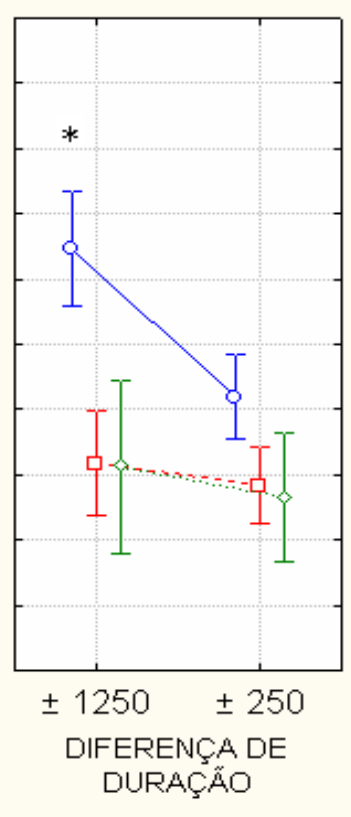

4 RETROSPECTIVO

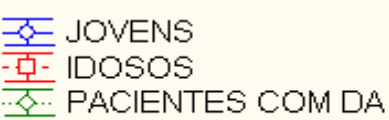

Figura 7.3.4. d' em função de $|\Delta t|$, considerando o tipo de experimento e o grupo experimental. As barras de erro se referem ao intervalo de confiança de $95 \%$.

Realizamos o teste post hoc de Newman-Keuls, que mostrou que o grupo de jovens foi diferente do grupo de idosos $(\mathrm{p}<0,001)$ e do grupo de pacientes com DA ( $\mathrm{p}$ $<0,001)$, como é apresentado na figura 7.3.3. Considerando $|\Delta t|= \pm 1250 \mathrm{~ms}$, grupo de jovens foi diferente do grupo de idosos $(\mathrm{p}<0,001)$ e do grupo de pacientes com DA ( $\mathrm{p}$ $<0,001$ ), vide figura 7.3.4. Já para $|\Delta t|= \pm 250 \mathrm{~ms}$, o grupo de jovens diferiu apenas do grupo de pacientes com DA $(\mathrm{p}=0,038)$. 
Realizamos, também, a análise da porcentagem de acertos (mais precisamente do arcseno da porcentagem de erros, usando a equação 8) com uma ANOVA $3 \times 3 \times 4$ para os fatores: grupo, tipo de experimento e diferença de duração $(\Delta t=-1250 \mathrm{~ms},-250$ $\mathrm{ms},+250 \mathrm{~ms}$ e $+1250 \mathrm{~ms}$. $)$. Encontramos apenas grupo experimental $(\mathrm{F}(2,21)=31,1 \mathrm{e}$ $\mathrm{p}<0,001)$ como efeito principal. Deve-se citar que a homogeneidade foi observada na maioria das variáveis (teste de Levene).

No post hoc, verificamos que, para a duração $\Delta \mathrm{t}=-1250 \mathrm{~ms}$, jovens são diferentes de idosos $(p=0,0013)$ e pacientes com DA $(p=0,0013)$. O mesmo acontece com $\Delta \mathrm{t}=+1250 \mathrm{~ms}$, com $\mathrm{p}=0,039$ (diferença entre jovens e idosos) e $\mathrm{p}<0,001$ (diferença entre jovens e pacientes com DA). Entretanto, não houve diferenças entre os grupos, considerando $\Delta \mathrm{t}=-250 \mathrm{~ms}$ e $\Delta \mathrm{t}=+250 \mathrm{~ms}$.

Realizamos o teste de correlação de Spearman entre d' (discriminando $|\Delta t|$ e tipo de experimento) e os testes cognitivos, entretanto não encontramos correlações estatisticamente significativas.

\subsection{Discussão do experimento 4}

Verificamos que há uma queda substancial da discriminabilidade (d') no grupo de idosos, resultado este que concorda com a literatura (BLOCK; ZAKAY; HANCOCK, 1998). Particularmente, o desempenho é significativamente pior para o módulo da diferença de duração $(|\Delta \mathrm{t}|)$ de $\pm 1250 \mathrm{~ms}$ (Figura 7.3.2.). Os idosos parecem não se beneficiar muito dos estímulos com $|\Delta t|$ maior $( \pm 1250 \mathrm{~ms})$ em relação aos jovens, sugerindo que para encontrar diferença similar entre o desempenho de jovens em $|\Delta t|$ maior e $|\Delta t|$ menor, dever-se-ia aumentar a diferença entre $|\Delta t|$ maior e $|\Delta t|$ menor. Esta diferença acontece em todos os tipos experimentais, o que sugere que seja um fenômeno essencialmente vinculado à capacidade de apreender o lapso de tempo. Poderíamos pensar na curva de porcentagem de acertos pelo $\Delta \mathrm{t}$ como uma curva que teria a forma de um U (vide Figura 5.3.4). Neste caso, para idosos, tal curva U seria mais aberta, o que significa que para obter uma mesma porcentagem de acerto, o $|\Delta t|$ deve ser maior.

Tal achado pode sugerir uma interpretação ao fato de que, com o envelhecimento, o tempo é percebido como passando mais rapidamente. Como há necessidade, em idosos em relação aos jovens, de um $\Delta \mathrm{t}$ maior para ser percebido como diferente, podemos supor que tal julgamento de tempo se estenda para períodos 
temporais maiores. Com isto, para apresentar a mesma percepção de tempo (avaliada pela acurácia na tarefa de discriminação temporal), idosos avaliariam $\Delta \mathrm{t}$ maiores $\mathrm{e}$ consequentemente, o tempo fisicamente medido seria maior, daí a certa surpresa com a "velocidade do tempo" quando comparado o tempo subjetivamente apreendido com o tempo objetivo.

Nossos resultados mostram que há uma piora significativa do desempenho no tipo de experimento, no qual não há conhecimento prévio do alvo (4R), como pode ser observado na figura 7.3.1. Baseado nos resultados e na discussão relativa ao segundo experimento, assume-se que estas diferenças se devam a fatores atencionais. Nesta discussão, assumiu-se que os participantes compararam a duração do estímulo padrão com os outros estímulos, no momento em que estes foram apresentados. Assim, no tipo experimental 4R, os sujeitos teriam julgado se um estímulo tinha duração menor ou maior em relação ao estímulo padrão durante a apresentação dos quatro estímulos. Acreditamos que esta estratégia seria mais econômica em termos de memória: o sujeito só deveria manter memorizada a figura e se esta apresentou duração maior ou menor em relação ao estímulo padrão. Nesta explicação, a atenção teria um papel importante, visto que o indivíduo, usando a metáfora da lente zoom, deveria aumentar o espaço, no qual a atenção estaria espraiada. O custo de tal processo seria uma diminuição da "densidade de recursos atencionais", isto é, admitindo-se que os recursos atencionais sejam limitados, se aumento a região sobre a qual devo "aplicar" minha atenção, menor serão os recursos atencionais aplicados a uma região particular.

Outra explicação alternativa, que não podemos descartar pelo desenho experimental, é de que o indivíduo tivesse mantido em sua memória a duração dos estímulos e, só quando solicitado, realizasse a comparação e tomasse a decisão. Neste caso, fatores atencionais atuariam na percepção da duração, mas haveria interferência na memória. Esta explicação, no entanto, implicaria em uma estratégia que levaria a mais "custos", tanto atencionais como, principalmente, de memória.

$\mathrm{Na}$ comparação entre jovens, idosos e pacientes com DA, observamos uma diminuição progressiva do d', respectivamente. Muito provavelmente, não encontramos diferença estatisticamente significante entre os grupos de idosos e de pacientes com DA, devido ao número pequeno de pacientes com DA, ainda que possamos observar uma tendência de resposta neste sentido, com pode ser observado na figura 7.3.4. 
Verifica-se que os idosos saudáveis e pacientes com DA, em relação aos jovens, tendem a não se beneficiar das apresentações, nas quais a duração do alvo é bem diferente da duração do estímulo padrão $(|\Delta \mathrm{t}|= \pm 1250 \mathrm{~ms})$.

Os idosos tendem a ter um desempenho pior com o aumento da dificuldade da tarefa, o que se associa ao fato de que uma maior demanda atencional leva a uma piora do desempenho. É curioso observar que o desempenho do grupo de idosos tende ao desempenho do grupo de pacientes com DA, no bloco 4R (vide Figura 7.3.4). Tal achado pode ser interpretado no sentido de que idosos, ao serem submetidos a uma grande demanda atencional, tem seu desempenho muito prejudicado, de forma similar ao que ocorre com pacientes com DA leve. Note, entretanto, que pacientes com DA apresentam um desempenho ruim, mesmo em tarefas simples, como o bloco 1C.

Deve-se salientar, no entanto, que a situação experimental pode não ter sido idêntica para o grupo de idosos e de pacientes com DA, ainda que o desenho tenha sido idêntico. O registro eletroencefalográfico certamente exigiu mais atenção dos idosos, uma vez que se preocupavam com relaxamento muscular e o ato de piscar. Já os pacientes com DA, por várias vezes, não se preocupavam com tais questões, mesmo quando orientados, após cada apresentação, a atentar para o grau de relaxamento muscular. Era-lhes muito difícil se ocupar da tarefa psicofísica e das orientações relativas ao registro eletroencefalográfico. Por isso, acreditamos que os idosos tenham dispensado maiores recursos atencionais na realização da tarefa, o que tem maior importância considerando o fato que tarefas de divisão da atenção estejam associadas a um pior desempenho com o envelhecimento (STUART-HAMILTON, 2002).

A deficiência colinérgica está em estreita associação aos déficits atencionais e de memória (PERRY; HODGES, 1999). Particularmente, o prosencéfalo basal tem sido implicado como região de aferências colinérgicas corticais associada à atenção (PARIKH; SARTER, 2008). Ainda que os pacientes com DA que participaram deste estudo estivessem usando inibidores da acetilconisterase, seu desempenho prejudicado está vinculado a uma menor disponibilidade de recursos atencionais ou dificuldade de manter o foco atencional no alvo. Neste sentido, as alterações atencionais podem ser associadas a um estado hipocolinérgico que não é completamente restabelecido pela medicação. Estudos antes e depois do uso de medicações são fundamentais para avaliar o papel da acetilcolina na percepção de tempo e principalmente, em sua modulação atencional. 


\section{DISCUSSÃO GERAL}

No presente trabalho, quatro experimentos foram realizados, sendo que os dois primeiros tiveram a finalidade de caracterizar os fatores que interfeririam na percepção de tempo, dando ênfase à função da atenção. $\mathrm{O}$ terceiro e quarto experimentos tiveram por finalidade comparar jovens, idosos e pacientes com DA, atentando para a diminuição dos recursos atencionais na explicação das diferenças entre os grupos.

Os dados psicofísicos do primeiro e segundo experimentos sugerem que a atenção tenha papel fundamental mais pronunciado na percepção de tempo de durações menores que 2,5 segundos. Tal relação é evidenciada pelo fato de que a superestimação esteve vinculada às tarefas que apresentavam maior demanda atencional. Particularmente, nas tarefas retrospectivas, o número de estímulo esteve relacionado à discriminabilidade, o que mostra que não se trata de um efeito associado à decisão ou à estratégia adotada. O fato da superestimação ter ocorrido nas durações curtas e não ocorrer subestimação proporcional à dificuldade da tarefa se opõe à hipótese de que se trate de um efeito da memória. Outro fato importante é a correlação do desempenho de idosos e pacientes com DA entre um teste cognitivo que mede atenção e a reprodução de tempo.

Neste sentido, é importante retomarmos a discussão a respeito dos fatores que poderiam explicar os resultados experimentais obtidos. Nossas tarefas foram produzidas com a finalidade de que a modulação atencional fosse obtida pela modificação de parâmetros associados à própria tarefa. Os parâmetros, ou melhor, as variáveis dependentes que foram utilizadas com esta finalidade foram: o número de estímulos e o conhecimento do alvo. No primeiro caso, havia modificação do número de distratores apresentados, uma vez que havia apenas um alvo. No segundo caso, o conhecimento do alvo interferiria no fato de ter que prestar atenção apenas no alvo (condição prospectiva) ou em todos os estímulos apresentação (condição retrospectiva). Assim, a atenção poderia ser modulada de duas maneiras. Na primeira, a atenção era supostamente modulada pela dificuldade em inibir a interferência dos distratores na percepção do lapso de tempo do alvo. Isto corresponde à avaliação do número de estímulos na condição prospectiva. Na segunda maneira, a atenção era supostamente modulada pela necessidade de "abrir o foco atencional" (metáfora da lente zoom) em função da quantidade de estímulos apresentados, o que corresponde à avaliação do número de estímulos na condição retrospectiva. 
Com este tipo de abordagem evitamos a modulação da atenção através do uso de tarefas concomitantes, o que corresponde ao arranjo experimental da quase totalidade dos trabalhos que abordam as relações da atenção com a percepção de tempo. Este é um mérito do trabalho, pois com tal abordagem, podemos evitar que a demanda por funções executivas interfiram nos resultados. Isto é de particular relevância para estudos que usem métodos de imagem ou métodos eletroencefalográficos, dado que regiões cerebrais que estejam ativadas, nestes estudos, podem estar vinculadas às funções executivas e não à atenção dispensada ao lapso de tempo. No caso de pacientes com doenças que afetam o cérebro é muito importante usar tarefas que evitem uma demanda excessiva por funções executivas, a fim de poder analisar o papel da atenção na percepção de tempo.

Entretanto, outros fatores poderiam ser responsáveis pelos resultados. Fatores importantes são a estratégia do indivíduo e o viés associado à decisão. A teoria de detecção de sinais tem a grande vantagem de permitir uma separação entre tais fatores e o efeito da atenção. Isto ocorre porque o critério está associado, entre outros fatores, à estratégia do indivíduo e ao seu viés decisional. Já o d' estaria associado, entre outros fatores, à atenção. Deve-se salientar, no entanto, que há, além da atenção, outros fatores associados ao d', tais como fatores puramente sensoriais. A excentricidade, por exemplo, é um fator que pode interferir em nossa capacidade de avaliar um dado estímulo. Quanto maior a excentricidade, mais afastado da mácula a imagem do estímulo se encontra, presumivelmente, pior a avaliação espacial e temporal deste estímulo será. É por tal motivo que nossos experimentos, realizados por jovens, idosos e pacientes com DA, quer seja em tarefas de discriminação ou reprodução de tempo, apresentavam estímulos com características físicas semelhantes. Destarte, era possível cotejar os resultados das tarefas de reprodução e discriminação, guardadas as diferenças relativas à tarefa. Assim, pelo fato do arranjo experimental ser semelhante, foi possível, primeiramente, comparar os resultados e, em segundo lugar, afastar a hipótese de que os resultados obtidos em tarefas de reprodução pudessem ser explicadas por fatores como estratégia ou viés decisional. Note que a análise relativa à teoria de detecção de sinais só era possível em tarefas de discriminação, mas era fundamental sua aplicação em tarefas de reprodução de tempo.

A análise das tarefas de reprodução de tempo, por sua vez, permite uma melhor interpretação das tarefas de discriminação de tempo. Os resultados relativos às tarefas reprodução nos mostram que há durações nos quais há maior acurácia e, 
consequentemente, maior d'. Devemos, ainda, adicionar critérios paramétricos, vinculados às maneiras pelas quais modulamos a atenção, ou seja, um dado efeito é, possivelmente, atencional se aumenta com o número de estímulos ou se é mais pronunciado na condição retrospectiva em relação à condição prospectiva.

Assim, cotejando a análise de tarefas de reprodução e de discriminação, é possível separar o efeito da estratégia individual, do viés decisional e da duração ${ }^{7}$ do efeito supostamente atencional.

Por fim, é necessário separar os efeitos atencionais daqueles vinculados à memória. No segundo experimento, os participantes conheciam previamente a duração do estímulo padrão e era-lhes informado que a duração do estímulo padrão era a mesma em cada bloco. Assim, acreditamos ser muito mais econômico que o participante julgasse o alvo no momento em que era apresentado, mantendo na memória se a duração do alvo era maior ou menor em relação à duração do estímulo padrão. Também seria mais econômico, nos blocos retrospectivos, que julgasse a duração dos estímulos apresentados em relação à duração do estímulo padrão, uma vez que manteria em sua memória apenas a informação relativa ao fato da duração ser maior ou menor. Por econômico, entendemos um processo que necessita de menor demanda quer seja atencional ou de memória. Assim, consideramos mais econômica a alternativa apresentada do que a suposição de que o participante deveria manter em sua memória as durações e só, na fase de resposta, proceder ao julgamento.

Nas tarefas de reprodução, em blocos prospectivos, encontramos superestimação maior para maior número de distratores. Neste caso, a memória não deveria ter papel fundamental na interpretação dos dados, já que os participantes conheciam previamente qual estímulo era o alvo. A melhor interpretação se alinha com a hipótese de que haja efeito dos distratores na avaliação da duração do alvo, efeito este que estaria vinculado à atenção, mais especificamente, à capacidade de inibir estímulos irrelevantes.

Com relação aos resultados experimentais dos blocos retrospectivos do primeiro experimento, é necessário fazer algumas considerações. Primeiramente, os participantes eram, enfaticamente, orientados a não usarem qualquer tipo de contagem. Parte-se do pressuposto que isto tenha sido realizado, até porque, os participantes eram indagados a

\footnotetext{
${ }^{7} \mathrm{O}$ efeito da duração é entendido como característica primária, relativa ao processo neurofisiológico, pelo qual o cérebro apreende o lapso de tempo, ou seja, há durações que são avaliadas com maior acurácia pelo cérebro humano e tal fato é entendido como uma característica que não está causalmente ligada a fatores como atenção. Os modelos que se valem de osciladores internos entendem que tal característica estaria vinculada à freqüência do oscilador.
} 
respeito de sua estratégia ao fim dos experimentos. Outra alternativa seria usar uma tarefa concomitante que interferisse na contagem, tal como o "digit span". Todavia, neste caso teríamos um problema, já mencionado anteriormente, associado ao fato de não podermos separar efeitos oriundos de maior demanda por memória e funções executivas daqueles estritamente atencionais. Por conseguinte, se aceitarmos o pressuposto de que os participantes mantiveram a duração dos estímulos e não a transformaram em números mediante contagem, seria esperado que nossos achados ocorressem em durações mais longas, se a memória pudesse ser usada na interpretação dos resultados. Na verdade, o oposto ocorre, pois, há superestimação em durações curtas, o que enfatiza que, valendo-se do arcabouço teórico do relógio interno, podemos interpretar nossos resultados pela modulação atencional que supostamente ocorreria no interruptor. Isto concorda com a asserção de que, para durações menores que 3 segundos, os efeitos são essencialmente atencionais, nos experimentos que avaliam percepção de tempo (ULBRICH et al., 2008).

Encontramos uma faixa de durações, nas quais o tempo percebido é similar ao tempo físico. Foram obtidos dois PIs, no primeiro experimento, que apresentavam valores encontrados na literatura. Os fatores que influenciaram o PI foram a complexidade da tarefa, a idade e o fato de apresentar DA. Nossos experimentos não puderam diferenciar uma lentificação do oscilador de uma influência da demanda atencional como fator essencial na modificação do PI, entretanto o resultado que associa a complexidade da tarefa com o PI, no primeiro experimento, sugere que haja efeito da demanda atencional na determinação do PI. Para avaliarmos a hipótese de que haveria lentificação do oscilador seria necessário utilizar tarefas como de estimativa verbal e de produção verbal.

Deve-se ressaltar que houve assimetria, no segundo experimento, que é compatível com os PIs encontrados no primeiro experimento. A comparação entre os PIs obtidos no terceiro experimento é prejudicada, pois há apenas quatro $\Delta \mathrm{t}$ e o número de participantes é reduzido, o que torna as incertezas proeminentes e diminui o poder estatístico, não permitindo avaliar efeitos que apresentem menor magnitude.

Há uma dificuldade de perceber o tempo em idosos saudáveis e em pacientes com DA, quando comparados com os jovens. No caso de idosos saudáveis, há um aumento do PI e diminuição do benefício advindo de durações do alvo muito diferentes da duração do estímulo padrão $(|\Delta \mathrm{t}|$ maior). Isto pode ser interpretado como uma alteração na curva psicofísica com deslocamento para a direita (aumento da 
superestimação e do PI) e achatamento da curva " $U$ " característica da tarefa de discriminação de tempo. Na reprodução de tempo, em idosos, também pudemos encontrar um maior superestimação vinculada à demanda atencional. Curiosamente, nas tarefas de discriminação de tempo do tipo 4R, o desempenho de idosos saudáveis foi semelhante aos pacientes com DA, sugerindo que o aumento da demanda atencional tem impacto mais significativo com o envelhecimento. Assim, uma menor quantidade de recursos atencionais ou uma dificuldade de aumentar o foco atencional podem explicar as diferenças encontradas na reprodução e discriminação entre jovens e idosos.

Deve-se notar que foi possível comparar melhor o desempenho de idosos com o desempenho de jovens, pois estes realizaram duas sessões, o que pelas dificuldades de locomoção, entre outras, dos pacientes com DA não foi possível realizar. Como o poder estatístico é maior, porque há um número maior de repetições, procedeu-se a análise entre jovens e idosos separadamente da análise entre jovens, idosos e pacientes com DA.

Esta análise (entre jovens e idosos) produziu um resultado curioso. Nas tarefas de discriminação de tempo, os blocos $1 \mathrm{C}$ e $4 \mathrm{R}$ não foram estatisticamente significantes. Já, nas tarefas de reprodução de tempo, os blocos 4P e 4R não foram estatisticamente significantes. A despeito de isto poder se dever a um problema vinculado à incerteza e, portanto, a fatores como o número de participante, podemos afirmar que a diferença entre tais blocos é, ao menos, de menor magnitude. Isto sugere que, nas tarefas de discriminação, como o julgamento é supostamente feito no momento em que os estímulos são apresentados, o fato de conhecer o alvo a priori, implica que há pouca interferência dos distratores. Já nas tarefas reprodutivas, como discutido na seção 4.3, a fase crítica para a avaliação do tempo seria na fase de reprodução, assim haveria a necessidade de manter as durações até a reprodução da duração do alvo. Neste caso, haveria a influência dos distratores, no bloco 4P. Devemos lembrar que as interpretações acima aventadas foram formuladas para os experimentos 1 e 2, mas explicam bem os resultados dos experimentos 3 e 4 .

Uma questão importante se refere ao fato de não termos comparado o grupo de idosos e pacientes com DA com os resultados do grupo de jovens do primeiro e segundo experimentos. Há duas razões para isto. A primeira razão se refere ao fato de que o primeiro e segundo experimentos, apesar serem idênticos quantos aos aspectos físicos (equipamentos, características dos estímulos, etc), apresentavam algumas diferenças: maior número de durações possíveis nas tarefas de reprodução, presença de blocos $2 \mathrm{P}$ e 
2R e duas durações padrão nas tarefas de discriminação. A segunda e principal razão é o fato de que o registro eletroencefalográfico concomitante e a necessidade de controlar o piscamento e contração muscular levaram a uma maior dificuldade na tarefa. Tanto é que o desempenho de jovens, comparando primeiro e terceiro experimentos e segundo e quarto experimentos, tende a ser pior nos experimentos com registro eletroencefalográfico concomitante. Isto ocorreu a despeito dos participantes terem sido informados que o mais importante era o desempenho psicofísico.

Pacientes com DA, além de apresentarem um aumento ainda mais pronunciado do PI, mostram uma grande superestimação de durações curtas e um desempenho próximo do encontrado para jovens e idosos, sugerindo que haja dificuldades para se concentrar em estímulos curtos. Além disto, o desempenho deste grupo foi muito parecido nos três blocos experimentais, particularmente nas tarefas de discriminação. Uma boa interpretação seria de que a dificuldade de atentar para o estímulo era tão grande para a apresentação de estímulo único, que o limite dos recursos atencionais já havia sido atingido. Por conseguinte, a necessidade de uma maior demanda atencional não era possível, em virtude do limite dos pacientes ter sido atingido, assim o desempenho era semelhante ou, alternativamente, as diferenças entre o desempenho nas condições experimentais eram muito pequenas. Deve-se salientar que o número reduzido de participantes pode interferir na significância estatística, particularmente, de diferenças de desempenho de menor magnitude.

Da mesma forma como descrito para o envelhecimento, pacientes com DA apresentam um pior desempenho que é interpretado como um déficit atencional mais intenso que aquele que ocorre em idosos, uma vez que apresentam diferença significativa em relação ao grupo de idosos, nos testes cognitivos que medem atenção, como pode ser observado nas figuras 6.3.4 e 6.3.5.

Uma questão importante é se os pacientes com DA entenderam a tarefa, uma vez que nossa interpretação dos resultados depende do pressuposto que sabiam o que estavam realizando. $\mathrm{O}$ primeiro argumento se refere ao fato de que os pacientes eram submetidos a algumas fases de treinamento até terem aprendido o que deveriam fazer, somente após tais fases, a coleta formal de dados era realizada. Eram constantemente lembrados sobre o que significavam as teclas que apertavam e temos evidências de que os conceitos socialmente aprendidos em relação ao tempo não estão alterados nas fases leves da doença de Alzheimer (LEVY; DREIER, 1997). O segundo argumento se refere aos resultados encontrados. Nas tarefas de reprodução, a forma de exponencial dos 
dados foi mantida para pacientes com DA, mostrando que as reproduções não eram realizadas ao acaso (vide Figura 6.3.2). Também nas tarefas de discriminação de tempo, verificamos certa assimetria entre $|\Delta \mathrm{t}|$ maiores e menores (vide Figura 7.3.2), o que sugere que nossos resultados relativos ao desempenho de pacientes com DA se refiram a uma dificuldade real de avaliar o tempo.

Como foi descrito em nossos métodos, o terceiro e quarto experimentos foram realizados com registro eletroencefalográfico concomitante. Algumas análises foram empreendidas e obtivemos alguns resultados significativos, tais como a diminuição da amplitude de certas faixas de freqüência que se correlacionava com a dificuldade da tarefa, o que poderia ser entendido como correlato eletrofisiológico de uma maior demanda atencional. Entretanto, estes resultados não foram incluídos no presente trabalho, porque havia a necessidade de uma avaliação mais aprofundada dos dados psicofísicos, uma vez que, para que qualquer correlação pudesse ser feita entre resultados comportamentais e modificações do registro eletroencefalográfico, era fundamental que houvesse um protocolo experimental bem estabelecido, que permitisse separar os efeitos das diversas funções cognitivas envolvidas. A segunda razão se refere à necessidade de utilizar outros métodos mais sofisticados de análise tais com a dessincronização/sincronização relacionada a eventos (PFURTSCHELLER; SILVA, 1999) e a coerência parcial direcional (SAMESHIMA; BACCALÁ, 1999) que necessitariam de tempo para produzir análises robustas. Outra razão é fato de seria importante que mais registros eletroencefalográficos fossem obtidos, sendo, portanto, que nossa análise poderia ser, neste momento, prejudicada por este problema. Assim sendo, preferimos empreender a análise e discussão dos dados eletroencefalográficos posteriormente. 


\section{CONCLUSÕES}

- Considerando nossos resultados, a atenção tem papel crítico na percepção de tempo. As diferenças de desempenho, quando variamos o número de estímulos apresentados e o conhecimento do alvo, são interpretadas como relativas à demanda atencional, isto é, quanto mais complexa é apresentação, maior é a demanda atencional.

- Parece-nos que memória, estratégia e aspectos decisionais associados, ainda que certamente presentes na realização das tarefas experimentais, não são suficientes para explicar as diferenças de desempenho encontradas no primeiro e segundo experimentos e que a melhor explicação se refere à modulação atencional.

- Verificamos a lei de Vierordt nos três grupos experimentais e em todas as condições experimentais empregadas nas tarefas de reprodução de tempo, ou seja, há uma tendência em superestimar durações curtas e subestimar durações longas. A modulação da atenção é crítica na avaliação de durações curtas, considerando nossos resultados.

- Os PIs se referem às durações que são reproduzidas de forma mais acurada. Os valores dos PIs são menores em jovens, intermediários em idosos e maiores em pacientes com DA, o que parece se associar de que o valor é maior quanto maiores as deficiências atencionais. Há ainda um aumento do valor do PI em blocos mais complexos. Tais resultados sugerem que fatores atencionais tenham papel na determinação dos PI, mas a hipótese de que haja uma lentificação do marca-passo não pôde ser avaliada com as tarefas experimentais empregadas.

- Pacientes com DA leve apresentaram diferenças em relação aos idosos saudáveis em teste cognitivos que avaliam atenção e memória episódica e o desempenho nas tarefas de reprodução se correlacionou com o desempenho em um teste cognitivo que mede atenção.

- Idosos apresentam desempenho pior em relação aos jovens, com dificuldade de inibir os efeitos do distratores, que é interpretado com um déficit atencional. Parece haver ainda dificuldade de atentar para uma região mais ampla, isto é, abrir o foco atencional (tomando a metáfora da lente zoom).

- Pacientes com DA leve apresentam um desempenho ruim que não apresenta muitas diferenças com o aumento da complexidade da tarefa. Isto se deve ao fato de que seus recursos atencionais estão tão diminuídos, que há dificuldade de atentar na apresentação de um único estímulo. 


\section{REFERÊNCIAS BIBLIOGRAFICAS*}

ADAMS, R. D.; VICTOR, M.; ROPPER, A. H. Principles of Neurology. 6 ed. New York: McGraw-Hill, 1997.

AgOSTINHO, SANTO. As Confissões. Coleção: Os Pensadores. Tradução J. O. SANTOS; A. A. PINA. São Paulo: Nova Cultural, 1996.

ALLAN, L. G.; GIBBON, J. Human bisection at the geometric mean. Learning and Motivation, v. 22, p. 39-58, 1991.

AMERICAN PSYCHIATRIC ASSOCIANTION. Diagnostic and Statistical Manual of Mental Disorders. 4th ed. Washington, DC: American Psychiatric Association, 1994.

ANDERSON, N. D.; IIDAKA, T.; KAPUR, S.; McKINTOSH, A. R.; CRAIK, F. I. M. The effects of divided attention on encoding- and retrieval-related brain activity: a PET study of younger and older adults. Journal of Cognitive Neuroscience, v. 12, n. 5, p. 775-792, 2000.

ANDRÉS, P.; PARMENTIER, F. B. R.; ESCERA, C. The effect of age on involuntary capture of attention by irrelevant sounds: A test of the frontal hypothesis of aging. Neuropsychologia, v. 44, p. 2564-2568, 2006.

ANGINAH, R.; KANDA, P. A. M.; JORGE, M. S.; MELO, A. C. P. Eletroencefalograma quantitativo e topográfico (mapeamento cerebral): estudo padrão normal para uma população adulta. Arquivos de Neuro-Psiquiatria, v. 56, n. 1, p. 5963, 1998.

AWH, E.; JONIDES, J. Overlapping mechanisms of attention and spatial working memory. Trends in Cognitive Science, v. 5, n. 3, p. 119-126, 2001.

BABILONI, C.; BINETTI, G.; CASSARINO, A.; DAL FORNO, G.; DEL PERCIO, C; FERRERI, F.; FRISONI, G.; GALDERISI, S.; HIRATA, K.; LANUZZA, B.; MINIUSSI, C.; MUCCI, A.; NOBILI, F.; RODRIGUEZ, G.; ROMANI, G.; ROSSINI, P. M. Sources of cortical rhythms in adults during physiological aging: a multicentric EEG study. Human Brain Mapping, v. 27, n. 2, p.162-172, 2007.

BALDO, M. V. C.; NAMBA, J. The attentional modulation of the flash-lag effect. Brazilian Journal of Medical and Biological Research, v. 35, p. 969-972, 2002.

BERTOLUCCI, P. H. F.; BRUCKI, S. M. D.; CAMPACCI, S.; JULIANO, Y. Mini Exame do Estado Mental e Escolaridade. Arquivos de Neuropsiquiatria, v. 52, n. 1, p. 1-7, 1994.

\footnotetext{
* De acordo com:

ASSOCIAÇÃO BRASILEIRA DE NORMAS TÉCNICAS. NBR 6023: Informação e documentação: referências: elaboração. Rio de Janeiro, 2002.
} 
BINETTI, G.; CAPPA, S. E.; MAGNI, E.; PADOVANI, A. Visual and spacial perception in the early phase of Alzheimer's Disease. Neuropsychology, v.12, n. 1, p. 29-33, 1998.

BLOCK, R. A.; ZAKAY, D.; HANCOCK, P. A. Human Aging and Duration Judgments: A Meta-Analytic Review. Psychology and Aging, v. 13, n. 4, p. 584-596, 1998.

BLOCK, R. A.; ZAKAY, D.; HANCOCK, P. A. Developmental changes in human duration judgments: a meta analytic review. Developmental Review, v. 19, p. 183-211, 1999.

BOTTINO, C. M. C.; LAKS, J.; BLAY, S. L. Demência e transtornos cognitivos em idosos. Rio de Janeiro: Ed. Guanabara Koogan, 2006.

BRAAK, H.; BRAAK, E. Neuropathological stageing of Alzheimer-related changes. Acta Neuropathologica, v. 82. p. 239-59, 1991.

BRAVER, T.; BARCH, D. M. A theory of cognitive control, aging cognition, and neuromodulation. Neuroscience and Behavioral Reviews, v. 26, p. 809-817, 2002.

BROWN, S. W.; WEST, A. N. Multiple timing and the allocation of attention. Acta Psychologica, v. 75, p. 103-121, 1990.

BROWN, S. W.; NEWCOMB, D. C.; KAHRL, K. G. Temporal-signal detection and individual differences in timing. Perception, v. 24, p. 525-538, 1995.

BROWN, S. W. The attenuation effect in timing: counteracting dual-task interference with time-judgment skill training. Perception, v. 37, p. 712-724, 2008.

BRUCKI, S. M. D.; MALHEIROS, S. M. F.; OKAMOTO, I. H.; BERTOLUCCI, P. H. F. Dados normativos para o teste de fluência verbal, categoria animais em nosso meio. Arquivos de Neuropsiquiatria, v. 55, n. 1, p. 56-61, 1997.

BUHUSI, C. V.; MECK, W. H. What makes us tick? Functional and neural mechanisms of interval timing. Nature Review Neuroscience, v. 6, p. 755-765, 2005.

CABEZA, R. Cognitive neuroscience of aging: contributions of functional neuroimaging. Scandinavian Journal of Psychology, v. 42, p. 277-286, 2001.

CAFFARRA, P.; VEZZADINI, G.; DIECI, F.; ZONATO, F.; VENNERI, A.; ReyOsterrieth complex figure: normative values in an Italian population sample. Neurological Sciences, v. 22, n. 6, p. 443-447, 2002.

CARRASCO, M.; GUILLEM, M. J.; REDOLAT, R. Estimation of short temporal intervals in Alzheimer's disease. Experimental Aging Research, v. 26, p.139-151, 2000 . 
CASINI, L.; MACAR, F. Prefrontal slow potentials in temporal compared to nontemporal tasks. Journal of Psychophysiology, v. 10, p. 225-264, 1996.

CASINI, L.; MACAR, F. Multiple approaches to investigate the existence of an internal clock using attentional resources. Behavioural Processes, v. 45, p. 73-85, 1999.

CASTEL, A. D.; CRAIK, F. I. M. The Effects of Aging and Divided Attention on Memory for Item and Associative Information. Psychology and Aging, v. 18, n. 4, p. $873-885,2003$.

CARRASCO, M. C.; BERNAL, M. C.; REDOLAT, R. Time estimation and aging: a comparison between young and elderly adults. International Journal of Aging and Human Development, v. 22, n. 2, p. 91-101, 2001.

CARREIRO, L. R. R.; HADDAD JR., H.; BALDO, M. V. C. The modulation of simple reaction time by the spatial probability of a visual stimulus. Brazilian Journal of Medical and Biological Research, v. 36, p. 907-911, 2003.

CHASTON, A.; KINGSTONE, A. Time estimation: the effect of cortically mediated attention. Brain and Cognition, v. 55, p. 286-289, 2004.

CHURCH, R. M. Properties of the internal clock. In: GIBBON, J.; ALLAN, L. B. Timing and time perception. Annals of the New York Academy of Sciences, v. 423, p. 52-77, 1984.

COELHO, M.; FERREIRA, J. J.; DIAS, B. SAMPAIO, C.; MARTINS, P. I.; CASTRO-CALDAS, A. Assessment of time perception: The effect of aging. Journal of the International Neuropsychology Society, v. 10, p. 332-341, 2004.

COULL, J. T.; VIDAL, F.; NAZARIAN, B.; MACAR, F. Functional Anatomy of the Attentional Modulation of time estimation. Science, v. 303, p. 1506-1508, 2004.

CRONIN-GOLOMB, A.; CORKIN, S.; RIZZO, J. F.; COHEN, J.; GROWDON, J.H.; BANKS, K.S. Visual dysfunction in Alzheimer's disease: relation to normal aging. Annals of Neurology, v. 29, p. 41-52, 1991.

DANCKETT, J.; MARUFF, P.; CROWE, S.; CURRIE, J. Inhibitory processes in covert orienting in patients with Alzheimer's disease. Neuropsychology, v. 12, n. 2, p. 225$241,1998$.

DEBRU, C. Time, from psychology to neurophysiology. A historical view. Compets Rendus Biologies, v. 329, p. 330-339, 2006.

DENNIS, A. D.; DASELAAR, S.; CABEZA, R. Effects of aging on transient and sustained successful memory encoding activity. Neurobiology of Aging, v. 28. p. 1749-1758, 2007.

EISLER, A.D.; EISLER, H. subjective time scaling: influence of age, gender and Type: A and Type B behavior. Chronobiologia, v. 21, p. 185-200, 1994. 
ESPINOSA-FERNÁNDES, L.; MIRÓ, E.; CANO, M.; BUELA-CASAL, G. Agerelated changes and gender differences in time estimation. Acta Psychologica, v. 112, p. 221-232, 2003.

FERRANDEZ, A. M.; HUGUEVILLE, L.; LEHÉRICY， S.; POLINE， J. B.; MARSAULT, C.; POUTHAS, V. Basal ganglia and supplementary motor area subtend duration perception: an fMRI study. Neuroimage, v. 19, p. 1532-1544, 2003.

FERNANDES, M. A.; PACURAR, A.; MOSCOVITCH, M.; GRABY, C. Neural correlates of auditory recognition under full and divided attention in younger and old adults. Neuropsychologia, v. 44, p. 2452-2464, 2006.

FOLSTEIN, M.F.; FOLSTEIN, S.E.; MC HUGH, P.R. "Mini-mental state". A practical method for grading the cognitive state of patients for the clinician. Journal of Psychiatry Research, v. 12, p. 189-198, 1975.

FOOS, P. W.; WRIGHT, L. Adult age differences in the storage of information in working memory. Experimental Aging Research, v.18, p.51-57, 1992.

FORTIN, C.; ROUSSEAU, R. Interference from shor-term memory processing on encoding and reproducing brief durations. Psychological Research, v. 61, p. 269-276, 1998.

FORTIN, C.; MASSÉ, N. Expecting a break in time estimation: attentional time-sharing without concurrent processing. Journal of Experimental Psychology: Human Perception and Performace, v. 26, n. 6, 2000.

FORTIN, C.; COUTURE, E. Short-term memory and time estimation: Beyond the 2second, critical value. Canadian Journal of Experimental Psychology, v. 56, n. 2, p.120-127, 2002.

FOSTER, J. K.; BEHRMANN, M.; STUSS, D. T. Visual attention deficits in Alzheimer's disease: simple versus conjoined feature search. Neuropsychology, v. 13, n. 2, p. 223-245, 1999.

FRAISSE, P. Perception and estimation of time. Annual Review of Psychology, v. 35, p. 1-36, 1984.

FULD, P. A.; MANSUR, D. M.; BLAU, A. D. Object-Memory Evaluation for prospective detection of dementia in normal functioning elderly: predictive and normative data. Journal of Clinical and Experimental Neuropsychology, v. 12, p. 520-528, 1990.

GAZZANIGA, M. S.; IVRY, R. B.; MANGUN, G. R. Cognitive Neuroscience: the Biology of the Mind. 2nd ed. New York: W. W. Norton \& Company, 2002.

GESHEIDER, B. A. Psychophysics: The Fundamentals. 3rd ed. London: Lawrence Erlbaum, 1997. 
GIBBON, J.; CHURCH, R. M.; MECK, W. H. Scalar timing in memory. In: GIBBON, J.; ALLAN, L. B. Timing and time perception. Annals of the New York Academy of Sciences, v. 423, p.52-77, 1984.

GIBBON, J.; MALAPANI, C.; DALE, C. L.; GALLESTEL, C. R. Toward a neurobiology of temporal cognition: advances and challenges. Current Opinion in Neurobiology, v. 7, p. 170-184, 1997.

GOLDSTONE, S.; BOARDMAN, W. K.; LHAMO, W. T. Kinesthetic cues in the development of time concepts. Journal of Genetic Psychology, v. 93, p.191-198, 1958.

GRADY, C. L. Cognitive neuroscience of aging. Annals of the New York Academy of Sciences, v. 1124, p.127-144, 2008.

GREEN, D.M.; SWETS, J. A. Signal detection theory and psychophysics. New York: John Wiley and Sons, 1966.

GREENWOOD, P. M.; PARASURAMAN, R.; ALEXANDER, G. E. Controlling the focus of spatial attention during visual search effects of advanced aging and Alzheimer's disease. Neuropsychology, v. 11, n. 1, p. 3-12, 1997.

GRONDIN, S. From physical time to the first and second moments of psychological time. Psychological Bulletin, v. 127, n. 1, p. 22-44, 2001.

GRONDIN, S.; GIRARD, C. About hemispheric differences in the processing of temporal intervals. Brain and Cognition, v. 58, p. 125-132, 2005.

HANDY, T. C.; GAZZANIGA, M. S.; IVRY, R. B. Cortical and subcortical contributions to the representation of temporal information. Neuropsychologia, v. 41, p. 1461-1473, 2003.

HARRINGTON, D. L.; HAALAND, K. Y.; KNIGHT, R. T. Cortical networks underlying mechanisms of time perception. The Journal of Neuroscience, v. 18, n. 3, p. 1085-1095, 1998.

HARRINGTON, D. L.; HAALAND, K.Y.; NEAL, H. Temporal processing in the basal ganglia. Neuropsychology, v. 12, n. 1, p. 3-12, 1998.

HARRINGTON, D. L.; LEE, R. R; BOYD, L. A.; RAPCSAK S. Z.; KNIGHT, R. T. Does the representation of time depend on the cerebellum? Effect of cerebellar stroke. Brain, v. 127, p. 561-74, 2004.

HAZELTINE, E.; HELMUTH, L. L.; IVRY, R. B. Neural mechanisms of timing. Trends in Cognitive Sciences, v. 1, n. 5, 1997.

HERRERA, JR. E.; CARAMELLI, P.; SILVEIRA, A. S.; NITRINI, R. Epidemiologic survey of dementia in a community-dwelling Brazilian population. Alzheimer Disease and Associated Disorders, v. 16, n. 2, p. 103-108, 2002. 
HOF, P. R.; MOBBS, C. V. Functional neurobiology of aging. London: Ed. Academic Press, 2001.

HOtotian, S. R.; BOtTiNO, C. M. C.; AZEVEDO, D. C. Critério e Instrumentos para o diagnóstico da síndrome demencial. In: BOTTINO, C. M. C.; LAKS, J.; BLAY, S. L. Demência e Transtornos Cognitivos em Idosos. Rio de Janeiro: Ed. Guanabara Koogan, 2006. p. 78-85.

HUGHES. J. R. EEG in clinical practice. 2nd ed. Washington: Ed. ButterworthHeinemann, 1994.

HUSSERL, E. Lições para uma Fenomenologia da Consciência Interna do Tempo. Lisboa: Imprensa Nacional - Casa da Moeda, 1994.

IVRY, R. B. The representation of temporal information in perception and motor control. Current Opinion in Neurobiology, v. 6, p. 851-857, 1996.

IVRY, R. B.; RICHARDSON, T. C. Temporal control and coordination: the multiple timer model. Brain and Cognition, v. 48, p. 117-132, 2002.

IVRY, R. B.; SPENCER, R. M. C. The neural representation of time. Current Opinion in Neurobiology, v. 14, p. 225-232, 2004.

JAMES, W. The principles of psychology, 1980. In: ADLER, M. J. Great Books of the Western World. Chicago: Encyclopaedia Britannica, 1952. v. 53.

JAMUS, D. R.; MÄDER, M. J. A figura complexa de Rey e seu papel na avaliação neuropsicológica. Journal of Epilepsy and Clinical Neurophysiology, v. 11, n. 4, p. 193-198, 2005.

JONES, C. R. G.; ROSENKRANZ, K.; ROTHWELL, J. C.; JAHANSHAHI, M. The right dorsolateral prefrontal cortex is essential in time reproduction: an investigation with repetitive trascranial magnetic stimulation. Experimental Brain Research, v. 158, p. 366-372, 2004.

JOUBERT, C. E. Subjective acceleration of time: Death anxiety and sex differences. Perceptual and Motor Skills, v. 57, p. 49-50, 1983.

KANDEL, E. R.; SCHWARTZ, J. H.; JESSEL, T. M. Principles of Neural Science. 4th ed. New York: McGraw-Hill, 2000.

KANEKO, R.; KUBA, Y.; SAKATA, Y.; KUCHINOMACHI, Y. Aging and Shifts of Visual Attention in Saccadic Eye Movements. Experimental Aging Research, v. 30, p.149-162, 2004.

KARRASCH, M.; LAINE, M.; RAPINOJA, P.; KRAUSE, C. M. Effects of normal aging on event-related desynchronization/synchronization during a memory task in humans. Neuroscience Letters, v. 366, n. 1, p. 18-23, 2004. 
KASAI, M.; MEGURO, K.; HASHIMOTO, R.; ISHIZAKI, J.; YAMADORE, A.; MORI, E. Non-verbal learning is impaired in very mild Alzheimer's disease (CDR 0,5): Normative data from the learning version of the Rey-Osterrieth Complex Figure Test. Psychiatry and Clinical Neurosciences, v. 60, n. 2, p. 136- 146, 2006.

KAZ, A.; BUSHE, J. Typologies of attentional networks. Nature Review Neuroscience, v. 7, p. 367-379, 2006.

KEEFOVER, R. W. Aging and cognition. Neurologic Clinics, v. 16, n. 3, p. 635-648, 1998.

KISLEY, M. A.; DAVALOS, D. B.; ENBLEMAN, L. L.; GUINTHER, P. M; DAVIS, H. P. Age-related change in neural processing of time-dependent stimulus features. Cognitive Brain Research, v. 25, p. 913-925, 2005.

KNUDSEN, E. I. Fundamental components of attention. Annual Review of Neuroscience, v. 30, p. 57-78, 2007.

KOYAMA, K.; HIRASAWA, H.; OKUBO, Y.; KARASAWA, A. Quantitative EEG correlates of normal aging in the elderly. Clinical Electroencephalography, v. 28, n. 3, p. 160-165, 1997.

LANDOLT, H. P.; BORBÉLY, A. Age-dependent changes in sleep EEG topography. Clinical Neurophysiology, v. 112, n. 2, p. 369-377, 2001.

LEJEUNE, H. Switching or gating? The attentional challenge in cognitive modes of psychological time. Behavioral Processes, v. 44, p. 127-145, 1998.

LEJEUNE, H.; WEARDEN, J. H.; Scalar properties in animal timing: conformity and violations. The Quarterly Journal of Experimental Psychology, v. 59, n. 11, p.18751908, 2006.

LESSER, P. L. Guideline for recording clinical EEG on digital media. Journal of Clinical Neurophysiology, v.11, p.114-115, 1994.

LEVY, B.; DREIER, T. Preservation of temporal skills in Alzheimer's disease. Perceptual and Motor Skills, v. 85, p. 83-96, 1997.

LEWIS, P. A. Finding the timer. Trends in Cognitive Sciences, v. 6, n. 5, p. 195-196, 2002.

LEWIS, P. A.; MIALL, R. C. Distinct systems for automatic and cognitively controlled time measurement evidence from neuroimaging. Current Opinion in Neurobiology, v. 13 , p. 250-255, 2003a.

LEWIS, P. A.; MIALL, R. C. Brain activation patterns during measurement of sub- and supra-second intervals. Neuropsychologia, v. 41, p. 1583-1592, 2003b.

LEZAK, M. D. Neuropsychological Assessment. New York: Oxford University Press, 1995. 
LIVESEY, A. C.; WALL, M. B.; SMITH, A. T. Time perception: manipulation of task difficulty dissociates clock functions from other cognitive demands. Neuropsychologia, v. 45. p. 321-331, 2007.

LUCCAS, F. J. C.; BRAGA, N. I. O.; FONSECA, L. C.; FROCHTENGARTEN, M. L. Recomendações para o registro e interpretação do mapeamento topográfico do eletrencefalograma (EEG) e potenciais evocados sensoriais (PES): Parte I: aspectos gerais. Brazilian Journal of Epilepsy and Clinical Neurophysiology, v. 2, p.175-182, 1996.

LUCZYWEK, E.; GABRYELEWICZ, T.; BARCZAK, A.; RELIGAS, D.; PFEFFER.; STYCZYNSKA, M.; PEPLONSKA, B.; CHODAKOWSKA, M.; EBROWSKA, Z.; BARCIKOWSKA, M. Neurocognition of centenarians: neuropsychological study of elite centenarians. International Journal of Geriatric Psychiatry, v. 22, p. 1004-1008, 2007

MACAR, F. Temporal judgments on intervals containing stimuli of varying quantity , complexity and periodicity. Acta Psychologica, v. 92, p. 297-308, 1996.

MACAR, F. Expectancy, controlled attention and automatic attention in prospective temporal judgments. Acta Psychologica, v. 111, p. 243-262, 2002.

MACAR, F.; LEJEUNE, H.; BONNET, M.; FERRARA, A.; POUTHAS, V.; VIDAL, F.; MAQUET, P. Activation of the supplementary motor area and of attentional networks during temporal processing. Experimental Brain Research, v. 142, p. 475485, 2002.

MACMILlAN, N. A.; CREELMAN, C. D. Detection Theory: a user's guide. 2nd ed. London: Lawrence Erlbaum, 2004.

MADDEN, D. J. Aging and Visual Attention. Current Directions in Psychological Science, v. 16, n. 2, p. 70-74, 2007.

MADDEN, D. J.; SPANIOL, J.; WHYTE, W. L.; BUCUR, B.; PROVENZALE, J. M.; CABEZA, R.; WHITE, L. E.; HUETTEL, S. A. Adult age differences in the functional neuroanatomy of visual attention: A combined fMRI and DTI study. Neurobiology of Aging, v. 28, n. 3, p. 459-476, 2006.

MADDEN, D. J.; TURKINGTON, T. G.; PROVENZALE, J.M.; HAWK, T. C.; HOFFMAN, J. M.; COLEMAN, E. R. Selective and divided visual attention: agerelated changes in regional cerebral blood flow measured by $\mathrm{H}_{2}{ }^{15} \mathrm{O}$ PET. Human Brain Mapping, v. 5, p. 389-409, 1997.

MANGELS, J. A.; IVRY, R. B.; SHIMIZU, N. Dissociable contributions of the prefrontal and neocerebellar cortex to time perception. Cognitive Brain Research, v. 7, p. 15-39, 1998.

MARUFF, P.; CURRIER, J. An attentional grasp reflex in patients with Alzheimer's disease. Neuropsychologia, v. 33, p. 689-701, 1995. 
MARUFF, P.; MALONE, V.; CURRIER, J. Asymmetries in the covert orienting of visual spatial attention to spatial and non-spatial cues in Alzheimer's disease. Brain, v. 118, p. 1421-1435, 1995.

MATTES, S.; ULRICH, R. Directed attention prolongs the perceived duration of a brief stimulus. Perception \& Psychophysics, v. 60, n. 8, p. 1305-1317, 1998.

MATTHEW, S. M.; MECK, W. H. Neuropsychological mechanisms of interval timing behavior. BioEssays, v. 22, p. 94-103, 2000.

MAUK, M. D.; BUONOMANO, D. V. The neural basis of temporal processing. Annual Review of Neuroscience, v. 27, p. 307-340, 2004.

MCKHANN, G.; DRACHMAN, D.; FOLSTEIN, M.; KARZMAN, R.; PRINCE, D.; STADLAN, E. M. Clinical diagnosis of Alzheimer's disease: report of the NINCDSADRDA work group under the auspices of Department of Health and Human Services Task Force of Alzheimer's disease. Neurology, v. 34, p. 1096-1105, 1984.

MCCORMACK, T.; BROWN, G. D. A.; MAYLOR, E. A. Effects of Aging on Absolute Identification of Duration. Psychology and Aging, v. 17, n. 3, p. 363-378, 2002.

MECK, W. H. Attentional bias between modalities: effect on the internal clock, memory and decision stages used in animal time discrimination. In: GIBBON, J.; ALLAN, L. B. Timing and time perception. Annals of the New York Academy of Sciences, v. 423, p. 528-541, 1984.

MECK, W. H. Affinity for the dopamine D2 receptor predicts neuroleptic potency in decreasing the speed of an internal clock. Pharmacology. Biochemistry and Behavior, v. 25, p. 1185-1189, 1986.

MECK, W.; ANGELL, K. E. Repeated administration of pyrithiamine leads to a proportional increase in the remembered duration of events. Psychobiology, v. 20, p. 39-46, 1992.

MECK, W. Neuropharmacology of timing and time perception. Cognitive Brain Research, v. 3, p. 227-242, 1996.

MECK, W. H.; BENSON, A. M. Dissecting the brain's internal clock: how frontalstriatal circuitry keeps time and shifts attention. Brain and Cognition, v. 48, p. 195$211,2002$.

MENDOLA, J.D.; CRONIN-GOLOMB, A.; CORKIN, S.; GROWDON, J.H. Prevalence of visual deficits in Alzheimer's disease. Optometry Visual Science, v. 72, p. 155-167, 1995.

MESULAM, M. Principles of Behavioral and Cognitive Neurology. 2nd ed. Oxford: Oxford Univesity Press, 2000. 
MILHAM, M. P.; ERICKSON, K.I.; BANICH, M. T.; KRAMER, A. F.; WEBB, A.; WSZLEK, T.; COHEN, N. J. Attentional Control in the aging brain: insights from an fMRI study of the stroop task. Brain and Cognition, v. 49, p. 277-296, 2002.

MOTA, A. M. Orientação da atenção visual na doença de Parkinson e no envelhecimento. 2006. 93 f. Dissertação (Mestrado em Fisiologia Humana) - Instituto de Ciências Biomédicas, Universidade de São Paulo, São Paulo, 2006.

NICHELLI, P.; VENNERI, A.; MOLINARI, M.; TAVANI, F.; GRAFMAN, J. Precision and accuracy of subjective time estimation in different memory disorders. Cognitive Brain Research, v. 1, p. 87-93, 1993.

NOBILI, L.; SANNITA, W. G. Cholinergic modulation, visual function and Alzheimer's dementia. Vision Research, v. 37, n. 24, 1997.

OKAMOTO, I.H.; BUSTAMANTE, S.E.Z. Teste de rastreio para o diagnóstico de demência. In: BOTTINO, C. M. C.; LAKS, J.; BLAY, S. L. Demência e Transtornos Cognitivos em Idosos. Rio de Janeiro: Ed. Guanabara Koogan, 2006. p. 78-85.

ORGANIZAÇÃO MUNDIAL DE SAÚDE. Classificação de transtornos mentais do comportamento da CID-10: descrições clínicas e diretrizes diagnósticas. Porto Alegre: Artes Médicas, 1993.

ORNSTEIN, R. On the experience of time. New York: Penguim Books, 1969.

OWSLEY, C.; BURTON-DANNER, K. B.; JACKSON, G. R. Aging and spatial localization during feature search. Gerontology, v. 46, p. 300-305, 2000.

PAPAGNO, C.; ALLEGRA, A.; CARDACI, M. Time estimation in Alzheimer's disease and the role of the central executive. Brain and Cognition, v. 54, p. 18-23, 2004.

PARASURAMAN, R.; HAXBY, J. V. Attention and brain function in Alzheimer's disease. Neuropsychology, v. 7, n. 3, p. 242-272, 1993.

PARASURAMAN, R.; GREENWOOD, P. M.; ALEXANDER, G. E. Alzheimer's disease constricts the dynamic range of spatial attention in visual search. Neuropsychologia, v. 38, p. 1126-1135, 2000.

PARIKH, V.; SARTER, M. Cholinergic mediation of attention contributions of phasic and tonic increases in prefrontal cholinergic activity. Annals of the New York Academy of Sciences, v. 1129, p. 225-235, 2008.

PASHLER, H. E. Psychology of Attention. Cambridge: MIT Press, 1999.

PERRI, R.; KOCH, G.; CARLESIMO, G. A.; SERRA, L.; FADDA, L.; PASQUALETTI, P.; PETTENATI, C.; CALTAGIRONE, C. Alzheimer's disease and frontal of variant of frontotemporal dementia: A very brief battery for cognitive and behavioral distinction. Journal of Neurology, v. 252, n. 10, p.1238-1244, 2005. 
PERRY, R. J.; HODGES, J. R. Attention and executive deficits in Alzheimer's disease: A critical review. Brain, v. 122, p. 383-404, 1999.

PFURTSCHELLER, G.; LOPES DA SILVA, F. Event-related EEG/MEG synchronization and desynchronization: basic principles. Clinical Neurophysiology, v. 110, p. 1842-1857, 1999.

PÖPPEL, E. A hierarchical model of temporal perception. Trends in Cognitive Sciences, v. 1, n. 2, 1997.

PÖPPEL, E. Lost in time: a historical frame, elementary processing units and the 3 second window. Acta Neurobiologiae Experimentalis, v. 64, p. 295-301, 2004.

POSNER, M. I.; PETERSEN, S.E. The attention system of the human brain. Annual Review of Neuroscience, v. 13, p. 25-42, 1990.

POSNER, M. I. Measuring Alertness. Annals of the New York Academy of Sciences, v. 1129, p. 193-199, 2008.

POUTHAS, V.; PERBAL, S. Time perception depends on accurate clock mechanisms as well as unimpaired attention and memory processes. Acta Neurobiologiae Experimentalis, v. 64, p. 367-385, 2004.

POUTHAS, V.; GEORGE, N.; POLINE, J. B.; PJEUTY, M.; VANDEMOORTEELE, P. F.; HUGUEVILLE, L.; FERRANDEZ, A. M.; LEHÉRICY, S.; LEBIHAN, D.; RENAULT, B. Neural network involved in time perception: an fMRI study comparing long and short interval estimation. Human Brain Mapping, v. 25, p. 433-441, 2005.

RAKITIN, B.C.; SCARMEAS, N.; LI, T.; MALAPANI, C. Single-dose Levodopa Administration and Aging. Journal of Cognitive Neuroscience, v. 18, n. 3, p. 376-387, 2006.

RAMMASAYER, T. H. Effects of benzodiazepine-induced sedation on temporal processing. Human Psychopharmacology, v. 7, p. 311-318, 1992.

RAMMSAYER, T. H.; VOGEL, W. H. Pharmacologic Properties of the Internal Clock Underlying Time Perception in Humans. Neuropsychobiology, v. 26, n. 1-2, p. 71-80, 1992.

RAMMSAYER, T. R. Ageing and temporal processing of durations within the psychological present. European Journal of Cognitive Psychology, v. 13, n. 4, p. 549-565, 2001.

REITAN, R. M.; WOLFSON, D. The Halstead-Reitan Neuropsychological Test Battery: Therapy and clinical interpretation. Tucson, AZ: Neuropsychological Press, 1985.

RIZZO, M.; ANDERSON, S. W. Vision and cognition in Alzheimer's disease. Neuropsychologia, v. 38, p. 1157-69, 2000. 
ROTH, M.; TYM, E.; MOUNTJOY, C. O.; HUPPERT, F. A.; HENDRIE, H.; VERMA, S.; GODDARD, R. CAMDEX: a standardized instrument for the diagnosis of mental disorders in the elderly with special reference to the early detection do dementia. British Journal of Psychiatry, v. 149, p. 698-709, 1986.

RUBIA, K.; SMITH, A. The neural correlates of cognitive time management: a review. Acta Neurobiologiae Experimentalis, v. 64, p. 329-340, 2004.

SAKAI, K.; HIKOSAKA, O.; MIYAUCI. S.; TAKINO, R.; TAMADA, T.; IWATA, N. K.; NIELSE, M. Neural representation of a rhythm depends on its interval ratio. The Journal of Neuroscience, v. 19, n. 22, p. 10074-10081, 1999.

SAMESHIMA, K.; BACCALÁ, L. A. Using partial directed coherence to describe neuronal ensemble interactions. Journal of Neuroscience Methods, v. 94, p. 93-103, 1999.

SARTER, M.; PARIKH, V. Choline transporters, cholinergic transmission and cognition. Nature Reviews Neuroscience, v. 6, p. 48-56, 2005.

SARTER, M.; HASSELMO, M. E.; BRUNO, J. P.; GIVENS, B. Unraveling the attentional functions of cortical cholinergic inputs: interactions between signal-driven and cognitive modulation of signal detection. Brain Research Reviews, v. 48, p. 98$111,2005$.

SCHMITTER-EDGECOMBE, M.; RUEDA, A. D. Time estimation and episodic memory following. Journal of Clinical and Experimental Neuropsychology, v. 30, n. 2, p. 212-223, 2008.

SHESKIN, D. J. Handbook of Parametric and Nonparametric statistical procedures. Boca Raton: Chapman \& Hall/CRC, 2000.

SMITH, A.; LIDZBA, K.; TAYLOR, E.; RUBIA, K. A right hemispheric fronto-striatal network for temporal discrimination. Neuroimage, v. 20, p. 344-350, 2003.

SMYTHE, E. J.; GODSTONE, S. The time sense: A normative, genetic study of the development of time perception. Perceptual and Motor Skills, v. 7, p. 49-59, 1957.

SPREEN, O.; STRAUSS, E. A. A compendium of neuropsychological tests: administration, norms and commentary. New York: Oxford University Press, 1991.

STEINBÜCHEL, $\mathrm{N}$ von. Temporal ranges of central nervous processing: clinical evidence. Experimental Brain Research, v. 123, p. 220-223, 1998.

STORANDT, M.; KASKIE, B.; VON DRAS, D. Temporal Memory for Remote Events in Healthy Aging and Dementia. Psychology and Aging, v. 13, n. 1, p. 4-7, 1998.

STUART-HAMILTON, I. (Ed.). Psicologia do envelhecimento: uma introdução. 3 ed. Tradução de Maria Adriana V. Veronese. São Paulo: Ed. Artmed, 2002. 
SZELAG, E.; KOWALSKA, J.; RYMARCZYK, K.; PÖPPEL, E. Duration processing in the children as determined by time reproduction: implications for a few seconds temporal window. Acta Psychologica, v. 110, p. 1-19, 2002.

SZELAG, E.; KANABUS, M.; KOLODZIEJCZYK, I.; KOWALSKA, J.; SZUCHNIK, J. Individual differences in temporal information processing in humans. Acta Neurobiologiae Experimentalis, v. 64, p. 349-366, 2004.

TOMBAUGH, T. N. Trail Making Test A and B: Normative data stratified by age and education. Archives of Clinical Neuropsychology, v. 19, p. 203-214, 2004.

TOMBAUGH, T.H.; MC INTYRE, N. J. The mini-mental state examination: a comprehensive review. Journal of Geriatric Society, v. 40, n. 9, p. 922-935, 1998.

TRACY, J. T.; FARO, S. H.; PISK, M.; PINUS, A. Functional localization of time keeper function separate from attentional resources and task strategy. Neuroimage, $v$. 11, p. 228-242, 2002.

TREISMAN, M. Temporal discrimination and the indifference interval: implications for a model of the "internal clock". Psychological Monographs, v. 77, n. 576, 1963.

ULBRICH, P.; CHURAN, J.; FINK, M.; WITTMANN, M. Temporal reproduction: Further evidence for two processes. Acta Psychologica, v. 125, p. 51-65, 2007.

VANNESTE, S.; POUTHAS, V. Timing in Aging: the role of Attention. Experimental Aging Research, v. 25, p. 49-67, 1999.

VALERIANI, M.; RANGHI, F.; GIAQUINTO, S. The effects of aging on selective attention to touch: a reduced inhibitory control in elderly subjects? International Journal of Psychophysiology, v. 49, p. 75-87, 2003.

VITULLI, W. F.; CRIMMINS, K. A. An experiment in time perception: separate rate of presentation from type of estimation. Perceptual and Motor Skills, v. 88, p. 961-969, 1999.

WEARDEN, J. H.; PENTON-VOAK, I. S. Feeling the heat: Body temperature and the rate of subjective time, revisited. Quarterly Journal of Experimental Psychology: Comparative and Physiological Psychology, v. 48B, n. 2, p. 121-141, 1995.

WEARDEN, J. H.; FERRARA, A. Stimulus range effects in temporal bisection by humans. The Quarterly Journal of Experimental Psychology, v. 49B, n. 1, p.24-44, 1996.

WEARDEN, J. H.; WEARDEN, A. J.; RABBITT, P. M. A. Age and IQ effects on stimulus and response timing. Journal of Experimental Psychology: Human Perception and Performance, v. 23, p. 962-979, 1997.

WEARDEN, J. H.; LEJEUNE, H. Scalar properties in human timing: conformity and violations. The Quarterly Journal of Experimental Psychology, v. 61, n. 4, p. 569587, 2008. 
WEARDEN, J. H.; JONES, L. A. Is the growth of subjective time in humans a linear or nonlinear function of real time? The Quarterly Journal of Experimental Psychology, v. 60 , n. 9, p.1289-1302, 2007.

WESCHSLER, D. Weschler memory scale-revised manual. The Psychological Corporation, San Antonio, 1987.

WITTMANN, M. Time perception and temporal processing levels of the brain. Cronobiology International, v. 16, n. 1, p. 17-32, 1999.

ZAKAY, D.; BLOCK, R. A. Prospective and retrospective duration judgments: an executive-control perspective. Acta Neurobiologiae Experimentalis, v. 64, p. 319-328, 2004.

ZAR, J. H. Biostatistical Analysis. 3rd ed. New Jersey: Prentice Hall, 1996. 


\author{
ANEXO A \\ TERMO DE CONSENTIMENTO LIVRE E ESCLARECIDO
}

\title{
ESTUDO: MODULAÇÃO ATENCIONAL DA PERCEPÇÃO DE CAUSALIDADE E DE TEMPO, UTILIZANDO A DEMÊNCIA DE ALZHEIMAER COMO MODELO
}

Você está sendo convidado(a) a participar do projeto de pesquisa acima citado. O documento abaixo contém todas as informações necessárias sobre a pesquisa que estamos fazendo. Sua colaboração neste estudo será de muita importância para nós, mas se desistir a qualquer momento, isso não causará nenhum prejuízo a você.

Eu,

(inserir

nome)

(profissão) residente e domiciliado na

portador da cédula de identidade,

RG

e inscrito

no

CPF

nascido(a) em _L_ _ abaixo assinado(a), concordo de livre e espontânea

vontade em participar como voluntário(a) do estudo "MODULAÇÃO

ATENCIONAL DA PERCEPÇÃO DE CAUSALIDADE E DE TEMPO,

UTILIZANDO A DEMÊNCIA DE ALZHEIMER COMO MODELO”. Declaro

que obtive todas as informações necessárias, bem como todos os eventuais

esclarecimentos quanto às dúvidas por mim apresentadas. 
Caso o indivíduo tenha diagnóstico de quadro demencial:

Eu, (inserir o nome)

(profissão)

(grau de parentesco: tutor, curado, etc) , residente e domiciliado na

portador da Cédula de Identidade.

RG , e inscrito no CPF

nascido(a) em , na qualidade de responsável legal, abaixo assinado(a), concordo de livre e espontânea vontade de que (inserir o nome)

(profissão) residente e domiciliado na portador da cédula de identidade, RG , e inscrito no CPF

nascido(a) em participe como voluntário(a) do estudo “MODULAÇÃO ATENCIONAL DA PERCEPÇÃO DE CAUSALIDADE E DE TEMPO, UTILIZANDO A DEMÊNCIA DE ALZHEIMER COMO MODELO”. Declaro que obtive todas as informações necessárias, bem como todos os eventuais esclarecimentos quanto às dúvidas por mim apresentadas.

Estou ciente que:

I) O estudo se faz necessário para que se possam conhecer melhor a neurofisiologia da percepção temporal e da causalidade (isto é, compreender como o indivíduo percebe o tempo e como percebe a causa entre dois estímulos que se relacionam), bem como as alterações que se processam nas pessoas que apresentam a "demência de Alzheimer" (doença que leva à perda progressiva da memória);

II) Serão feitos algumas sessões de testes psicofísicos (testes realizados no

computador) com registro eletroencefalográfico concomitante (isto é, será realizado um exame de eletroencefalograma enquanto eu estiver realizando os testes em um computador);

III) Estes exames serão feitos apenas para este estudo e em nada 
influenciarão o tratamento: não vão me curar; não vão me causar nenhum problema;

IV) A participação neste projeto não tem objetivo de me submeter a um tratamento, bem como não me acarretará qualquer ônus pecuniário com relação aos procedimentos médico-clínico-terapêuticos efetuados com o estudo (ou seja, não precisarei pagar por nenhum exame, remédio ou consulta relacionada a este projeto, enquanto participar desta pesquisa);

V) Tenho a liberdade de desistir ou de interromper a colaboração neste estudo no momento em que desejar, sem necessidade de qualquer explicação;

VI) A desistência não causará nenhum prejuízo à minha saúde ou bem estar físico. Não virá interferir no atendimento ou tratamento médico:

VII) Os resultados obtidos durante este ensaio serão mantidos em sigilo, mas concordo que sejam divulgados em publicações científicas, desde que meus dados pessoais não sejam mencionados.

VIII) Caso eu desejar, poderei pessoalmente tomar conhecimento dos resultados, ao final desta pesquisa.

( ) Desejo conhecer os resultados desta pesquisa.

( ) Não desejo conhecer os resultados desta pesquisa.

São Paulo, de de 200 .

( ) Paciente / ( )Responsável

Testemunha 1 :

Nome / RG / Telefone

Testemunha 2 :

Nome / RG/ Telefone

Responsável pelo projeto:

DR. EDUARDO V. CAMPANHA, MÉDICO PSIQUIATRA.

CRM: 97375. Telefone para contato: 3091-7214 


\section{ANEXO B \\ DESCRIÇÃO DO CIRCUITO DE TRIGGER}

A porta de triger do circuito de EEG-Captações possui sensibilidade limitada, segundo o fabricante, por uma corrente mínima ( $\left.\mathrm{I}_{\mathrm{min}}\right)$ igual a $5 \mathrm{~mA}$ (mili Amperes) e período mínimo $(\mathrm{T})$ de $2,5 \mathrm{~ms}$. O fabricante informa ainda que existe uma resistência de entrada de 470 Ohms e uma queda de tensão no dispositivo de proteção de, aproximadamente, 2 Volts.

Visando atender estes requisitos foi elaborado um programa no computador gerador de estímulos que envia sinais digitais pela porta serial deste computador a uma taxa de 300bps (bits por segundo), na forma de ondas quadradas de amplitudes que variam de $-12 \mathrm{~V}$ à $+12 \mathrm{~V}$ (padrão RS232). Estes sinais passam por um circuito, composto por um dispositivo conversor de sinais (MAX232), capaz de transformar sinais no padrão RS232 para o padrão TTL (variação de 0V à 5V).

Como resultado temos sinais digitais com variações entre 0 e 5 Volts de período 3,3ms. Tais sinais são capturados pelo software EEG-Captações e utilizados como marcações das leituras.

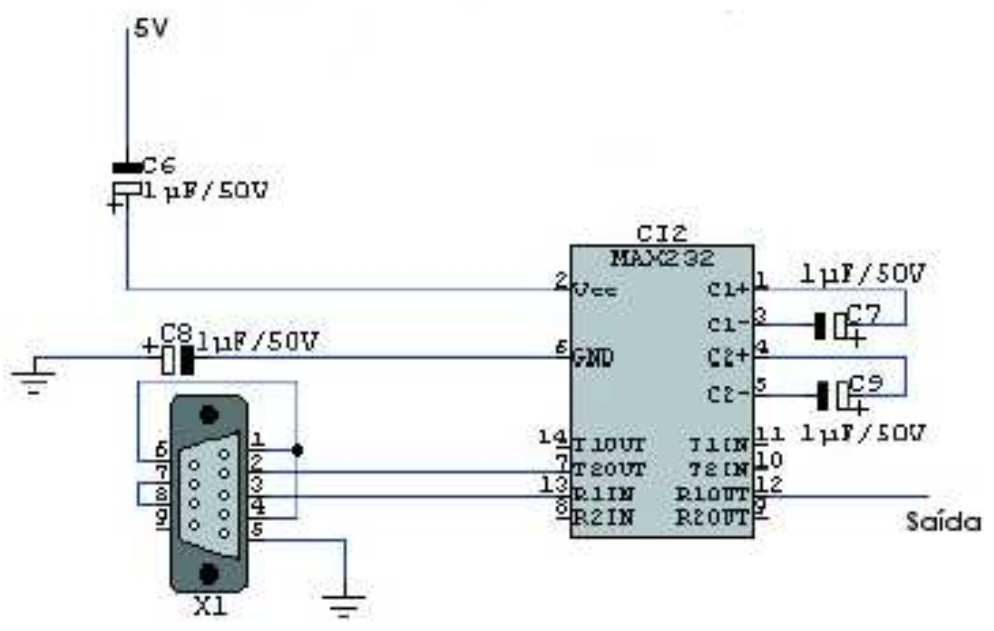

Figura B.1. A figura acima apresenta as especificações técnicas do circuito responsável por mandar sinais de sincronização para o eletroencefalógrafo. 


\section{ANEXO C}

\section{TESTES COGNITIVOS}

Os testes cognitivos têm por finalidade avaliar a atenção, memória, linguagem e outras funções cognitivas dos grupos de pacientes com DA e do grupo controle de idosos. Com isto, podemos verificar a homogeneidade dos grupos, bem como estabelecer relações entre seu desempenho nos testes cognitivos e sua performance nos testes psicofísicos. Utilizamos uma bateria concisa de testes que avaliavam funções cognitivas que presumivelmente, seriam importantes no desempenho das tarefas psicofísicas. A atenção foi medida pelo teste de trilhas, a prova dos sete que se encontra do mini exame do estado mental (MEEM) e os dígitos inversos; a linguagem na fluência verbal e no MEEM. A memória pode ser dividida quanto ao tempo de estocagem e quanto a modalidade sensorial utilizada, assim a memória de longo prazo visual foi medida no teste da figura complexa de Rey, a memória multimodal de longo prazo, bem como a aprendizagem, foram aferidas com o FOME e a memória verbal de longo prazo no mini exame do estado mental. A memória operacional ou de curto prazo foi medida usando-se o dígito direto.

Reconhecemos a fragilidade dos conceitos clínicos envolvidos nos testes cognitivos. Um bom exemplo é citar o fato de diferenciação de memória operacional e atenção, atenção dividida e atenção concentrada, conceitos que nem sempre apresentam substrato neurofisiológico correlato bem definido. Outro problema é o pressuposto de que as funções cognitivas possam ser separadas claramente pelo teste. Entretanto, os testes cognitivos elencados têm a vantagem de serem reproduzíveis, serem normatizados e serem úteis na diferenciação entre os estados mórbidos e a normalidade.

A seguir, descreveremos resumidamente as características dos testes empregados.

\section{Mini-Exame do Estado Mental (MEEM)}

O MEEM foi elaborado para auxiliar o clínico a estimar quantitativamente o prejuízo cognitivo de seus pacientes (FOLSTEIN; FOLSTEIN; MC HUGH, 1975). Além disto, o MEEM também tem sido empregado para classificar a demência em leve, moderada e grave. 
Este instrumento consiste em várias questões agrupadas em sete categorias de funções cognitivas, totalizando 30 pontos: orientação temporal (5 pontos), orientação espacial (5 pontos), registro de três palavras (3 pontos), atenção e cálculo ou prova dos sete ( 5 pontos), evocação de três palavras ( 3 pontos), linguagem ( 8 pontos) e construção verbal (1 ponto). A pontuação menor ou igual a 23 pontos tem sido reconhecida, pela maior parte dos estudos, como indicativo de prejuízo cognitivo (OKAMOTO; BUSTAMANTE, 2006).

O MEEM tem sido amplamente usado em diversos estudos na etapa de rastreio para o diagnóstico de demência. Um problema do teste é a influência da escolaridade, por exemplo, escores maiores ou iguais a 18 podem ser considerados normais para analfabetos (BERTOLUCCI et al., 1994). Por outro lado, suas propriedades psicométricas mostraram um elevado grau de confiabilidade (TOMBAUGH; MC INTYRE, 1992).

\section{Teste da Figura Complexa de Rey-Osterrieth.}

A finalidade deste teste é avaliar a capacidade construtiva visuo-espacial e a memória visual tardia. Foi desenvolvido por Rey em 1941 e padronizado por Osterrieth 1944.

A Figura Complexa de Rey consiste em uma figura geométrica complexa composta por um retângulo grande, bissetores horizontais e verticais, duas diagonais e detalhes geométricos adicionais interna e externamente ao retângulo grande (Figura anexo C.1). O desenho é apresentado horizontalmente e o examinando deve copiá-lo em uma folha em branco.

O método empregado baseia-se no modo de administração utilizado pelos autores (LEZAK, 1995; SPREEN; STRAUSS, 1998): pede-se para copiar o desenho, sem mudá-lo de posição e preferencialmente realizando a tarefa entre 2,5 e 5 minutos. Neste teste o desempenho é mais importante que o tempo empregado na execução da tarefa. Após 30 minutos de latência o sujeito deverá reproduzir o que lembra da figura.

Tanto a cópia como a reprodução tardia são submetidas a mesma quantificação. A figura é tipicamente dividida em 18 elementos. Cada elemento recebe 0,5 a 2 pontos dependendo do acerto quanto à forma e quanto à localização: 2 pontos se a forma e a localização estão corretas; 1 se a forma ou a localização forem corretas; 0,5 se forem 
desenhadas incorretamente e 0 se o elemento estiver ausente ou não puder ser reconhecido.

Abaixo mostramos a figura e seus elementos a serem pontuados.

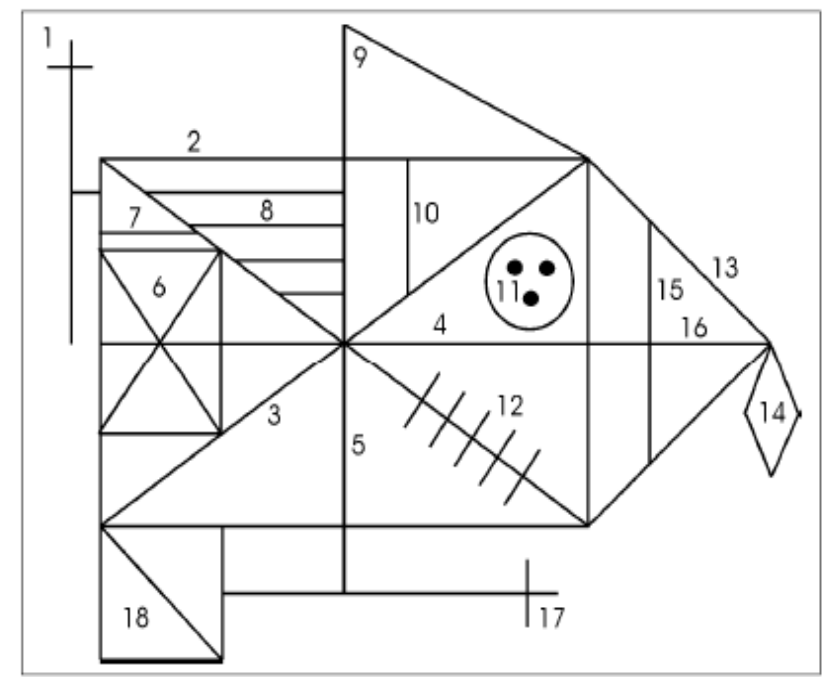

Figura C.1. Figura complexa de Rey-Osterrieth com os elementos numerados.

O teste da figura complexa tem sido usado freqüentemente na avaliação de pacientes com alterações neuropsiquiátricas, incluindo as demências (JAMUS; MÄDER, 2004).

Pacientes com DA, não apresentam problemas na visão em 3 dimensões, o que foi avaliado em vários trabalhos (CRONIN-GOLOMB et al., 1991) e o padrão de disfunção da percepção visual reflete alterações neuroanatômicas no córtex visual associativo, com pouco acometimento das áreas visuais primárias. As dificuldades de percepção visual em pacientes com DA indicam problemas na discriminação entre figura e fundo (MENDOLA et al., 1995).

Em um estudo que tinha por objetivo avaliar a percepção visual e espacial de pacientes com DA leve (BINETTI et al., 1998), mostrou-se que o desempenho de pacientes com DA em tarefas de percepção visual (incluindo a cópia da figura complexa de Rey-Osterrieth) e espacial não mostram diferenças em relação a controles pareados. Pacientes com DA tiveram como escores $24,7 \pm 7,5$ e os controles obtiveram pontuação de 26,5 $\pm 10,1$ na cópia da figura complexa. Já o desempenho em tarefas que exigiam 
nomeação e avaliação semântica mostrou-se consideravelmente prejudicado em pacientes com DA. Outro dado interessante deste estudo foi a avaliação que ocorreu nestes pacientes 8 meses após a primeira avaliação, neste caso houve decréscimo considerável dos escores na cópia da figura complexa $(18,1 \pm 7,8)$. Deve-se salientar que os pacientes com DA não receberam medicação neste período.

Em um estudo italiano (PERRI et al., 2005) que tinha por objetivo comparar pacientes com DA com pacientes com demência fronto-temporal, obteve-se escores de $12 \pm 9$ para a cópia da figura complexa e 1,4 $\pm 3,2$ para a reprodução para pacientes com DA. Deve-se citar que o estágio da doença era um pouco mais avançado em comparação com o estudo anterior.

Em um estudo japonês (KASAI et al., 2006), verificamos uma diferença estatística entre sujeitos controle $(\mathrm{CDR}=0)$ e pacientes com quadro de quadro de demência questionável $(\mathrm{CDR}=0,5)$, tanto na cópia como na reprodução tardia, o que mostra a sensibilidade do teste. Há diferenças mesmo quando a reprodução tardia é feita em 10 minutos de latência (CAFFARA et al., 2001).

\section{Dígito Direto}

A dissociação entre velocidade de processamento (medida, por exemplo, por testes com o teste de trilhas) e a capacidade de processamento (medida pelos dígitos) são dimensões neuropsicológicas básicas da atenção: quão rápido os sistemas atencionais operam e quanto podem processar de uma vez (LEZAK, 1995). É evidente que a velocidade e a capacidade de processamento estão relacionadas entre si, quanto mais rápido um sistema processa informação maior será seu processamento em um dado instante. Entretanto, estes parâmetros atencionais devem ser avaliados separadamente, visto que lesões cerebrais podem levar a alterações diferentes nestes parâmetros.

O dígito direto é um sub-teste da Escala de Memória de Wechsler (WECHSLER, 1987) e tem por finalidade avaliar o volume de informações que precisam ser armazenadas por um espaço de tempo curto durante uma única tarefa, que é a de repetir uma seqüência de dígitos cada vez mais extensa na foram direta. $\mathrm{O}$ examinador deve pronunciar os dígitos um por segundo. Quando a sequiência é repetida corretamente, a próxima seqüência mais longa de ser lida. 


\section{Dígito Inverso}

Também consiste em um sub-teste da Escala de Memória de Wechsler (WECHSLER, 1987). Nesta tarefa os dígitos são ditos a uma velocidade de um dígito por segundo e o indivíduo deve repeti-los na ordem inversa. Estas seqüências de números também são apresentadas de uma forma crescente em relação ao número de dígitos a ser repetido.

Ao contrário do dígito direto que sofre pouca ação da idade, o dígito inverso tende a ter escores mais baixos em indivíduos com idade maior que 60 anos. Há também influência da escolaridade.

Tanto os dígitos diretos como os dígitos inversos são sensíveis às lesões cerebrais difusas e em hemisfério esquerdo.

\section{Teste de Trilhas}

O teste de trilhas permite obter informações sobre busca visual, atenção, flexibilidade mental e função motora. Originalmente, foi parte constituinte da "Army Individual Test Battery" (1944) e foi subseqüentemente incorporado na bateria de Halstead-Reitan (REITAN; WOLFSON, 1985). O teste consiste de duas partes. Na parte A, o sujeito tem como tarefa conectar, sequencialmente, 25 números distribuídos aleatoriamente em uma folha de papel. Na parte B, o sujeito deve ligar, alternadamente, números e letras (exemplo: 1, A, 2, B, 3, C, etc.). Em cada parte, a quantidade de tempo requerida para completar a tarefa é a medida utilizada. $\mathrm{O}$ modo de administração seguiu as normas descritas por Spreen e Strauss (1991). Neste modo de administração o erro é avaliado indiretamente, pelo aumento no tempo.

Tanto a parte A com a parte B são sensíveis ao declínio cognitivo na demência, conseguindo diferenciar pacientes demenciados de controles, mesmo quando a demência é leve (LEZAK, 1995). O teste, entretanto, sofre a influência da idade e dos anos de escolaridade (TOMBAUGH, 2004).

\section{Fluência Verbal Semântica}

O teste de fluência verbal também é extremamente simples e avalia a memória semântica (conhecimento geral sobre o mundo, sem relação com o momento do seu 
aprendizado). Consiste na avaliação de categorias semânticas pré-definidas tais como animais e frutas. Solicita-se ao paciente que enumere o máximo de animais em 1 minuto. É informado de que estes animais podem ser de qualquer espécie.

O trabalho de Brucki et al. (1997) determinou, em nosso país, 9 como o nível de corte para indivíduos com até 8 anos de escolaridade e 13 para o grupo de escolaridade maior.

\section{FOME}

FOME é o acrônimo de "Fuld Object-Memory Evaluation" (FULD; MANSUR; BLAIR, 1990). Este é um teste que tem por finalidade avaliar aprendizado, memória e reconhecimento tátil. Consiste em colocar 10 objetos em uma bolsa e pedir para que o paciente, sem olhar, reconheça o objeto. Após o reconhecimento, os objetos são colocados um a um na bolsa. O paciente realiza então uma tarefa de fluência e verbal de 30 segundos. Pede-se, então, para tentar lembrar os objetos que estavam na bolsa. Os objetos não mencionados em 1 minuto são pronunciados pelo médico. São realizados 5 sessões e pode-se obter diversos escores: evocação total (soma de todos os acertos), armazenamento (total de objetos lembrados, pelo menos uma vez), evocação repetida (soma das vezes nas quais os objetos que foram evocados corretamente, em sessões consecutivas) e evocação não repetida (soma das vezes nas quais os objetos não foram evocados consecutivamente).

Este teste apresenta uma boa diferenciação entre pacientes com depressão e pacientes com quadros demenciais e apresenta a vantagem de avaliar a memória nãoverbal, além de apresentar pouco impacto da escolaridade (LEZAK, 1995).

\section{CAMDEX}

O CAMDEX é uma entrevista estruturada, composta de 8 seções: A investigação do estado atual do paciente (mental e físico), seus antecedentes pessoais e sua história familiar; B- teste cognitivo com 67 itens (CAMCOG), que inclui o MEEM, e avalia orientação, linguagem, memória, praxia, atenção, pensamento abstrato, percepção e cálculo; C- observações do examinador sobre o estado do paciente; Dexame físico e neurológico; E- resultados de exames laboratoriais e radiológicos; F- 
registro de medicações atualmente em uso; G- informações adicionais relevantes, sobre o paciente, obtidas no curso da entrevista; $\mathrm{H}$ - entrevista com familiar ou informante .

Com as informações fornecidas pela entrevista podem-se classificar os pacientes, segundo os critérios do NINCDS-ADRDA (MCKHANN et al., 1984), CID10 (OMS, 1993), e DSM-IV (APA, 1994). O CAMDEX apresenta as vantagens de apresentar alta confiabilidade entre avaliadores, bons resultados na distinção entre quadros demenciais, depressivos e idosos sem doenças que afetam a cognição e de ser traduzido e adaptado para o português (HOTOTIAN; BOTTINO; AZEVEDO, 2006).

O teste cognitivo do CAMDEX (CAMCOG) apresenta uma pontuação máxima de 107 e utiliza-se um ponto de corte de 79/80 para diferenciar pacientes com demência e sujeitos normais (ROTH et al., 1986). 


\section{ANEXO D \\ TESTE DE AVALIAÇÃO DA SIMETRIA NA POPULAÇÃO}

Podemos medir a simetria de uma dada curva tomando o "skewness" ou simetria. Um teste para avaliar a simetria é o teste de paramétrico de avaliação da simetria de uma população (SHESKIN, 2000).

A hipótese nula é de que a distribuição é simétrica. O algoritmo usado neste teste é descrito abaixo, Onde $\mu$ é a média, s é o desvio padrão.

$$
\begin{aligned}
& m_{3}=\frac{(X-\mu)^{3}}{n} \\
& g_{1}=\frac{m_{3}}{s^{3}} \\
& \sqrt{b_{1}}=\frac{(n-2) g_{1}}{\sqrt{n(n-1)}} \\
& \mathrm{A}=\sqrt{b_{1}} \sqrt{\frac{(n+1)(n+3)}{6(n-2)}} \\
& \mathrm{B}=\frac{3\left(n^{2}+27 n-70\right)(n+1)(n+3)}{(n-2)(n+5)(n+7)(n+9)} \\
& \mathrm{C}=\sqrt{2(B-1)}-1 \\
& \mathrm{D}=\sqrt{C} \\
& \mathrm{E}=\frac{1}{\sqrt{\ln D}} \\
& \mathrm{~F}=\frac{A}{\sqrt{\frac{2}{C-1}}} \\
& \mathrm{Z}=E \ln \left(F+\sqrt{\left.F^{2}+1\right)}\right.
\end{aligned}
$$

Para interpretar o resultado do teste, após ter sido encontrado o valor de $\mathrm{z}$ da distribuição devemos comparar com o z crítico de uma distribuição norma $z_{0,05}=1,96 \mathrm{e}$ $z_{0,01}=2,33$, para uma distribuição bi caudal.

Se o valor do $\mathrm{z}$ encontrado para a distribuição for menor que o $\mathrm{z}$ crítico, a hipótese nula não pode ser rejeitada, isto é, de que a distribuição é simétrica. 